Universidad de Lima

Facultad de Comunicación

Carrera de Psicología

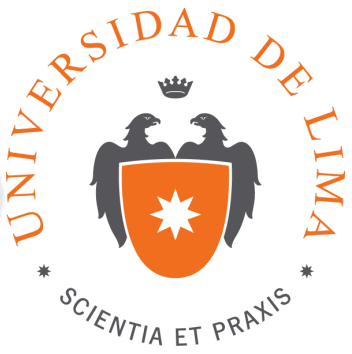

\title{
PROPIEDADES PSICOMÉTRICAS DE LA ESCALA DE ESTRÉS COTIDIANO INFANTIL EN NIÑOS DE 3ERO A 5TO GRADO DE PRIMARIA DE COLEGIOS DE LIMA METROPOLITANA
}

Tesis para optar el título profesional de Licenciado en Psicología

María Fernanda Flores Mazulis

Código 20090406

Asesor

Andrés Burga León

Lima - Perú

Febrero del 2017 


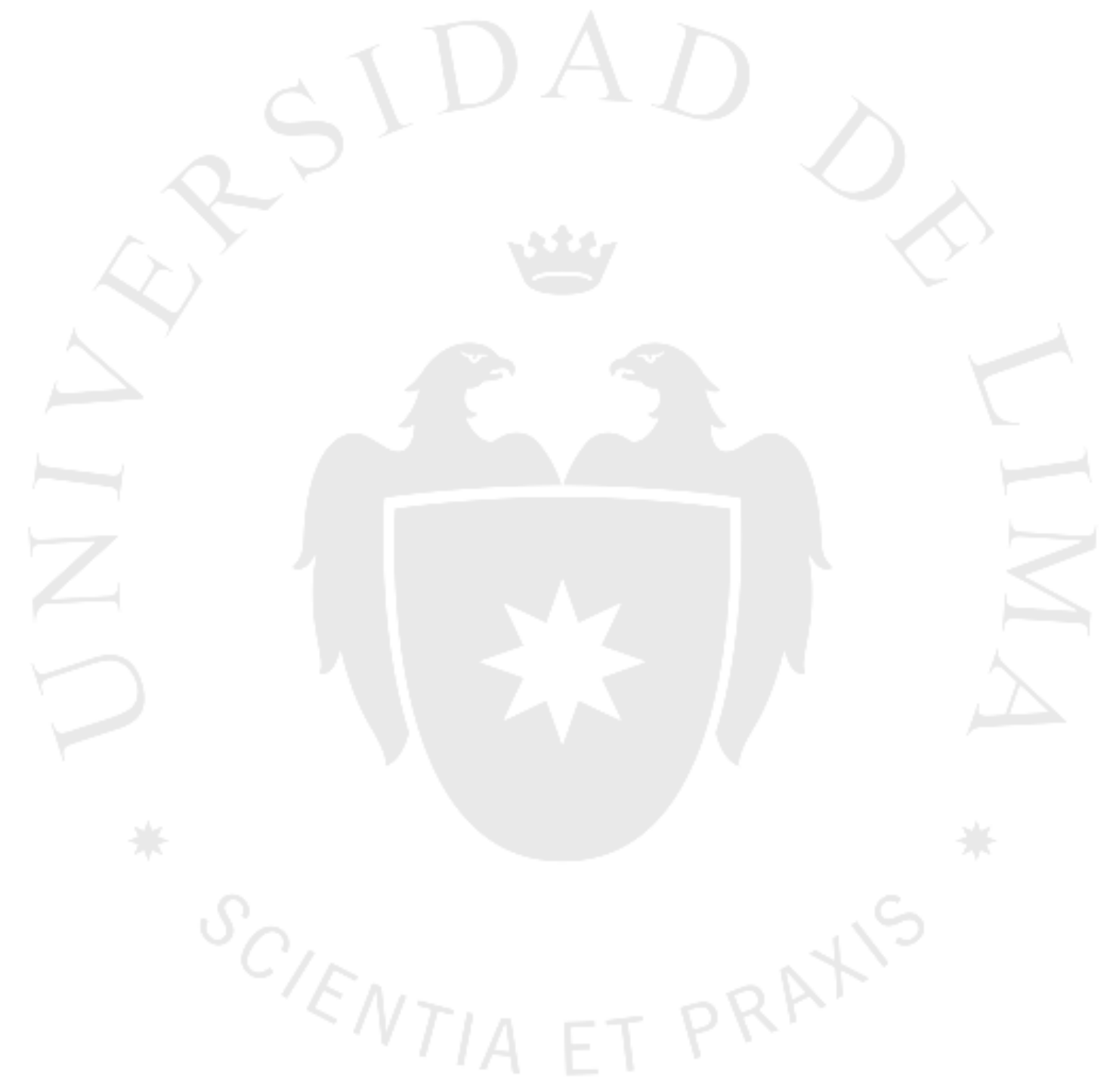




\section{AGRADECIMIENTOS}

El estudio del estrés en niños es un tema que surgió de interés en mí a partir de mi experiencia de trabajo con niños. Parte de mi motivación para la realización de este proyecto es poder encontrar una manera de prevenir algo que puede tener un impacto tan severo en personas tan pequeñas, como lo son los niños.

Agradezco a la Universidad de Lima por brindarme la oportunidad de realizar un internado, a partir del cual pude conectar con este tema que significa mucho para mí, así como también por brindar el servicio de profesores extraordinarios tanto a nivel profesional, como a nivel personal.

Agradezco a mi profesora de seminario 2 y de muchos otros cursos más, Sandra Inurritégui, quien me orientó y animó a seguir con el desarrollo de este trabajo. Gracias por el apoyo dentro y fuera del ambiente universitario y por la dedicación de cada corrección hecha.

Un agradecimiento especial a mi asesor de tesis, el profesor Andrés Burga, quien me ayudó, de manera académica, a través de sus grandes conocimientos y personal, a través de su sentido del humor, con lo que ahora es este trabajo. También agradezco sinceramente al profesor Luis Miguel Escurra, mi profesor de estadística 1 y 2, quien, de la manera más noble, escuchó mis ansiedades y contribuyó a la solución de cada una de ellas.

Cuando pienso en la culminación de este trabajo, resulta inevitable pensar en mis padres. Es gracias a ellos que he contado con la oportunidad tan privilegiada de poder estudiar. A ellos, gracias infinitas, por brindarme las facilidades, el cariño y apoyo constante.

También quisiera agradecer el apoyo de mi amiga Ximena Meneses, con quien realicé innumerables tardes maratónicas de trabajo de tesis, en donde estaban incluidos no solo nuestros avances y dudas, sino también nuestras conversaciones de desahogo y relajo.

Finalmente, agradezco mucho el constante apoyo de Benjamín Lira, quien no sólo me ayudó de manera incondicional y muy pacientemente con el asesoramiento de mis análisis estadísticos, sino también animándome a continuar con la culminación de este trabajo. 


\section{PROPIEDADES PSICOMÉTRICAS DE LA ESCALA DE ESTRÉS COTIDIANO INFANTIL EN NIÑOS DE 3ERO A 5TO GRADO DE PRIMARIA DE COLEGIOS DE LIMA METROPOLITANA}




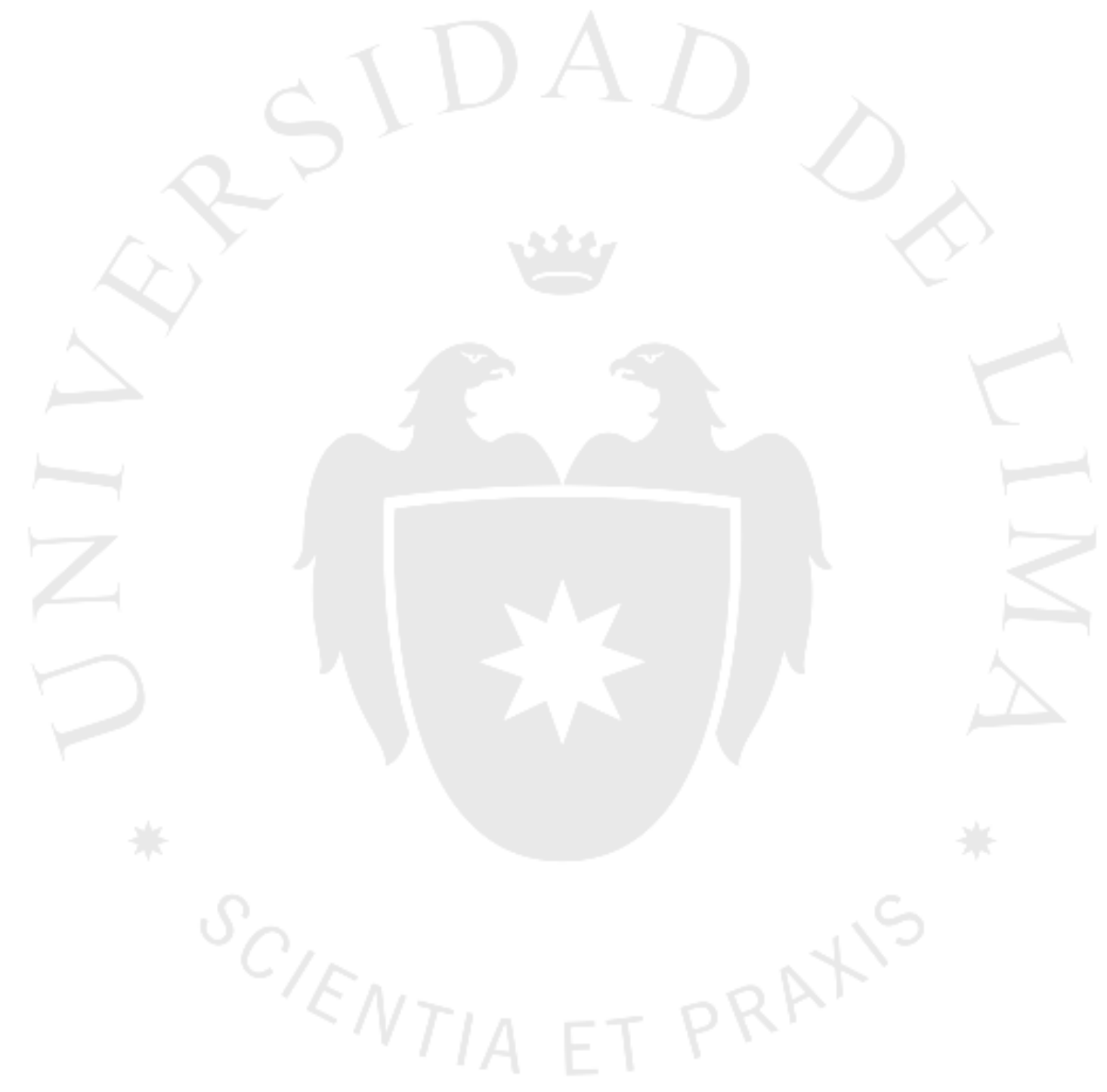




\section{TABLA DE CONTENIDOS}

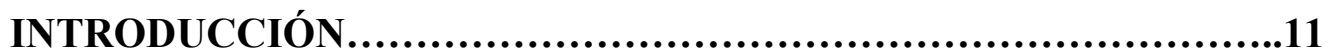

CAPÍTULO I: PLANTEAMIENTO DEL PROBLEMA..................13

1.1 Descripción del problema......................................13

1.2 Justificación y relevancia.......................................15

CAPÍTULO II: MARCO TEÓRICO........................................17

2.1 Etimología del término estrés.................................17

2.2 Definición del estrés...........................................18

2.2.1 El estrés como estímulo ......................................18

$2.2 .2 \mathrm{El}$ estrés como proceso.................................20

2.2.3 El estrés como respuesta.................................22

2.2.4 El estrés como modelo procesual.............................24

2.3 Componentes del estrés.....................................24

2.4 Estrés cotidiano.............................................25

2.5 Estrés y ansiedad.............................................28

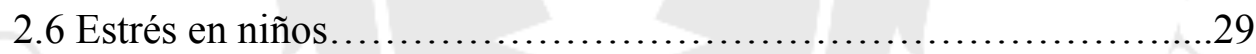

2.6.1 Dominios del estrés infantil...............................29

2.7 Impacto del estrés en niños....................................30

2.8 Moderación del estrés.............................................31

2.8.1 Variables ambientales.....................................31

2.8.2 Variables personales......................................31

2.9 Medición del estrés en niños.....................................32

CAPÍTULO III: OBJETIVOS Y DEFINICIÓN DE VARIABLES.......35

3.1 Objetivos................................................... 35

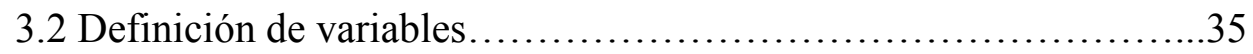

CAPÍTULO IV: MÉTODO..............................................37

4.1 Tipo y diseño de investigación..................................37

4.2 Participantes................................................. 37

4.3 Técnicas de recolección de datos.................................39 
4.4 Procedimiento de recolección de datos . .41

CAPÍTULO V: RESULTADOS....................................42

5.1 Análisis psicométricos.....................................42

5.2 Análisis complementarios....................................55

CAPÍTULO VI: DISCUSIÓN........................................56

6.1 Objetivos de la investigación.................................56

6.2 Adecuación del análisis psicométrico de la EECI de acuerdo a los estándares para la evaluación educativa y psicológica (AERA, APA

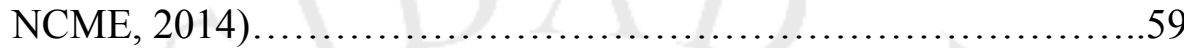

6.3 Análisis complementarios....................................65

CONCLUSIONES.........................................................67

RECOMENDACIONES.............................................68

REFERENCIAS.....................................................69

ANEXOS..............................................................76 


\section{ÍNDICE DE TABLAS}

Tabla 1. Escala de reajuste social.........................................19

Tabla 2. Clasificación de estresores según periodo evolutivo....................27

Tabla 3. Matrícula de educación primaria de tipo de gestión y sexo según

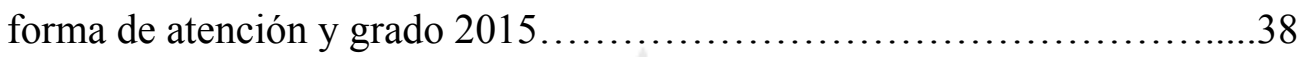

Tabla 4. Distribución de los participantes según grado, sexo y tipo de

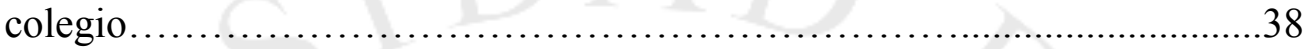

Tabla 5. Matriz de la Escala de Estrés Cotidiano Infantil.........................39

Tabla 6. Coeficiente V de Aiken para los ítems de la EECI según representatividad del tema...........................................43

Tabla 7. Coeficiente V de Aiken para los ítems de la EECI según claridad en la redacción..............................................43

Tabla 8. Primera versión de la estructura factorial de la EECI a través del análisis factorial exploratorio.......................................46

Tabla 9. Versión final de la estructura factorial de la EECI......................48

Tabla 10. Alfa de Cronbach, alfa ordinal y error estándar de medición para cada uno de ellos según sexo, grado y tipo de colegio..................49

Tabla 11. Correlación poliserial ítem-resto para los ítems

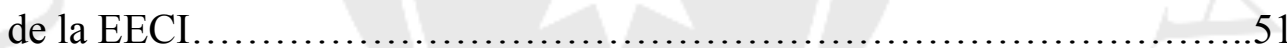

Tabla 12. Análisis factorial exploratorio de los ítems de la LCCAN por medio del método de Hull...............................................52

Tabla 13. Prueba de Shapiro-Wilk de bondad de ajuste a la curva normal para la EECI y la LCCAN............................................53

Tabla 14. Baremos clasificados en quintiles de las puntuaciones de estrés

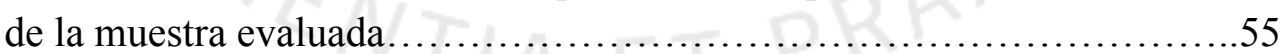




\section{ÍNDICE DE FIGURAS}

Figura 1. Fases del Síndrome de Adaptación General (SAG) de Hans Selye.

$\mathrm{A}=$ reacción de alarma, $\mathrm{B}=$ estado de resistencia y $\mathrm{C}=$ fase de agotamiento...23

Figura 2. Histograma de las puntuaciones de la EECI.........................54 


\section{ÍNDICE DE ANEXOS}

Anexo 1. Matriz de evaluación de criterio de jueces para la Escala de Estrés

Cotidiano Infantil (EECI) .......................................... 77

Anexo 2. Ficha técnica de la Escala de Estrés Cotidiano Infantil (EECI)......85

Anexo 3. Versión inicial de la Escala de Estrés Cotidiano Infantil (EECI)......87

Anexo 4. Lista de Chequeo Conductual de Ansiedad en Niños (LCCAN)

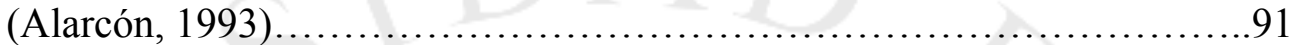

Anexo 5. Segundo procedimiento del análisis factorial exploratorio para las puntuaciones de la EECI...........................................93

Anexo 6. Tercer procedimiento del análisis factorial exploratorio para las puntuaciones de la EECI............................................94

Anexo 7. Versión final de la Escala de Estrés Cotidiano Infantil (EECI).......95

Anexo 8. Consentimiento informado........................................98 


\section{RESUMEN}

Es común experimentar estrés de vez en cuando, pero este puede generar consecuencias negativas de no manejarse adecuadamente. Se han llevado a cabo investigaciones sobre el estrés en adultos; sin embargo, sobre el estrés en niños, existen pocas pruebas o ninguna en el caso del contexto peruano. La presente investigación tuvo como objetivo construir la Escala de Estrés Cotidiano Infantil (EECI) y reportar sus propiedades psicométricas. La prueba fue aplicada en 421 niños y niñas de 3ero, 4to y 5 to grado de primaria de colegios públicos y privados de Lima Metropolitana. Se proporcionan evidencias de validez relacionadas al contenido de la prueba por medio de un criterio de jueces conformado por nueve expertos. También, se reportan evidencias de validez relacionadas a la estructura interna de la prueba, por medio del análisis factorial, encontrándose una estructura unidimensional (alfa ordinal $=.91, \mathrm{EEM}=3.66$ ). Asimismo, las evidencias de validez vinculadas a la relación con otras variables se llevaron a cabo a partir de la correlación entre la EECI y la Lista de Chequeo Conductual de Ansiedad en Niños (LCCAN) propuesta por Alarcón (1993). Esta correlación fue estadísticamente significativa y fuerte. Finalmente, se realizó una comparación de los niveles de estrés según el sexo, el grado y el tipo de colegio y no se hallaron diferencias estadísticamente significativas. Por ello, se realizó una clasificación de baremos en quintiles sin necesidad de dividirlos en subgrupos.

Palabras clave: Estrés, ansiedad, EECI, LCCAN, evidencias de validez, confiabilidad. 


\begin{abstract}
It is normal to experiment stress from time to time, but it can have a negative impact if it is not well-handled. There are plenty of studies about stress in adults; however, research is limited when looking for stress in children, especifically within peruvian context. This research pretended to construct the Daily Infant Stress Scale (DISS) and report its psychometric properties. The test was applied on 421 boys and girls, from 3th, 4th and 5th grade, from public and private Lima Metropolitana schools. Appropiate validity evidence based on test content was estimated by nine subject matter experts. Also, validity evidence based on internal structure is reported and it showed an unidimensional structure (ordinal alpha $=.91, \mathrm{SEM}=3.66$ ). In addition, appropriate validity evidence based on the relations to other variables was estimated through a strong correlation between the DISS and Anxiety Behavioral Checklist for Children (ABCC) constructed by Alarcón (1993). Finally, a comparison between the total scores of stress and the groups according to sex, grade and type of school was analyzed and no statistically significant differences were found. Thus, norms were reported in a classification of quintiles and it was not necessary to classify it in subgroups.

Key words: Stress, anxiety, DISS, ABCC, validity evidences, reliability.
\end{abstract}




\section{INTRODUCCIÓN}

La presente investigación tiene como objetivo reportar las propiedades psicométricas de la Escala de Estrés Cotidiano Infantil (EECI) en una muestra de 421 niños y niñas de 3ero, 4to y 5to grado de primaria de colegios públicos y privados de Lima Metropolitana.

En el primer capítulo, la investigación responde al planteamiento del problema, en donde se explaya la descripción del problema de investigación, la justificación y la relevancia del estudio.

El segundo capítulo abarca el marco teórico, a partir del cual se presenta información sobre el estrés, constructo a evaluar por medio de la EECI, y sobre pruebas que midan este concepto. Dentro del tema de estrés, se proporciona información sobre la etimología del término, las teorías que explican el concepto, los componentes del estrés, el estrés cotidiano, la similitud entre estrés y ansiedad, el estrés en los niños (situaciones donde se manifiesta), el impacto del estrés en los niños y la moderación del estrés. Por otro lado, dentro del tema de medición del estrés, se encuentran pruebas que miden el estrés en adultos y también en niños, cada una de ellas con la información más relevante.

En el tercer capítulo, se presentan los objetivos de la investigación y las definiciones de las variables a evaluar, en este caso, estrés y ansiedad. Para cada una de ellas, se ofrece una definición conceptual, tal y como son presentadas en la literatura, y una operacional, la manera en la que se va a medir en la presente investigación.

En el cuarto capítulo, se proporciona información importante sobre el método empleado para realizar la investigación. Datos como el tipo y diseño de investigación, participantes del estudio, las técnicas de recolección de datos (donde se incluye la descripción de la EECI) y el procedimiento empleado para recolectar los datos se encuentran detalladamente explicados en aquella sección.

En el quinto capítulo, se encuentran reportados los resultados de la investigación. Dentro de ellos, se reportan los análisis psicométricos, la elaboración 
de baremos y los análisis complementarios. A su vez, dentro de cada una de estas subsecciones se encuentran los datos acorde a cada uno de los objetivos planteados previamente.

En el sexto capítulo, se proporciona una discusión de la investigación. A partir de esta, se realiza una interpretación de las propiedades psicométricas encontradas en el capítulo cinco. Asimismo, se exponen los estándares de calidad con los que la presente investigación psicométrica cuenta, a partir de los Estándares para la Evaluación Educativa y Psicológica (AERA, APA y NCME, 2014). Y por último, se comparan los resultados encontrados en los análisis complementarios con información relevante hallada en la literatura.

Finalmente, se ofrece una sección de conclusiones y recomendaciones a partir de las cuales se resume la información encontrada, así como las sugerencias para futuros estudios. La última sección corresponde a la de anexos, a partir de la cual se pueden encontrar documentos importantes empleados antes y en el transcurso de la investigación. 


\section{CAPÍTULO I: PLANTEAMIENTO DEL PROBLEMA}

\subsection{Descripción del problema}

A lo largo de los años, se ha venido estudiando el impacto del estrés en la salud física y psicológica de las personas. Existen diferentes tipos de estrés: se habla de un estrés reciente, o también llamado estrés por sucesos vitales, estrés crónico y estrés cotidiano (Sandín, 2003). La presente investigación se focalizará, principalmente, en este último tipo de estrés.

El estrés cotidiano o también conocido como estrés por sucesos menores explica la presencia de posibles factores inductores de estrés del día a día, referidos a contrariedades, que generan sensaciones de angustia y ansiedad (Sandín, 2003). Se afirma que las contrariedades pueden estar determinadas situacionalmente (e.g. tráfico) o ser repetitivas (e.g. problemas en el ámbito laboral), ya sea porque la persona se encuentra siempre en un mismo contexto o porque sus estrategias de afrontamiento frente a esas demandas son inefectivas (Kanner, Coyne, Schaefer y Lazarus, 1981).

Por otro lado, recientemente, se ha venido estudiando el estrés experimentado por los niños (Morales, Trianes y Miranda, 2012). Se ha encontrado que las fuentes de estrés de éstos son distintas a las de los adultos. En los niños, los estresores, son principalmente las presiones académicas, los problemas familiares y las relaciones con los pares (Oros y Vogel, 2005). No obstante, la experiencia de estrés es subjetiva y por lo tanto, puede llegar a ser muy similar en ambos casos. Así por ejemplo, si para un niño resulta estresante pelearse con un compañero y para un adulto, tener una deuda grande, no se puede juzgar cuál de las dos experiencias es más "impactante" o “importante", ya que éstas son vividas personalmente (Trianes, 2003).

Asimismo, se ha estudiado que el estrés experimentado durante la vida temprana puede generar alteraciones en la estructura cerebral, perturbando funciones importantes y generando un impacto a largo plazo (Brietzke et al., 2012). De esta manera, las personas que han experimentado estrés de niños tienen una alta probabilidad de experimentar síntomas de ansiedad o de depresión en la adolescencia o adultez (Tsoory, Cohen y Richter-Levin 2007). 
A partir de esto, resulta conveniente realizar evaluaciones que permitan intervenir en los casos de niños que estén experimentando estrés. Así, éstos podrán aprender a lidiar con situaciones estresantes o en el mejor de los casos, prevenirlas y evitar posibles síntomas de ansiedad o depresión en el futuro.

Existen diferentes técnicas para medir el estrés en niños. Unas de ellas son las medidas fisiológicas a partir de las cuales se estima el estrés en base a los niveles de cortisol que presentan cada uno de los participantes (Osika, Friberg y Währborg, 2007). Otra de las técnicas de medición son las pruebas psicológicas, las cuales miden el estrés mediante el autorreporte de cada uno de los sujetos (Fernández-Ballesteros, 1996). Debido a que la primera técnica de medición requiere de materiales especializados así como de procedimientos muy complejos, se emplean, con mayor frecuencia, los instrumentos psicológicos.

Dentro de las pruebas que miden estrés en niños, se han encontrado las siguientes: el Repertorio de Eventos Estresantes de Lewis (Lewis, Siegel y Lewis, 1984), el Inventario de Estrés Infantil (IEI) (Zaira, Hernández, Juárez, Martínez, Ortega y López, 2007), el Cuestionario de Estrés en Niños (SiC) (Osika et al., 2007), el Inventario Infantil de Estresores Cotidianos (IIEC) (Trianes, Mena, Fernández, Escobar, Maldonado y Muñoz, 2009), la Escala de Depresión, Ansiedad y Estrés (DASS) (Patrick, Dyck y Bramston, 2010), el Cuestionario de Estrés, Emociones y Afrontamiento (CEEA) (Zaira, Muñoz, Berra, Nava y Gómez, 2012) y la Escala de Estrés Cotidiano en el Contexto Escolar (EECE) (Encina y Ávila, 2015). A diferencia de las que miden estrés en adultos, los instrumentos que miden estrés en niños son limitados y ninguno de aquellos se encuentra validado al contexto peruano. A partir de esto, la presente investigación busca completar el vacío metodológico y práctico, construyendo un instrumento que permita medir el estrés cotidiano en niños.

Debido a que el uso de un nuevo instrumento resulta imposible sin antes conocer sus propiedades psicométricas, la pregunta de investigación del proyecto es la siguiente: ¿Cuáles son las propiedades psicométricas derivadas de las puntuaciones de la Escala de Estrés Cotidiano Infantil? 


\subsection{Justificación y relevancia}

Previo al planteamiento de la presente investigación, se llevó a cabo una búsqueda exhaustiva de pruebas que miden estrés cotidiano infantil en la población que se pretende estudiar. Se realizó la búsqueda en base de datos como EBSCO Host Research Databases, ProQuest, Psicodoc y APA PsycNET. Si bien se encontraron instrumentos de medición de estrés, los que miden este constructo, específicamente, en los niños son limitados. Asimismo, ninguno de ellos se encuentra adaptado al medio de estudio; es por ello que se decidió continuar con la elaboración del instrumento.

Se puede afirmar que la construcción de una escala que mida estrés cotidiano infantil supone un aporte metodológico y práctico importante.

Por un lado, es un aporte metodológico, ya que consiste en la elaboración de una herramienta de investigación. Se decidió construir un instrumento que mida el estrés en niños en vez de validar uno ya construido, principalmente, debido a la antigüedad de los instrumentos encontrados durante el momento de construcción de la Escala de Estrés Cotidiano Infantil. La escala de medición de estrés en niños más reciente, encontrada durante los primeros pasos de construcción del estudio, fue publicada en el 2012 (Zaira et al., 2012). Lazarus y Folkman (1987) mencionan que el estrés es un constructo, cuyo estudio debe ser actualizado debido a que, constantemente, cambian las interpretaciones de las personas con respecto a su entorno y por lo tanto, también con respecto a los eventos amenazantes o estresantes.

Además, se afirma que los enfoques propuestos por los autores de los instrumentos encontrados son distintos al que se plantea en la presente investigación. Estudios previos abarcan la investigación de estresores (eventos estresantes), afrontamiento de situaciones estresantes o niveles de estrés en los niños (Lewis et al., 1984; Zaira et al, 2007; Trianes et al., 2009). Sin embargo, ninguno de estos considera la medición del estrés en niños a partir de la evaluación de los componentes del estrés y las situaciones en donde este surge. Así, se afirma que la construcción de la EECI supone una contribución en tanto se pretende medir de una manera nueva el estrés en la infancia. 
Asimismo, contar con una prueba estandarizada es una tarea científica de suma importancia, ya que permite elaborar nuevas técnicas de estudio y evaluación de un conjunto diverso de constructos psicológicos (Fernández-Ballesteros, 1996). Adicionalmente, corresponde a una gran contribución en estudios posteriores. A partir de la construcción de un instrumento, se pueden proporcionar estándares de calidad mediante los cuales se pueden llevar a cabo investigaciones adecuadas en relación al constructo estudiado, en este caso, estrés cotidiano infantil (AERA, APA, NCME, 2014).

Por otro lado, la elaboración del instrumento brinda un aporte práctico respondiendo a la necesidad preventiva del estrés infantil. Los resultados obtenidos a partir de la aplicación de la escala pueden brindar información que facilite, más adelante, la prevención de situaciones que generan estrés en los niños, así como el aprendizaje de los procesos para afrontarlas (Zaira et al., 2007). Esto podría contribuir a generar estrategias de prevención para evitar desventajas y malestar en áreas académicas, sociales y familiares (Oros y Vogel, 2005). De esta manera, se reduciría el impacto que el estrés tiene a nivel neurológico (Brietzke et al., 2012) así como la frecuente incidencia en la adultez (Escobar et al., 2013). 


\section{CAPÍTULO II: MARCO TEÓRICO}

\subsection{Etimología del término estrés}

El término estrés se remonta al origen anglosajón (stress), cuyo significado es "tensión" o "presión". El primer uso de esta palabra se dio en el siglo XIV cuando Robert Hooke, un físico-biólogo, realizó un análisis de ingeniería sobre estrés. A partir de este, introdujo tres conceptos elementales: carga, estrés y tensión. Carga hacía referencia a las fuerzas externas, como el peso. Estrés se relacionaba con el área en donde la carga era aplicada. Y tensión correspondía a la deformación de la estructura, debido a la carga y el estrés (Lazarus, 2000). El trabajo de Hooke influyó, posteriormente, de manera significativa en lo que, actualmente, se considera estrés y términos relacionados a ello.

Durante el siglo XX, "estrés" pasó a ser un término bastante estudiado, debido a la importancia que implicaba dentro de la salud de las personas. Así, causó tanta atención que se creó una disciplina nueva llamada estresología (Humphrey y McCarthy, 1998). A partir de ella, se estudiaron las teorías, causas y efectos del estrés en las personas.

Hoy en día, existen muchos estudios y discusiones acerca del tema. Las investigaciones realizadas pretenden intervenir en contextos en donde el estrés es muy elevado y por otro lado, prevenir en otros contextos (Morrison y Bennett, 2008).

A partir de los estudios realizados sobre estrés, se identificaron un conjunto de eventos que solían generarlo con mayor frecuencia en las personas (Holmes y Rahe, 1967). Asimismo, se halló que la sensación de alerta, generada por el estrés, podía ser precedida tanto por eventos negativos como positivos. Así fue que se plantearon los términos distrés y eustrés (Gutiérrez, 1998).

El distrés es el estado de estrés a partir del cual la experiencia trae emociones negativas, debido a que las situaciones son interpretadas como amenazas, daños o pérdidas, por ejemplo: rendir un examen, divorciarse, perder a un ser querido, etc. Por otro lado, el eustrés es el estado de estrés a partir del cual la experiencia trae emociones positivas, ya que las situaciones son interpretadas como desafíos o retos, por ejemplo: planear un viaje, planear una fiesta, casarse, etc. (Gutiérrez, 1998). Además, se afirma 
que cuando se trata de una situación de distrés se presenta una excesiva activación psicofisiológica y en el caso de una situación de eustrés, la activación psicofisiológica es adecuada para culminar con éxito una determinada tarea (Pereyra, 2008).

\subsection{Definición del estrés}

\subsubsection{El estrés como estímulo}

El estrés visto como estímulo hace referencia a los acontecimientos del entorno, principalmente, acontecimientos vitales. La premisa principal de esta teoría se centra en que existen ciertos eventos que son considerados estresantes de manera universal (Toledo, Barreto y Ferrero, 2000). De esta manera, el estrés es localizado fuera del individuo que lo experimenta (Pereyra, 2008).

Esta definición de estrés como suceso externo es respaldada por la teoría de los eventos vitales propuesta por Holmes y Rahe (1967). Estos autores investigaron sobre un gran número de situaciones que generaban altos niveles de estrés en las personas y que más adelante, tendrían consecuencias perjudiciales en su salud física (Oblitas, 2009).

A partir de sus investigaciones, Holmes y Rahe, crearon la escala de apreciación de reajuste social (Holmes y Rahe, 1967). Esta presenta una lista de sucesos vitales, situaciones generadoras de estrés y sus unidades de cambio vital (UCV), valores que hacen referencia a la intensidad y periodo de tiempo necesarios para ajustarse a un evento vital (Oblitas, 2009). Se encontró que aquellas personas que registraban menos de 150 UCV presentaban $30 \%$ de posibilidades de enfermarse en el futuro, los que alcanzaban entre 150 y 299 UCV tenían un 50\% de probabilidades, mientras que los que registraban 300 UCV o más, alcanzaban un 80\% de probabilidades (Pereyra, 2008). A continuación, se muestra la Tabla 1 de sucesos vitales junto con sus UCVs, extraída de Holmes y Rahe (1967): 


\section{Tabla 1}

\section{Escala de reajuste social}

Posición

\begin{tabular}{|c|c|c|}
\hline 1 & Muerte del cónyuge & 100 \\
\hline 2 & Divorcio & 73 \\
\hline 3 & Separación matrimonial & 65 \\
\hline 4 & Encarcelamiento & 63 \\
\hline 5 & Muerte de un familiar cercano & 63 \\
\hline 6 & Lesión o enfermedad personal & 53 \\
\hline 7 & Matrimonio & 50 \\
\hline 8 & Despido del trabajo & 47 \\
\hline 9 & Reconciliación matrimonial & 45 \\
\hline 10 & Retiro & 45 \\
\hline 11 & Cambio de salud de un miembro de la familia & 44 \\
\hline 12 & Embarazo & 40 \\
\hline 13 & Dificultad o problemas sexuales & 39 \\
\hline 14 & Incorporación de un nuevo miembro de la familia & 39 \\
\hline 15 & Reajuste de negocio & 39 \\
\hline 16 & Cambio de situación financiera & $38=$ \\
\hline 17 & Muerte de un amigo íntimo & 37 \\
\hline 18 & Cambio de tipo de trabajo & 36 \\
\hline 19 & Cambio en el número de disputas con el cónyuge & 35 \\
\hline 20 & Hipoteca superior a 10000 dólares & 31 \\
\hline 21 & Juicio hipotecario por crédito o hipoteca & 30 \\
\hline 22 & Cambio de responsabilidad en el trabajo & 29 \\
\hline 23 & Hijo o hija que dejan el hogar & 29 \\
\hline 24 & Problemas legales & 29 \\
\hline 25 & Logro personal notable $\sqrt{-12}$ & 28 \\
\hline 26 & La esposa comienza o deja de trabajar & 26 \\
\hline 27 & Comienzo o fin de la escolaridad & 26 \\
\hline 28 & Cambio de condiciones de vida & 25 \\
\hline 29 & Revisión de los hábitos personales & 24 \\
\hline 30 & Problemas con el jefe & 23 \\
\hline 31 & Cambio de turno o de condiciones laborales & 20 \\
\hline 32 & Cambio de residencia & 20 \\
\hline
\end{tabular}




$\begin{array}{lll}33 & \text { Cambio de colegio } & 20 \\ 34 & \text { Cambio de actividades de ocio } & 19 \\ 35 & \text { Cambio de actividad religiosa } & 19 \\ 36 & \text { Cambio de actividades sociales } & 18 \\ 37 & \text { Hipoteca o crédito inferior a 10000 dólares } & 17 \\ 38 & \text { Cambio de hábito de dormir } & 16 \\ 39 & \text { Cambio en el número de reuniones familiares } & 15 \\ 40 & \text { Cambios de hábitos alimentarios } & 15 \\ 41 & \text { Vacaciones } & 13 \\ 42 & \text { Fiestas navideñas } & 12 \\ 43 & \text { Leves transgresiones a la ley } & 11\end{array}$

Fuente: Holmes, T.H. \& Rahe, R. H. (1967). The social readjustment rating scale. Journal of Psychosomatic Research, 11, 213-218.

Una de las críticas más resaltantes sobre este modelo es el hecho de que no toma en cuenta las diferencias individuales (Pereyra, 2008). Si bien señala las situaciones universales de estrés, no se hace mención al hecho de que cada persona puede reaccionar de manera distinta sobre estas (Oros y Vogel, 2005). Asimismo, se ha encontrado que el estrés no siempre tiene efectos negativos en las personas; esto quiere decir que, distinto a lo que Holmes y Rahe señalan, estrés y enfermedad no siempre están vinculados. Por el contrario, se afirma que situaciones estresantes pueden activar señales de alerta positivas y generar, posteriormente, resiliencia (Pianta y Walsh, 1998). Finalmente, Oblitas (2009) señala que los autores de esta teoría realizaron sus estudios de manera retrospectiva, es decir, se les preguntaba a los pacientes ya enfermos por eventos vitales que hayan generado estrés en sus vidas. Sin embargo, al aplicarse el estudio de manera prospectiva, no se encontró relación estadísticamente significativa entre estrés y enfermedad.

\subsubsection{El estrés como proceso}

Según Lazarus y Folkman (1986), el estrés es definido como la relación particular entre el individuo y el entorno, que es evaluado por éste como amenazante o desbordante de sus recursos y pone en peligro su bienestar. Desde la perspectiva de estos autores, se puede afirmar que el estrés presenta un componente cognitivo significativo. La respuesta negativa de estrés, en la mayoría de los casos, puede ser revertida, ya que está ligada a una interpretación personal (Trianes, 2003). Esto último es lo que hace que el 
estrés sea vivido de manera subjetiva (Oros y Vogel, 2005). Así, dos niños pueden tener respuestas distintas frente a una misma situación de estrés, ya que sus interpretaciones pueden diferir (Trianes et al., 2009).

\subsubsection{El modelo transaccional del estrés}

Frente a las diversas situaciones de estrés, y por lo tanto diversas interpretaciones, Lazarus y Folkman (1987) plantean un modelo transaccional. Este supone una serie de evaluaciones por parte del individuo frente a la situación de estrés experimentada. Y estas evaluaciones se relacionan, a su vez, con la estrategia de afrontamiento que tomará la persona frente a situaciones estresantes (Zaira et al., 2012).

La primera evaluación de este modelo es la evaluación primaria. Se refiere a cómo el individuo percibe o interpreta la situación. Esta puede ser: (1) irrelevante, (2) positiva o beneficiosa y (3) estresante. En el primer caso, la situación no se considera amenazante ni beneficiosa; en el segundo, las consecuencias de la situación traen beneficios y en el tercero, las consecuencias son negativas, pueden traer pérdidas o amenazas (Pereyra, 2008).

La segunda evaluación es la secundaria. Esta se caracteriza por una forma de evaluación orientada a determinar qué es lo que se puede hacer frente a la situación ya identificada como estresante (Lazarus y Folkman, 1987). Así, mediante este segundo tipo de evaluación la persona evalúa cuáles son los recursos que tiene para hacer frente. A partir de esta evaluación, la persona pasará a realizar un afrontamiento de la situación y escoger de qué manera hacer frente a su problema. En el caso de los niños, la consideración de la estrategia de afrontamiento varía dependiendo de las características personales, el momento de desarrollo en el que se encuentre y las exigencias del entorno (Toledo et al., 2000).

Finalmente, se lleva a cabo una reevaluación, la cual se refiere a los procesos de retroalimentación que el individuo va percibiendo conforme interpreta, evalúa y afronta la situación. De esta manera, después de afrontar la situación, la interpretación de ésta, inicialmente considerada estresante, cambia. (Toledo et al., 2000).

De esta manera, se puede afirmar que el hecho de que una situación provoque una respuesta de estrés dependerá de la evaluación que se haga sobre la situación y de 
los recursos que se encuentren disponibles para afrontarla (Toledo et al., 2000). Es importante recalcar el papel activo que le asignan Lazarus y Folkman al individuo durante todo el proceso de evaluación y afrontamiento, ya que la experiencia de estrés dependerá, finalmente, de la interpretación personal que se le de al evento vivido.

Si bien el modelo de Lazarus y Folkman es considerado un modelo completo (Pereyra, 2008), presenta algunas críticas. La crítica principal es la circularidad del enfoque (Oblitas, 2009). Se afirma que existe dependencia ontológica (definición) entre los términos de valoración primaria, la demanda, y valoración secundaria, los recursos o capacidad de afrontamiento. De esta manera, uno no puede ser explicado sin el otro; lo cual conduce a una segunda crítica referida la tautología del modelo (Hobfoll, 1989). Se afirma que no existen definiciones independientes para cada uno de estos términos. Así, las demandas siempre dependen de los recursos de afrontamiento y a su vez, estos dependen de las demandas, situación que no se cumple según las investigaciones de Zohar y Dayan (1999).

\subsubsection{El estrés como respuesta}

Selye (1956) define el estrés como una respuesta inespecífica por parte del organismo frente a la demanda de un agente nocivo que atenta contra el equilibrio homeostático. Frente a situaciones de peligro o estrés, el organismo se prepara para huir o pelear mediante la liberación de sustancias, como la adrenalina, noradrenalina y la hormona adrenocorticotropa (ACTH) (Oblitas, 2009).

Independientemente de la naturaleza del estímulo nocivo, el organismo responde de manera estereotipada. Frente a ello, este debe realizar un esfuerzo para adaptarse a la nueva condición a la que ha sido sometido (Selye, 1956). A esto, se le denominó síndrome de adaptación general (SAG). 
El SAG comprende las siguientes etapas (Pereyra, 2008):

- Reacción de alarma: es la alteración fisiológica que se da en el organismo debido a las circunstancias experimentadas. En esta fase, se activan una serie de glándulas y se liberan hormonas, como la ACTH y la corticoides.

- Estado de resistencia: el individuo se adapta frente a la situación amenazante a la que ha sido sometido. Se da un equilibrio u homeostasis entre los factores internos y externos.

- Fase de agotamiento: fase en la que la adaptación se pierde, después de un tiempo prolongado de exposición frente a la amenaza.

Las fases implicadas en el SAG se muestran, a continuación, en la Figura 1:
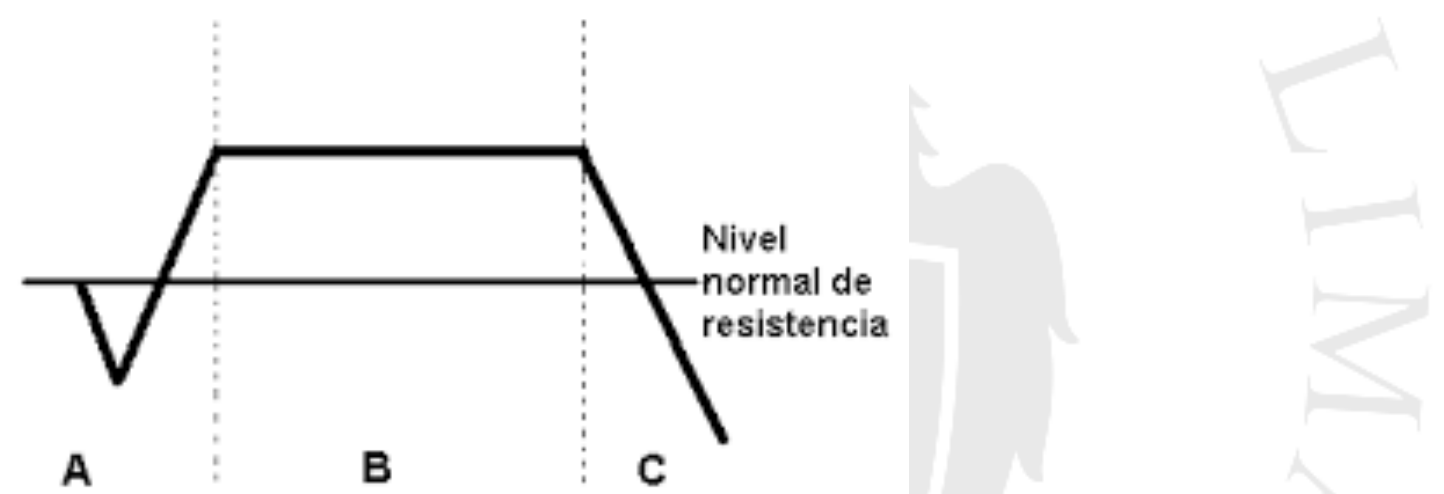

Figura 1. Fases del Síndrome de Adaptación General (SAG) de Hans Selye. A = reacción de alarma, $\mathrm{B}=$ estado de resistencia y $\mathrm{C}=$ fase de agotamiento

Fuente: Selye, H. (1950). The physiology and pathology of exposure to stress. Montreal: Acta.

A pesar de la importancia histórica que tiene el modelo de Selye (Pereyra, 2008), este ha recibido críticas por parte de algunos autores. Según Sandín (2003), la teoría no señala las condiciones para que un estímulo sea considerado estresor independientemente de los efectos que traiga. Es decir, sólo se puede hablar de un estresor observando los efectos que éste provoque. Por otro lado, Selye señala que la respuesta de estrés no es específica porque, independientemente de la situación que genere estrés, la respuesta del organismo es la misma. Frente a esto, se ha demostrado que la respuesta del organismo está generada más por un estímulo emocional que por el 
físico (Pereyra, 2008). De esta manera, la respuesta fisiológica estaría estrechamente relacionada a la respuesta emocional.

\subsubsection{El estrés como modelo procesual}

Se define al estrés por medio de la integración de la concepción del estrés como estímulo, proceso interactivo y respuesta (Sandín, 2008).

Este modelo integrador presenta siete etapas. La primera empieza con demandas psicosociales, referidas a los estresores externos, que se encuentran en el medio en donde la persona se desenvuelve. En la segunda etapa, la persona lleva a cabo una evaluación acerca de estas variables externas estresantes. La tercera etapa surge como consecuencia de la segunda; a partir de aquella se generan respuestas sobre la evaluación de las variables estresantes, las respuestas son fisiológicas, motoras y cognitivas. En la etapa cuatro se da un proceso de afrontamiento por parte de la persona en relación al estresor. La quinta etapa involucra las variables personales de cada uno en donde se incluyen factores genéticos y adquiridos, que serán útiles dentro del afrontamiento que se realice. En la sexta etapa se toman en consideración los factores sociales como el contexto político, la cultura y el nivel socio económico; variables que también van a influir en el proceso de percepción y afrontamiento del estrés. Y finalmente, en la última etapa (la séptima) se evalúa el estado de salud mental de la persona luego de hacer frente las seis primeras etapas.

\subsection{Componentes del estrés}

Desde la perspectiva de Lazarus y Folkman (1986) el estrés está compuesto por los siguientes factores:

- La existencia de una demanda del entorno

- La percepción de esa demanda como amenaza, pérdida o daño

- La falta de recursos para responder dicha demanda

- La experiencia emocional negativa

- El peligro de inadaptación o psicopatología 
En el 2009, Trianes y sus colaboradores agrupan los factores del estrés, específicamente en niños, y los clasifican en cuatro grandes componentes. Estos son los siguientes:

- Componente cognitivo: pensamientos relacionados a las situaciones estresantes. Por ejemplo: "me va a salir mal", "se van a burlar de mî".

- Componente fisiológico: sensaciones fisiológicas involuntarias que acompañan al estado de estrés. Por ejemplo: sudoración, palpitaciones, dolor de estómago.

- Componente afectivo: estado subjetivo de estar estresado. Por ejemplo: sensación de angustia.

- Componente conductual: relacionado con la conducta intencional que se lleva a cabo frente a situaciones estresantes. Por ejemplo: escapar, evitar.

\subsection{Estrés Cotidiano}

Se le llama estresor o molestia cotidiana a aquellos eventos que generan frustración, irritación y estrés y que se dan en el día a día durante las transacciones que se llevan a cabo con el ambiente en donde la persona se desenvuelve (Kanner et al., 1980). Ejemplos de estos pueden ser encontrarse atascado en el tráfico, pelear con la pareja o algún amigo cercano, tener una sobre caga de responsabilidades, no tener suficiente dinero para comprar comida, entre otras (Oblitas, 2009).

Se afirma que existe una diferencia entre los estresores inhabituales y los estresores cotidianos. Los primeros se refieren a eventos como la muerte de un ser querido o el divorcio de los padres; mientras que los segundos se dan por actividades como las tareas escolares. Asimismo, se sostiene que éstos últimos son los que más daño podrían generar, debido a que si bien tienen un impacto menor, su presencia es continua (Sandín, 2003).

De manera contraria a los grandes eventos vitales, o también conocidos como estresores inhabituales, la persona que se enfrenta a estresores cotidianos no requiere gran ajuste para manejarlos. Esto se debe a que es uno de los varios eventos que ocurren en el día a día de una persona (Oblitas, 2009). Sin embargo, Sandín (2003) afirma que si bien tienen un impacto menor, al mostrar una presencia continua podrían generar más daño y volverse desadaptativo. 
Kanner y sus colaboradores (1981) reafirman lo que Sandín (2003) postula: las molestias o estresores cotidianos se encuentran relacionados a síntomas físicos y mentales negativos. Es por ello, que a pesar de que se tratan de molestias pequeñas no se debe subestimar el impacto y consecuencias que estas puedan presentar en la salud de las personas (Selye, 1956). Asimismo, esto se debe a que el estrés es un fenómeno subjetivo y se vive de manera individual (Oros y Vogel, 2005).

En los niños, los estresores presentan un carácter evolutivo; las vivencias amenazantes cambian conforme los niños van creciendo. Esto se debe a que cambia la manera en la que se percibe el mundo y la interacción que tienen con este. Así, para un niño pequeño el estrés se encontrará más relacionado al núcleo familiar y las relaciones de apego; para un niño en edad escolar, los estresores se hallarán en el contexto escolar y la interacción con los pares; y para un adolescente, serán los cambios corporales y de interacción con padres, amigos y personas del sexo opuesto (Oros y Vogel, 2005).

Vargas (2014) afirma que uno de los estresores más intensos para un niño son los procesos de separación, divorcio o ruptura conyugal. Esto se da porque, al ser un evento estresante para toda la familia y que puede repercutir en la salud de sus miembros, también presenta un impacto significativo en el bienestar de los hijos, llegando a poder desarrollar abandono y rechazo, inseguridad, baja autoestima e inadaptación personal, familiar, escolar y social. No obstante, se sostiene que, con un manejo adecuado, los efectos podrían revertirse con el tiempo.

Asimismo, Lau (2002) indica que mientras menor sea el niño, mayor será el impacto de nuevos acontecimientos y mayores probabilidades de experimentar niveles altos de estrés. Asimismo, se afirma que la repercusión del estrés será mayor en aquellos niños menores a 10 años, que hayan nacido prematuros, que son hombres y que tienen una capacidad cognitiva limitada o que hayan vivenciado estrés pre-natal (Monk et al., 2000).

La Tabla 2 muestra la organización de estresores infantiles según el ciclo evolutivo, integrando la opinión de diversos autores (Del Barrio 1997 adaptado de Oros y Vogel, 2005). 
Tabla 2

Clasificación de estresores según periodo evolutivo

\begin{tabular}{cc}
\hline Periodo evolutivo & Estresores relacionados con \\
\hline De 0 a 6 años & Pérdidación \\
Apego & Abuso \\
Abandono \\
\hline De 7 a 12 años & Compañeros \\
& Escuela \\
& Socialización \\
& Hermanos \\
& Identidad \\
\hline De 13 a 18 años & Cambio \\
\hline Interacción con otro sexo \\
Disfunción familiar \\
Competencia
\end{tabular}

Fuente: Oros, L. y Vogel, G. (2005) Eventos que generan estrés en la infancia: diferencias por sexo y edad. Enfoques XVII, 3, 85-101.

Por otro lado, con respecto a las diferencias sobre el estresores percibidos por los niños según sexo, Oros y Vogel (2005) señalan que no hay evidencias estadísticamente significativas. Sin embargo, afirman la existencia de diferencias en la naturaleza de los estresores. Así, indican que las niñas perciben más estresores relacionados con las injusticias escolares, familiares, la pérdida afectiva de personas significativas, los problemas socioeconómicos y los problemas de salud. Mientras que los niños, muestran estresores relacionados a las pérdidas afectivas de mascotas y las pérdidas materiales.

De manera contraria, Kanner et al. (1980) encuentran diferencias estadísticamente significativas de la percepción de estresores según sexo, pero en sujetos adultos. Estos investigadores llevaron a cabo una investigación a partir de la cual se evaluaron las molestias cotidianas (sucesos negativos) y las situaciones descritas como "satisfacciones" (sucesos positivos). Se encontró que ambos sexos presentan 
síntomas psicológicos negativos con respecto a las molestias cotidianas (sucesos negativos). No obstante, en el caso de las mujeres, estas también experimentan síntomas psicológicos negativos frente a situaciones satisfactorias (sucesos positivos). Esto indica que, para las mujeres adultas, cualquier cambio requiere de un proceso de ajuste; mientras que para los hombres adultos, el ajuste solo es requerido si se trata de una molestia o estresor cotidiano. Esto sugiere que las mujeres adultas pueden verse afectadas por el cambio, ya sea positivo o negativo (Oblitas, 2009).

Por otro lado, al evaluarse la diferencia de estresores según edad, Oros y Vogel (2005) encontraron que, al igual con la variable de sexo, no existen diferencias estadísticamente significativas. No obstante, se mostraron diferencias en la naturaleza de los estresores según la edad de los participantes. En el caso de los niños más pequeños, sus estresores se encontraban más enfocados en la salud personal y el descontento con la disciplina parental; mientras que en los niños más grandes, sus preocupaciones se encontraron en los problemas socioeconómicos, las situaciones académicas, los problemas interpersonales con los padres, entre los padres y los conflictos con los pares.

\subsection{Estrés y ansiedad}

Los síntomas del estrés y de la ansiedad son similares, ya que en ambos casos, la persona que los experimenta, interpreta la situación que tiene en frente como amenazante o una posibilidad de daño inminente (Lazarus y Folkman, 1986). De esta manera, la reacción del estrés se encuentra directamente relacionada con la respuesta de ansiedad (Beck, Emery y Greenberg, 1985).

Asimismo, no existe certeza sobre cuál de los dos surge como causa del otro. Ivancevich y Matteson (1991) indican que inicialmente la ansiedad puede ser considerada como consecuencia del estrés: al pasar por situaciones estresantes, se experimentan síntomas de ansiedad. Sin embargo, existe evidencia que respalda que, en casos de estrés crónico se desarrollan síntomas de ansiedad generalizada lo cual, al mantener al individuo hipervigilante, puede traer consigo percepciones de estrés reales o irreales (Beck et al., 1985).

Adicionalmente, se sabe que en ambos casos la persona experimenta una serie de síntomas fisiológicos que hacen que se mantenga alerta. No obstante, al darse por un 
periodo de tiempo prolongado, esto hace que percibir eventos como estresantes y experimentar ansiedad en grandes dosis afecte la salud, debilitando el sistema inmunológico y favoreciendo la aparición de enfermedades (Barlow, 1988).

\subsection{Estrés en niños}

\subsubsection{Dominios del estrés infantil}

Si bien se ha visto que no existen diferencias estadísticamente significativas entre la percepción de los estresores entre niños y adultos, sí existe una diferencia en los dominios en los que estos lo experimentan (Oros y Vogel, 2005). Los principales dominios de estrés en los niños pueden agruparse en tres: el familiar, el académico y el social.

\section{- Social}

Trianes (2007) afirma que es normal que los niños experimenten estrés dentro de un ámbito social. Esto se debe a que las interacciones sociales con amigos o compañeros de clase se incrementan significativamente en la adolescencia temprana y media. Así, se sabe que las principales fuentes de estrés en esta área están relacionadas a las siguientes: la pérdida de un amigo, el ingreso a un grupo, el comienzo de actividades deportivas, inicio de relaciones con pares del sexo opuesto, etc. (Kearney, Drabam y Beasley, 1993).

\section{- Académico}

En esta área, se ha identificado como estresante para un niño las siguientes situaciones: ser cambiado de centro escolar, el exceso de demandas escolares, realizar exámenes, llevar a casa malas notas, conflictos o discusiones con los profesores, cambio de profesor, preocupaciones relacionadas al futuro académico, llegar tarde al colegio, la repetición de grado, entre otras (Oros y Vogel, 2005; Trianes, 2007; Lau, 2002).

Trianes (2007) señala que, dentro de este ámbito, la situación de estrés a la que se le ha dado mayor importancia es la de transición de niveles educativos. Se sabe que este evento puede generar un impacto negativo intenso y crear una influencia significativa en el rendimiento académico de los alumnos. 
- Familiar

La familia es considerada como uno de los más importantes sistemas que favorecen la salud y facilitan el mejoramiento de la calidad de vida. Y se sabe que la disfunción de ésta se encuentra, cada vez más, ligada a sensaciones de estrés y daño en la salud mental (Vargas, 2014).

Se ha encontrado que el tamaño de la familia tiene una relación con la presencia de sintomatología del estrés, como la ansiedad. En este caso, se afirma que familias de especialmente más de 5 miembros podrían mostrar una predisposición a experimentar indicadores de ansiedad. Asimismo, se sabe que los divorcios y separaciones conyugales resaltan como los eventos familiares más estresantes experimentados por una familia (Vargas, 2014).

De esta manera, Oros y Vogel (2005) señala que los eventos más estresantes, dentro del ámbito familiar, para un niño, son los siguientes: el nacimiento de un nuevo hermano, conflictos en la relación con los padres, fallecimiento de algún familiar, enfermedad de algún familiar, cambio de domicilio, etc.

\subsection{Impacto del estrés en niños}

Algunos eventos de la vida temprana, como complicaciones de embarazo, traumas infantiles o abuso de sustancias, interactúan con rasgos genéticos y pueden conducir a trastornos del neurodesarrollo y trastornos mentales en la adultez temprana (Brietzke et al., 2012). Así, se ha comprobado que el estrés infantil tiene consecuencias negativas en el desarrollo de niños y adolescentes y que estas persisten hasta la adultez (Escobar et al., 2013).

Se afirma que la exposición a traumas emocionales severos durante la niñez puede causar alteraciones en la estructura cerebral. Así por ejemplo, el abuso y abandono infantil generan cambios a largo plazo en la reactividad al estrés y en el desarrollo del cerebro (Bremmer, 1999). En general, una vida de estrés puede alterar la sinaptogénesis y la proliferación dendrítica, pero no se manifiesta hasta la adolescencia o temprana adultez. 
También, se ha encontrado que los efectos neurobiológicos del estrés varían en las diferentes etapas de desarrollo. Así, las diferencias de las imágenes cerebrales entre niños y adultos podrían ser parcialmente explicadas por las diferencias en la maduración cerebral (Brietzke et al., 2012).

\subsection{Moderación del estrés}

Las situaciones que generan estrés en el día a día son poco predecibles e incontrolables (Lazarus y Folkman, 1987). Por ello, resulta importante conocer qué variables ayudan a moderar las consecuencias del estrés en los niños. Esto es importante porque a partir de esta información se pueden prevenir las consecuencias negativas en la salud física y mental de los niños, así como del atentado a su bienestar en general (Escobar et al, 2013).

\subsubsection{Variables ambientales}

Se ha encontrado que una de las variables moderadoras del estrés es la naturaleza cercana (Corraliza y Collado, 2011). Se sostiene que la naturaleza del entorno residencial y del entorno escolar presenta un efecto amortiguador sobre los niños. De esta manera, cuanto mayor es el acceso de los más pequeños a áreas naturales cercanas, mayor es su capacidad para manejar situaciones que generen estrés. Así, los niños que disfrutan de un mayor contacto con el medio natural sufren menos estrés del que se esperaría si no contaran con el factor de la naturaleza.

\subsubsection{Variables personales}

Con respecto a las variables moderadoras personales, se afirma la existencia de una relación significativa ente estrés y autoestima (Verduzco, Gómez-Marqueo y Durán, 2004). A mejor autoestima percibida por los niños, menores son sus niveles de estrés. Así, con una alta autoestima, la persona puede tener el control de las situaciones que ocurren y afrontar directamente los problemas o buscar soluciones que modifiquen una situación estresante con la confianza de lograrlo exitosamente. Por el contrario, con una autoestima baja, el comportamiento se rige por la duda, defensa y el miedo. Se tiende a recurrir a diferentes formas de afrontar las situaciones a través de las personas y renunciado a cualquier tipo de control. Estas últimas actúan en función de los demás y 
no de sí mismas. Y también, los sucesos estresantes son percibidos con mayor intensidad.

De la misma manera, se sostiene que existen relaciones ente el estrés y las habilidades sociales en los niños (Zaira et al., 2009). Se sostiene que el estrés está asociado a componentes de apoyo social y en este caso, a las habilidades sociales, que son un componente importante de afrontamiento. Así, los niños con mayores habilidades sociales tienden a experimentar niveles menores de estrés que los niños con menores habilidades sociales.

Finalmente, si bien existen eventos aversivos en sí mismos, no son condición exclusiva para que se produzca estrés. Esto se debe a que el proceso de evaluación cognitiva permitirá identificar y diferenciar las situaciones favorables de las no favorables, dándose de manera individual y dependiendo de las características propias de cada persona (Oros y Vogel, 2005). Así, se afirma que frente a una situación de estrés, la interpretación de la situación puede contribuir a reducir los síntomas negativos que esta trae consigo (Lazarus y Folkman, 1987).

\subsection{Medición del estrés en niños}

Cuando se habla de estrés, resulta más común pensar en el estrés que experimentan los adultos antes de pensar en el que experimentan los niños (Trianes et al., 2009). De alguna manera, se piensa que esta postura se ve reflejada en la diferencia en cantidad y acceso a las pruebas que existen para medir estrés en niños y en adultos (Zaira et al, 2007). A continuación, se muestran las escalas que miden estrés en niños y sus propiedades psicométricas.

Dentro de las pruebas encontradas en la literatura para evaluar estrés, se muestran las siguientes:

- Repertorio de Eventos Estresantes de Lewis (Lewis et al., 1984): se exponen situaciones que constituyen fuentes de estrés psicológico y los participantes deben escoger las perturbadoras. El instrumento estuvo conformado por 20 ítems y fue aplicado a 2480 niños y niñas que cursaban el 5to grado de primaria. Se realizó un análisis factorial a partir del cual se encontraron tres dimensiones: (1) ansiedades en relación al conflicto con los padres, (2) imagen personal y presión grupal en las 
relaciones y (3) movilidad geográfica. También, se estimó la confiabilidad, presentando un alfa de Cronbach de .82 .

- Inventario de Estrés Infantil (IEI) (Zaira et al, 2007): evalúa la percepción de estrés en niños 40 niños de 6 a 8 años en tres áreas: daño-pérdida, social y familiar. Esta escala constó de 52 ítems y por cada uno de ellos las opciones de respuesta fueron: Muy Tranquilo, Poco Tranquilo, Poco Nervioso y Muy Nervioso. La estimación de la confiabilidad de esta prueba se llevó a cabo por medio del coeficiente de alfa de Cronbach el cual fue de .83. No se llevaron a cabo mayores análisis psicométricos.

- Cuestionario de Estrés en Niños (SiC) (Osika et al., 2007): este instrumento evalúa niveles de estrés en niños y se empleó para comparar estos niveles con medidas de depresión, ansiedad, irritabilidad, conductas disruptivas y autopercepción negativa. Participaron 181 niños de entre 9 a 12 años de edad. Se estimó la confiabilidad por medio del coeficiente alfa de Cronbach, siendo de .86. Asimismo, se brindaron evidencias de validez vinculadas a la relación con otras variables por medio de la correlación del SiC con el Inventario de Jóvenes de Beck y medición de cortisol. Se encontraron asociaciones estadísticamente significativas en con la primera medida, pero no con la segunda. No se proporcionan información sobre mayores análisis psicométricos.

- Inventario Infantil de Estresores Cotidianos (IIEC) (Trianes et al., 2009): evaluación de los estímulos estresores y de las respuestas psicofisiológicas, emocionales, cognitivas o conductuales que se emiten en la infancia al sufrir la acción de dichos estresores. Contiene preguntas relacionadas al ámbito de salud, la escuela e iguales y familia. La muestra estuvo conformada por 1094 niños de edades entre 8 a 12 años. El inventario estuvo conformado por 41 ítems dicotómicos de respuestas: si o no. Doce de los 41 ítems se encontraron redactados en relación a la salud; otros doce, en la escuela y diecisiete, a síntomas experimentados durante la aplicación del cuestionario. Se estimó la consistencia interna de la prueba a través del alfa de Cronbach, que fue de .70. Asimismo, se brindaron evidencias de validez vinculadas a la relación con otras variables, mediante la correlación entre la puntuación total de la IIEC y las siguientes medidas: la puntuación total del SiC (Cuestionario de Estrés en Niños) $(\mathrm{r}=.3, \mathrm{p}<.05)$, el ratio de Cortisol/DHEA-s medida en saliva $(\mathrm{r}=.22$, $\mathrm{p}<.05)$, calificaciones en lenguaje y matemáticas $(\mathrm{r}=.66, \mathrm{p}<.01)$, la puntuación en 
historia estructurada del desarrollo, que representa los problemas de salud informados por los padres de los participantes $(\mathrm{r}=.23, \mathrm{p}<.05)$ y la puntuación en las escalas SRP-C (Autoinforme de Personalidad para niños) del BASC (Sistema de Evaluación de la Conducta de Niños y Adolescentes), en donde todos los coeficientes fueron altos y estadísticamente significativos. No se proporcionan evidencias psicométricas sobre la estructura factorial de la prueba.

- Escala de Depresión, Ansiedad y Estrés (DASS) (Patrick et al., 2010): es empleada para evaluar síntomas severos de depresión, ansiedad y estrés en niños y adolescentes. Esta prueba estuvo conformada por 21 ítems y fue aplicada en 425 participantes cuyas edades oscilaron entre 11 y 17 años. Se llevó a cabo un análisis por componentes principales, a partir del análisis paralelo, en donde se encontró la existencia de un solo componente que explicó el $49.3 \%$ de la varianza compartida. Asimismo, se estimó la confiabilidad por medio del coeficiente alfa de Cronbach el cual fue mayor a .80 .

- Cuestionario de Estrés, Emociones y Afrontamiento (CEEA) (Zaira et al., 2012): evalúa emociones positivas y negativas experimentadas ante dos tipos de situaciones: estresantes y placenteras. Está conformado por 27 preguntas, calificadas del 1 al 4 en donde 1 es Nada y 4 es Mucho. Esta escala fue aplicada en 80 adolescentes de entre 11 a 15 años de edad. Se realizó un análisis por componentes principales con rotación varimax y se identificaron tres factores. (1) El primer factor explicó el $51.17 \%$ de la varianza compartida y en él, se agruparon la mayoría de ítems de emociones positivas del evento estresante. (2) En el segundo factor, se agruparon las emociones positivas sobre el evento placentero y (3) en el último, las emociones negativas que se presentaron en el evento estresante. Asimismo, se encontró un coeficiente de alfa de Cronbach de .85 .

- Escala de Estrés Cotidiano en el Contexto Escolar (EECE) (Encina y Ávila, 2015): se evaluaron los niveles de estrés presentados en contextos escolares en 734 niños y niñas de entre 10 a 17 años. Se llevó a cabo un análisis factorial, por medio del método de análisis paralelo y con una rotación oblicua promin y se encontraron tres dimensiones: (1) estrés académico, (2) estrés y violencia relacional y (3) estrés ambiental. Asimismo, se estimó el índice de consistencia interna, por medio del alfa de Cronbach, que fue de .90 . 


\section{CAPÍTULO III: OBJETIVOS Y DEFINICIÓN DE VARIABLES}

\subsection{Objetivos}

El siguiente estudio pretende conocer las propiedades psicométricas de la Escala de Estrés Cotidiano Infantil (EECI) elaborada para la valoración de los aspectos cognitivos, afectivos, fisiológicos y conductuales en los ámbitos académico, social y familiar en niños de 3ero a 5to grado de primaria de colegios de Lima Metropolitana. Para ello, se plantearon los siguientes objetivos de investigación:

- Obtener evidencias de validez vinculadas con el contenido a través del criterio de jueces.

- Obtener evidencias de validez vinculadas a la estructura interna de la prueba a través del análisis factorial.

- Obtener evidencias de validez vinculadas a la relación con otras variables, de tipo convergente, a través de la correlación entre las puntuaciones derivadas de la aplicación de la EECI y la Lista Chequeo Conductual de Ansiedad en Niños (Alarcón, 1993).

- Analizar la discriminación de los ítems de cada subescala que conforman la EECI.

- Estimar la confiabilidad por consistencia interna de las puntuaciones obtenidas en la EECI a través del coeficiente alfa de Cronbach y alfa ordinal.

- Elaborar baremos para niños de 3ero a 5to grado de primaria de colegios de Lima Metropolitana.

\subsection{Definición de variables}

\section{Estrés cotidiano}

El estrés es definido como la relación particular entre el individuo y el entorno, que es evaluado por éste como amenazante o desbordante de sus recursos y pone en peligro su bienestar (Lazarus y Folkman, 1986). El estrés cotidiano, por otro lado, se define como las frustrantes demandas y contrariedades que acarrea la interacción cotidiana con el 
medio ambiente (Kanner et al., 1981). Corresponde a los síntomas de tensión frente a sucesos o circunstancias de alta frecuencia, baja intensidad y alta predictibilidad (Seiffge-Krenke, 2000). No se trata de síntomas patológicos, porque no atenta contra la salud de la persona que lo experimenta. En ocasiones, incluso, puede ser considerado como beneficioso, debido a que ayuda a obtener una respuesta más rápida en menor cantidad de tiempo (Hüther, 2012).

En el caso de la presente investigación, el estrés cotidiano será definido operacionalmente como la puntuación obtenida del autorreporte brindado por los niños frente a la EECI. A partir de ello, un mayor puntaje implicará mayor estrés cotidiano y un mejor puntaje, menor estrés cotidiano.

\section{Ansiedad}

La ansiedad puede ser entendida como una anticipación de cualquier peligro, amenaza o daño. La idea de un potencial peligro prepara a la persona que lo experimenta para hacer frente a él; por ello, viene siempre acompañada de sensaciones de malestar y tensión (Hamilton, 1959).

En el presente estudio, se ha definido operacionalmente la ansiedad como las puntuaciones obtenidas a partir de la aplicación de La Lista de Chequeo Conductual de Ansiedad Infantil (Alarcón, 1993). 


\section{CAPÍTULO IV: MÉTODO}

\subsection{Tipo y diseño de investigación}

La presente investigación es de tipo psicométrica ya que el objetivo es obtener evidencias de validez y confiabilidad de las puntuaciones derivadas del instrumento construido (Alarcón, 2013). Asimismo, los puntajes numéricos obtenidos permitirán generar baremos de acuerdo a las características demográficas de la muestra (Hernández, Fernández y Baptista, 2014).

El diseño de la investigación es no experimental, debido a que no se presenta una manipulación de variables, ni existe posibilidad de causalidad. Asimismo, es transeccional, ya que los datos fueron recolectados en un solo momento y tiempo único (Hernández et al., 2014).

\subsection{Participantes}

La población objetivo de la investigación fueron niños y niñas de tercero a quinto grado de primaria de colegios públicos y privados de Lima Metropolitana.

De acuerdo con los datos del ESCALE de la página web del Ministerio de Educación del Perú, son 413240 los estudiantes que pertenecen a la población objetivo de la investigación (recuperado del sitio web del Ministerio de Educación del Perú: http://escale.minedu.gob.pe/magnitudes-

portlet $/$ reporte $/$ cuadro anio $=21 \&$ cuadro $=345 \&$ forma $=U \& d p t o=15 \&$ prov $=1501 \&$ dist $=$ $\&$ dre=\&tipo_ambito=ambito-ubigeo). La distribución de los alumnos según grado, sexo y tipo de gestión se puede apreciar a partir de la Tabla 3. 
Tabla 3

Matrícula de educación primaria por tipo de gestión y sexo según forma de atención y grado 2015

\begin{tabular}{cccccc}
\hline \multirow{2}{*}{ Grado } & Total & \multicolumn{2}{c}{ Gestión } & \multicolumn{2}{c}{ Sexo } \\
& & Pública & Privada & Masculino & Femenino \\
\hline Tercer grado & 133827 & 63972 & 69855 & 68434 & 65393 \\
Cuarto grado & 135930 & 66203 & 69727 & 69641 & 66289 \\
Quinto grado & 143483 & 72864 & 70619 & 72378 & 71105 \\
\hline
\end{tabular}

La muestra de la investigación estuvo conformada por 421 niños y niñas de tres instituciones educativas: dos privadas y una estatal. El tamaño de esta se estableció a partir del criterio propuesto por Nunally (1987) para poder llevar a cabo un análisis factorial exploratorio. Con el fin de minimizar el error de muestreo, el criterio establecido sugiere presentar un tamaño de la muestra equivalente a 10 veces el número de ítems que componen al instrumento. Debido a que la Escala de Estrés Cotidiano Infantil cuenta con 36 ítems, se requerirían de 360 participantes. En el caso de la presente investigación, al contar con 421 participantes, se supera aquel número y por lo tanto, se afirma que la muestra es adecuada para realizar los análisis posteriores. A continuación, la Tabla 4 muestra la distribución de los participantes según grado, sexo y tipo de colegio.

Tabla 4

Distribución de los participantes según grado, sexo y tipo de colegio

\begin{tabular}{lcccccc}
\hline & \multicolumn{2}{c}{ Total } & \multicolumn{2}{c}{ Gestión } & \multicolumn{2}{c}{ Sexo } \\
Grado & $n$ & Pública & Privada & Masculino & Femenino \\
\hline Tercer grado & 176 & 41.8 & 55.8 & 36.2 & 43.7 & 39.8 \\
Cuarto grado & 156 & 37.1 & 44.2 & 34.2 & 36.7 & 37.6 \\
Quinto grado & 89 & 21.1 & 0 & 29.6 & 19.6 & 22.6 \\
Total & 421 & 100 & 100 & 100 & 100 & 100 \\
\hline
\end{tabular}


El muestreo que se llevó a cabo fue no probabilístico, debido a que la muestra no fue seleccionada aleatoriamente, sino que se recuperaron las puntuaciones de quienes quisieron participar voluntariamente (Hernández et al., 2014). Asimismo, el tipo de muestreo también fue por conveniencia, ya que la selección de los participantes dependió del acceso a las instituciones educativas (Fraenkel, Wallen y Hyun, 2011). De esta manera, se evaluó a los participantes de cuyos centros educativos se encontraron disponibles para la investigación.

\subsection{Técnicas de recolección de datos}

Para llevar a cabo la recolección de datos de la presente investigación, se emplearon dos pruebas: la escala de estrés cotidiano infantil y la lista de chequeo conductual de ansiedad en niños.

\subsubsection{Escala de estrés cotidiano infantil (EECI)}

La escala de estrés cotidiano infantil es un instrumento elaborado por la investigadora para satisfacer los objetivos de la investigación. Este instrumento se encuentra dirigido a niños de 3ero a 5to grado de primaria. Consta de 36 ítems formulados para medir los componentes del estrés (cognitivo, afectivo, fisiológico y conductual) (Trianes et al., 2009) en cada una de las situaciones en las que este puede presentarse, específicamente en los niños: familiar, académico y social (Oros y Vogel, 2005). La ficha técnica ubicada en el anexo 2 contiene mayor información.

A continuación, la Tabla 5 muestra la distribución de los ítems de la EECI según los componentes y las situaciones del estrés.

\section{Tabla 5}

Matriz de la Escala de Estrés Cotidiano Infantil

\begin{tabular}{ccccc}
\hline $\begin{array}{c}\text { Situación de } \\
\text { estrés }\end{array}$ & Cognitivo & Afectivo & Fisiológico & Conductual \\
\hline Social & $29,16,36$ & $4,17,33$ & $26,19,25$ & $11,7,34$ \\
Familiar & $12,13,27$ & $30,32,9$ & $22,18,20$ & $3,8,35$ \\
Académico & $5,14,28$ & $6,24,23$ & $1,15,21$ & $2,10,31$ \\
\hline
\end{tabular}

Nota: los números hacen referencia a cada número de ítem de la escala. 
Las opciones de respuesta a los ítems fueron diseñadas en términos de frecuencia, contando con cuatro posibilidades de alternativa: (1) Nunca, (2) Casi nunca, (3) Casi siempre y (4) Siempre. La aplicación de la prueba duró aproximadamente 20 minutos.

\subsubsection{Lista de Chequeo Conductual de Ansiedad en Niños}

La lista de chequeo conductual de ansiedad es un instrumento construido por Alarcón (1993), dirigido a niños de entre 6 a 12 años.

Para la construcción de los ítems, se tomaron en cuenta los cuatro componentes de la ansiedad: fisiológico, emocional, cognitivo y motor. La prueba cuenta con un total de 26 ítems y las opciones de respuesta se formularon en términos de frecuencia en una escala de 0 a 2 , en donde $0=$ Nunca, $1=$ Algunas veces y $2=$ Frecuentemente. De esta manera, se afirma que un mayor puntaje la prueba, implicará un mayor nivel de ansiedad.

Respecto a las propiedades psicométricas del instrumento, se proporcionan evidencias de validez e indicadores de confiabilidad.

Primero, sobre los evidencias de validez, se proporcionan evidencias de validez relacionadas al contenido de los ítems a través del criterio de jueces. En este participaron cinco psicólogos, cuyas edades oscilaron entre los 30 y 57 años. La versión inicial de la prueba contaba con 31 ítems, dentro de los cuales 30 fueron aceptados en un $100 \%$ por los jueces; sin embargo, uno de ellos obtuvo un $30 \%$ de aceptación, por lo que pasó a ser eliminado. Por otro lado, las evidencias de validez vinculadas con la estructura interna de la prueba mostraron correlaciones significativas $(p<.05)$ entre los ítems, cuyas puntuaciones iban desde .20 hasta .43. Así, se pasó a eliminar los cuatro ítems de puntajes más bajos, quedando, finalmente, 26 ítems válidos. Finalmente, se reporta evidencias de validez vinculadas a las relaciones con otras variables aplicando métodos convergentes. Se halló una correlación estadísticamente significativa entre la Lista de Chequeo Conductual de Ansiedad en Niños y el Inventario de Personalidad de Eysenck para Niños $(r=.85, p<.001)$.

Por último, se estimó la confiabilidad de las puntuaciones obtenidas de la Lista de Chequeo Conductual Ansiedad en Niños a través del método test-retest y dos mitades, obteniendo, respectivamente, un coeficiente de estabilidad de $.93(p<.001) \mathrm{y}$ coeficiente de consistencia interna de .96 . 


\subsection{Procedimiento de recolección de datos}

Para llevar a cabo la recolección de datos, primero, se solicitó el permiso de las organizaciones educativas seleccionadas para la investigación. Se les brindó una carta elaborada por la institución educativa de la investigadora, en donde se señalaron los objetivos de la investigación y las condiciones de confidencialidad. También, se les proporcionó, a cada uno de los centros educativos, un consentimiento informado explicando detalladamente la prueba a evaluar, así como los objetivos de esta, el anonimato y la confidencialidad de los resultados.

Seguidamente y con el permiso de las instituciones, se coordinaron los horarios de aplicación junto con el departamento psicopedagógico de estas. Una vez que se obtuvo el acceso a los salones de los participantes, se conversó con los profesores de cada aula para contar con su apoyo durante la aplicación. Así, se pasó a realizar la aplicación de manera grupal, explicándoles la prueba y brindándoles libertad para realizar cualquier pregunta.

Conforme los participantes terminaron de completar la EECI, se les pasó a explicar la segunda prueba a desarrollar: la Lista de Chequeo Conductual de Ansiedad en Niños (LCCAN). El tiempo de aplicación de ambas pruebas, en conjunto fue de, aproximadamente, 30 minutos.

Finalmente, se llevó a cabo la codificación de los datos de ambas pruebas en los programas estadísticos SPPS 22, Factor v.9.3.1 y R v.3.13 y posteriormente, se pasó a analizarlos e interpretarlos. 


\section{CAPÍTULO V: RESULTADOS}

A continuación, se presenta un resumen de las propiedades psicométricas del instrumento construido, reportando las evidencias de confiabilidad y validez de las puntuaciones derivadas de la aplicación de la EECI. Luego, se exponen los estadísticos descriptivos, así como la prueba de normalidad de las puntuaciones obtenidas por la muestra. Finalmente, se presentan los análisis complementarios en los que se efectuó la comparación de las puntuaciones en la EECI en función al sexo, grado y tipo de colegio.

\subsection{Análisis psicométricos}

A continuación, se proporciona las evidencias de validez del instrumento construido, así como también la estimación de la confiabilidad.

\subsubsection{Evidencias de validez vinculadas al contenido}

Con el objetivo de obtener evidencias de validez vinculadas al contenido de la EECI, se estimó el coeficiente de $\mathrm{V}$ de Aiken, para lo cual se llevó a cabo un criterio de jueces.

La V de Aiken es definida como el grado de acuerdo de un grupo de jueces derivado de las valoraciones de estos con respecto a un conjunto de ítems. Estas valoraciones pueden ser dicotómicas (0-1) o politómicas (0-5) (Escurra, 1997); en el caso de la presente investigación, durante el criterio de jueces realizado, se empleó el segundo tipo de valoración.

El proceso de criterio de jueces estuvo conformado por nueve jueces. Dentro de ellos, dos hombres y siete mujeres. Todos los expertos son docentes universitarios y psicólogos de profesión. Siete de los nueve tienen el grado académico de magíster y dos, son licenciados. Sus edades oscilaron entre los 29 y los 69 años de edad. Si bien comparten la misma profesión, ejercen especialidades distintas, dentro de estas se encontraron las siguientes: psicología clínica enfocada en el trabajo con niños, psicología educativa, psicología enfocada a la investigación, especialistas en construcción y diseño de instrumentos y expertos en psicometría.

Debido a que se trató de nueve jueces y se trabajó con una significancia de .05, la V de Aiken mínima aceptable fue de .74 (Aiken, 1985). Las tablas 6 y 7 muestran las puntuaciones para cada uno de los ítems en función a la representatividad del tema y claridad en la redacción, respectivamente. 
Tabla 6

Coeficiente V de Aiken para los items de la EECI según representatividad del tema

\begin{tabular}{cccc}
\hline Ítem & V de Aiken & Ítem & V de Aiken \\
\hline 1 & $1.00^{*}$ & 19 & $1.00^{*}$ \\
2 & $1.00^{*}$ & 20 & $1.00^{*}$ \\
3 & $.94^{*}$ & 21 & $1.00^{*}$ \\
4 & $1.00^{*}$ & 22 & $1.00^{*}$ \\
5 & $1.00^{*}$ & 23 & $1.00^{*}$ \\
6 & $1.00^{*}$ & 24 & $1.00^{*}$ \\
7 & $.94^{*}$ & 25 & $1.00^{*}$ \\
8 & $1.00^{*}$ & 26 & $1.00^{*}$ \\
9 & $1.00^{*}$ & 27 & $1.00^{*}$ \\
10 & $1.00^{*}$ & 28 & $.94^{*}$ \\
11 & $1.00^{*}$ & 29 & $1.00^{*}$ \\
12 & $1.00^{*}$ & 30 & $1.00^{*}$ \\
13 & $1.00^{*}$ & 31 & $.89 *$ \\
14 & $1.00^{*}$ & 32 & $.89 *$ \\
15 & $.94^{*}$ & 33 & $1.00^{*}$ \\
16 & $1.00^{*}$ & 34 & $.83 *$ \\
17 & $1.00^{*}$ & 35 & $1.00^{*}$ \\
18 & $.97 *$ & 36 & $1.00^{*}$ \\
\hline
\end{tabular}

${ }^{*} p<.05$.

Tabla 7

Coeficiente $V$ de Aiken para los items de la EECI según claridad en la redacción

\begin{tabular}{cccc}
\hline Ítem & V de Aiken & Ítem & V de Aiken \\
\hline 1 & $.92^{*}$ & 19 & $.97^{*}$ \\
2 & $.94^{*}$ & 20 & $.94^{*}$ \\
3 & $.92^{*}$ & 21 & $1.00^{*}$ \\
4 & $.97^{*}$ & 22 & $.97^{*}$ \\
5 & $.92^{*}$ & 23 & $.97^{*}$ \\
6 & $.94^{*}$ & 24 & $.92^{*}$ \\
7 & $.89^{*}$ & 25 & $1.00^{*}$ \\
8 & $.94^{*}$ & 26 & $.92^{*}$ \\
9 & $1.00^{*}$ & 27 & $1.00^{*}$ \\
10 & $.94^{*}$ & 28 & $1.00^{*}$ \\
11 & $.94^{*}$ & 29 & $.97^{*}$ \\
12 & $.94^{*}$ & 30 & $.94^{*}$ \\
13 & $.97^{*}$ & 31 & $1.00^{*}$ \\
14 & $.94^{*}$ & 32 & $.97^{*}$ \\
15 & $1.00^{*}$ & 33 & $1.00^{*}$ \\
16 & $1.00^{*}$ & 34 & $.94^{*}$ \\
17 & $1.00^{*}$ & 35 & $.92^{*}$ \\
18 & $.94^{*}$ & 36 & $1.00^{*}$ \\
\hline
\end{tabular}

$* p<.05$. 
Adicionalmente, de manera cualitativa, se le mostró la escala construida a un grupo de 6 niños de las edades de la muestra de la investigación (dos de 8 años, una de 9 años y tres de 10 años) y se les preguntó individualmente si comprendían los ítems de la prueba. Cuatro de los niños afirmaron entender la escala sin problemas; uno de los dos restantes, mencionó no saber cómo responder al ítem 22 ("Me duele la cabeza cada vez que discuto con mi papá") y 27 ("Pienso que mis papás discuten mucho"), debido a que él no cuenta con la presencia de su papá ni de ninguna otra figura paterna; finalmente, una última niña señaló tener problemas para entender las indicaciones, pero no para comprender los ítems.

Con respecto a estas dos acotaciones por parte de los niños se decidió, en primer lugar, no tomar en consideración las pruebas de niños que no cuenten con figura paterna para poder llevar a cabo un análisis más preciso. En segundo lugar, se realizaron modificaciones en las instrucciones, junto con la ayuda de los jueces, para que éstas sean más fáciles de comprender.

\subsubsection{Evidencias de validez vinculadas a la estructura interna de la EECI}

Con el objetivo de analizar las evidencias de validez relacionadas a la estructura interna de la prueba, se realizó un análisis factorial exploratorio (AFE) de la Escala de Estrés Cotidiano Infantil.

El análisis factorial exploratorio es el proceso a partir del cual los ítems de un instrumento son agrupados en diferentes factores latentes dependiendo de las cargas factoriales que presenten (Field, 2009).

Este procedimiento se llevó a cabo sobre los 36 ítems de la EECI a partir de un método de extracción ULS y el método Hull de retención de factores, ya que este ha demostrado tener una mejor recuperación de la estructura factorial (Lorenzo-Seva, Timmerman y Kiers, 2011). Asimismo, se propuso una rotación promax oblicua, dado que se asumió que existía una dependencia teórica entre los factores del estrés. Adicionalmente, se calculó la matriz de correlaciones mediante la correlación policórica, ya que los ítems son variables ordinales y las alternativas de respuesta de estos son politómicas (Burga, 2006).

Como punto de partida, se verificó el indicador de Kaiser-Meyer-Olkin (KMO), encontrando una buena adecuación muestral para llevar a cabo el AFE $(\mathrm{KMO}=.86)$, lo 
que significa que las relaciones entre las variables son lo suficientemente fuertes como para factorizarlas. Asimismo, el test de esfericidad de Barlett indica que las correlaciones entre los ítems de la EECI son estadísticamente significativas, $X^{2}(630)=$ 3311.1, $p<.001$. A partir de ello, se pasaron a realizar los análisis pertinentes.

Se llevaron a cabo tres análisis factoriales exploratorios antes de procesar la versión final de la estructura de la EECI. En el primer análisis, el método de Hull sugirió la extracción de un solo factor que explicaba el $26 \%$ de la varianza común compartida. A continuación, la Tabla 8 muestra la estructura de este primer análisis. 
Tabla 8

Primera versión de la estructura factorial de la EECI a través del análisis factorial exploratorio

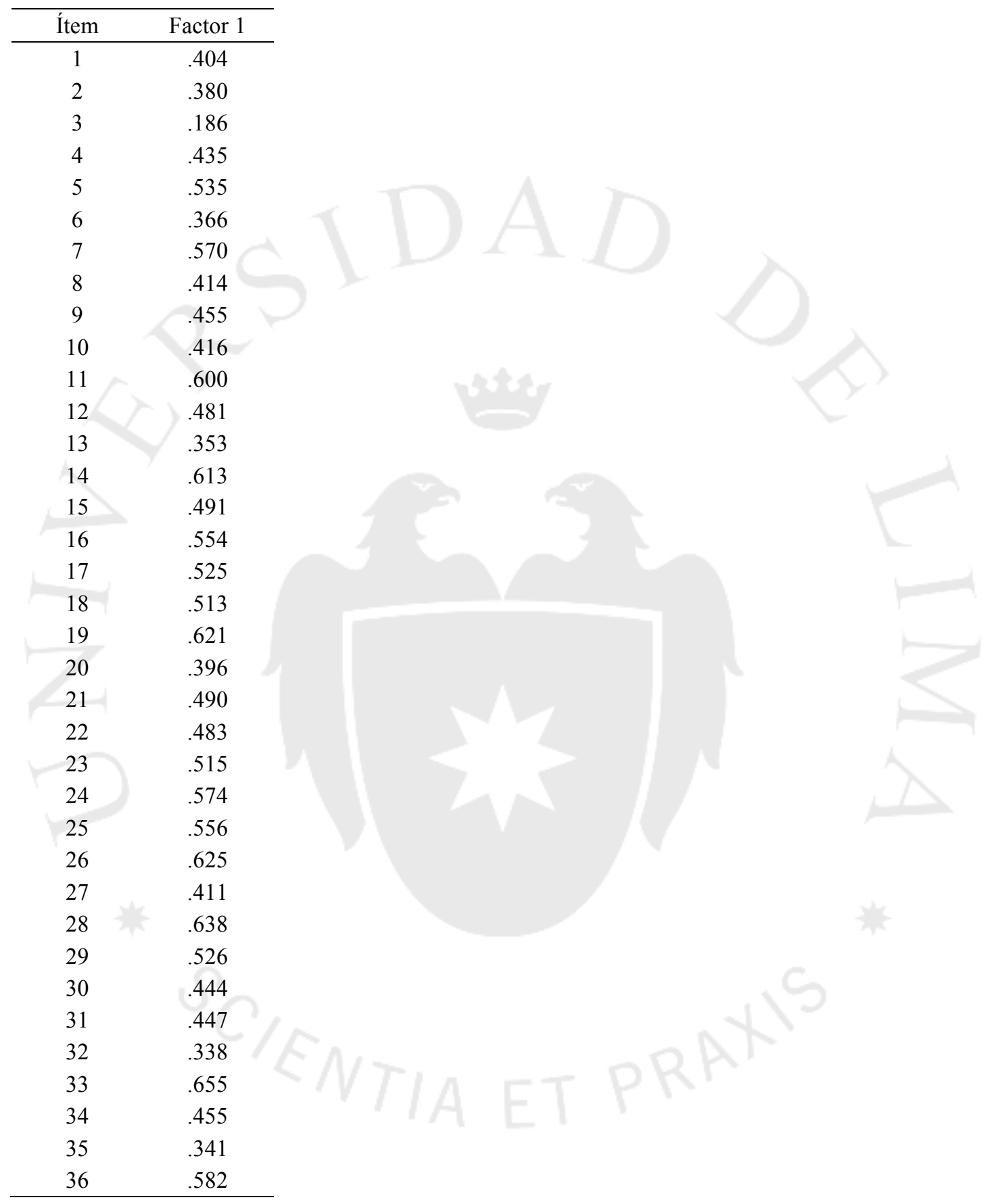


Con el objetivo de obtener una mayor precisión en la factorización, se pasó a verificar los ítems cuyas cargas factoriales puntuaban menor a .30 para ser eliminados (Hair, Anderson, Tatham y Black, 2007). A partir de este criterio se eliminó el ítem 3 ("No cumplo con mis responsabilidades en casa"), cuya carga factorial fue de .19. Una vez eliminado, se pasó a realizar el AFE nuevamente y en esta ocasión, la varianza explicada común compartida fue de $27 \%$ (ver anexo 5).

Posteriormente, se consideró pertinente, para aún mayor precisión, eliminar los ítems cuyas cargas factoriales sean menores a .40 (Hair et al., 2007). Al aplicar este criterio, se pasaron a eliminar los ítems 2 ("Me muerdo las uñas cuando estudio"), 13 ("Pienso que mis papás me dan muchas responsabilidades"), 20 ("Cuando estoy en casa sin mis papás me dan ganas de llorar"), 32 ("Me siento fastidiado(a) si paso mucho tiempo en casa") y 35 ("No respondo las preguntas que me hacen mis papás"), verificando, previamente, que no correspondan a un único componente del estrés. Tras la eliminación de estos ítems, la nueva varianza explicada común compartida fue de $28 \%$ (ver anexo 6).

Como último procedimiento, se verificaron las cargas factoriales de los ítems de la nueva estructura y se eliminó, nuevamente, aquellos cuyas cargas factoriales eran menores a .40. Así, pasaron a ser eliminados los ítems 6 ("Me asusta olvidarme de lo que iba a decir durante una exposición”) y 10 ("Muerdo el lápiz o lapicero cada vez que doy un examen") y la nueva varianza explicada común compartida fue de $30 \%$, quedando un número total de 28 ítems. Esta nueva propuesta de la organización de los ítems se muestra en la Tabla 9. 
Tabla 9

Versión final de la estructura factorial de la EECI

\begin{tabular}{|c|c|}
\hline Ítem & Factor 1 \\
\hline 1 & .408 \\
\hline 4 & .434 \\
\hline 5 & .512 \\
\hline 7 & .557 \\
\hline 8 & .428 \\
\hline 9 & .425 \\
\hline 11 & .599 \\
\hline 12 & .479 \\
\hline 14 & .617 \\
\hline 15 & .482 \\
\hline 16 & .568 \\
\hline 17 & .528 \\
\hline 18 & .515 \\
\hline 19 & .624 \\
\hline 21 & .463 \\
\hline 22 & .493 \\
\hline 23 & .509 \\
\hline 24 & .558 \\
\hline 25 & .555 \\
\hline 26 & .620 \\
\hline 27 & .422 \\
\hline 28 & .610 \\
\hline 29 & .523 \\
\hline 30 & .431 \\
\hline 31 & .445 \\
\hline 33 & .659 \\
\hline 34 & .468 \\
\hline 36 & .590 \\
\hline
\end{tabular}

\subsubsection{Estimación de la confiabilidad de las puntuaciones derivadas de los ítems de}

\section{la EECI}

Con el objetivo de estimar la confiabilidad del instrumento construido, se llevó a cabo el método de alfa de Cronbach. El alfa de Cronbach es un coeficiente que indica la fuerza de correlación entre todas las puntuaciones derivadas de los reactivos de un instrumento, partiendo de una matriz continua de correlaciones (Gadermann, Guhn y Zumbo, 2012). Este coeficiente estimará la confiabilidad por medio del método de consistencia interna y puede tomar dos formas, como alfa clásico o como alfa ordinal. 
El alfa de Cronbach clásico indica la fuerza de correlación de las puntuaciones de los ítems de un instrumento empleando como elemento matriz la correlación de Pearson (Field, 2009). Mientras que el alfa ordinal indica la fuerza de correlación de las puntuación de los ítems policóricos de un instrumento basados en una matriz de correlaciones policóricas (Bonanomi, Ruscone y Osmetti, 2013).

De esta manera, por medio del programa SPSS 22, se estimó el alfa de Cronbach clásico de $.86 \mathrm{y}$, por medio del programa R v. 3.1.3, se estimó el alfa ordinal de .91 para las puntuaciones derivadas de la aplicación de los ítems de la EECI. Se puede afirmar que ambas puntuaciones son adecuadas, ya que se encuentran por encima del criterio .70 (Nunally y Bernstein, 1995). A su vez, esto indica que los ítems de la prueba muestran homogeneidad para evaluar un mismo constructo (Kline, 1995).

Asimismo, se llevó a cabo el cálculo del error estándar de medición tanto para el alfa de Cronbach clásico, como para el ordinal. El error estándar de medición estima cómo los puntajes de medidas repetidas de una persona en un mismo instrumento tienden a ser distribuidas alrededor de su "verdadero" puntaje (Bishop, 1996). En el caso del alfa de Cronbach clásico, el error estándar de medición fue de 4.56 y en el caso del alfa ordinal, 3.66.

Adicionalmente, la Tabla 10 muestra la confiabilidad y los errores estándar de medición para cada uno de los grupos evaluados.

Tabla 10

Alfa de Cronbach, alfa ordinal y error estándar de medición para cada uno de ellos según sexo, grado y tipo de colegio

\begin{tabular}{|c|c|c|c|c|c|}
\hline \multicolumn{2}{|c|}{ Grupos } & $\alpha$ & $\mathrm{EEM} \alpha$ & $\alpha_{0}$ & EEM $\alpha o$ \\
\hline \multirow{2}{*}{ Sexo } & Hombre & 0.85 & 4.65 & 0.90 & 3.70 \\
\hline & Mujer & 0.87 & 4.47 & 0.92 & 3.51 \\
\hline \multirow{3}{*}{ Grado } & Tercero & 0.87 & 4.54 & 0.92 & 3.60 \\
\hline & Cuarto & 0.86 & 4.49 & 0.91 & 3.66 \\
\hline & Quinto & 0.86 & 4.34 & 0.92 & 3.35 \\
\hline \multirow{2}{*}{$\begin{array}{l}\text { Tipo de } \\
\text { colegio }\end{array}$} & Público & 0.90 & 3.98 & 0.93 & 3.34 \\
\hline & Privado & 0.85 & 4.65 & 0.90 & 3.77 \\
\hline
\end{tabular}


Por otro lado, con respecto al análisis de la discriminación a través de la correlación poliserial ítem-resto, realizada a través del programa R v. 3.1.3, se puede afirmar que no hubo necesidad de eliminar ningún ítem más, ya que todas las correlaciones fueron mayores a .20 (Kline, 1995) y además, se observa que la eliminación de cualquiera de los ítems no supone un incremento mayor en el alfa de Cronbach ordinal. Esta información se muestra en la Tabla 11. 
Tabla 11

Correlación poliserial ítem-resto para los ítems de la EECI

\begin{tabular}{|c|c|c|}
\hline Ítem & $\mathrm{rpi}_{\mathrm{r}}$ & $\begin{array}{c}\alpha_{0} \text { si el ítem se } \\
\text { elimina }\end{array}$ \\
\hline 1 & .37 & .91 \\
\hline 4 & .43 & .91 \\
\hline 5 & .52 & .91 \\
\hline 7 & .54 & .91 \\
\hline 8 & .40 & .91 \\
\hline 9 & .42 & .91 \\
\hline 11 & .59 & .91 \\
\hline 12 & .42 & .91 \\
\hline 14 & .58 & .90 \\
\hline 15 & .46 & .91 \\
\hline 16 & .52 & .91 \\
\hline 17 & .54 & .91 \\
\hline 18 & .46 & .91 \\
\hline 19 & .62 & .90 \\
\hline 21 & .44 & .91 \\
\hline 22 & .49 & .91 \\
\hline 23 & .51 & .91 \\
\hline 24 & .56 & .91 \\
\hline 25 & .50 & .91 \\
\hline 26 & .61 & .90 \\
\hline 27 & .42 & .91 \\
\hline 28 & .60 & .90 \\
\hline 29 & .52 & .91 \\
\hline 30 & .34 & .91 \\
\hline 31 & .41 & .91 \\
\hline 33 & .65 & .90 \\
\hline 34 & .45 & .91 \\
\hline 36 & .57 & .91 \\
\hline
\end{tabular}

\subsubsection{Evidencias de validez vinculadas a la relación con otras variables}

Con el objetivo de presentar evidencias de validez vinculadas a la relación con otras variables, se proporciona información sobre la relación que guardan las puntuaciones derivadas de la EECI con las puntuaciones derivadas de la LCCAN. Como se mencionó previamente, al ser constructos similares se espera encontrar una correlación alta y 
positiva entre las puntuaciones derivadas de ambas.

Antes de realizar la correlación, se procedió a verificar las propiedades psicométricas de la LCCAN.

A partir de las puntuaciones obtenidas de la aplicación de la LCCAN, se pasó a realizar el análisis factorial de la prueba a través del programa estadístico Factor (Lorenzo-Seva y Fernando, 2015) y mediante el método de extracción ULS y el método Hull para retener factores. Los resultados permitieron establecer que el constructo de ansiedad presenta ítems organizados en un solo factor. Asimismo, todas las cargas factoriales fueron superiores a .34 , lo que indica que no es necesario eliminar ningún ítem de la prueba (Hair et al., 2007). La Tabla 12 muestra información más detallada al respecto.

Tabla 12

Análisis factorial exploratorio de los items de la LCCAN por medio del método de ULS

\begin{tabular}{|c|c|}
\hline Ítem & Factor 1 \\
\hline 1 & .489 \\
\hline 2 & .535 \\
\hline 3 & .454 \\
\hline 4 & .516 \\
\hline 5 & .566 \\
\hline 6 & .507 \\
\hline 7 & .387 \\
\hline 8 & .441 \\
\hline 9 & .508 \\
\hline 10 & .451 \\
\hline 11 & .669 \\
\hline 12 & .575 \\
\hline 13 & .354 \\
\hline 14 & .510 \\
\hline 15 & .500 \\
\hline 16 & .479 \\
\hline 17 & .508 \\
\hline 18 & .397 \\
\hline 19 & .406 \\
\hline 20 & .639 \\
\hline 21 & .395 \\
\hline 22 & .644 \\
\hline 23 & .514 \\
\hline 24 & .516 \\
\hline 25 & .516 \\
\hline 26 & .516 \\
\hline
\end{tabular}


Por otro lado, con respecto a la estimación de la confiabilidad de las puntuaciones obtenidas de la prueba, se sabe que esta cuenta con un coeficiente de consistencia interna de .96, así como un coeficiente de estabilidad de $.93(p<.001)$ (Alarcón, 1993).

Una vez comprobadas las propiedades psicométricas de la LCCAN, se llevaron a cabo las pruebas de normalidad a nivel poblacional para ambas variables (estrés y ansiedad). Para ello, se empleó la prueba de Shapiro-Wilk de bondad de ajuste a la curva normal, debido a que se ha mostrado que es una prueba más potente que otras pruebas estadísticas enfocadas a realizar el contraste del supuesto de normalidad (Razali y Wah, 2011). Tanto para la variable de estrés como para la de ansiedad, se mostraron evidencias empíricas para rechazar la hipótesis nula, lo que indica que ambas variables provienen de poblaciones no distribuidas normalmente. La Tabla 13 muestra la información descrita.

Tabla 13

Prueba de Shapiro-Wilk de bondad de ajuste a la curva normal para la EECI y la $L C C A N$

\begin{tabular}{cccc}
\hline Pruebas & $\boldsymbol{D}$ & $\boldsymbol{g} \boldsymbol{l}$ & $\boldsymbol{p}$ \\
\hline EECI & .98 & 421 & $<.001$ \\
LCCAN & .95 & 421 & $<.001$ \\
\hline
\end{tabular}

Debido a la asimetría de las poblaciones para ambas variables, se emplearon correlaciones no paramétricas para realizar la comparación. Esta se llevó a cabo por medio de la prueba de Spearman (Field, 2009). El coeficiente de correlación entre ambas es de .66, considerado como una correlación fuerte (Cohen, 1992). Esto afirma la relación positiva existente entre estrés y ansiedad; así, se esperaría que una persona con altos niveles de estrés presente, también, altos niveles de ansiedad. 


\subsubsection{Elaboración de baremos}

El puntaje total de la EECI presentó una media de 47.32 y una desviación estándar de $12.18(N=421)$. La prueba de normalidad de Shapiro-Wilk mostró evidencias empíricas que afirman que las puntuaciones derivadas de la EECI provienen de una población que no tiene distribución normal, existiendo una asimetría de .91 y una curtosis de 1.50. En la Figura 2 se aprecia la existencia de la tendencia hacia la izquierda de puntajes bajos de estrés en la muestra evaluada.

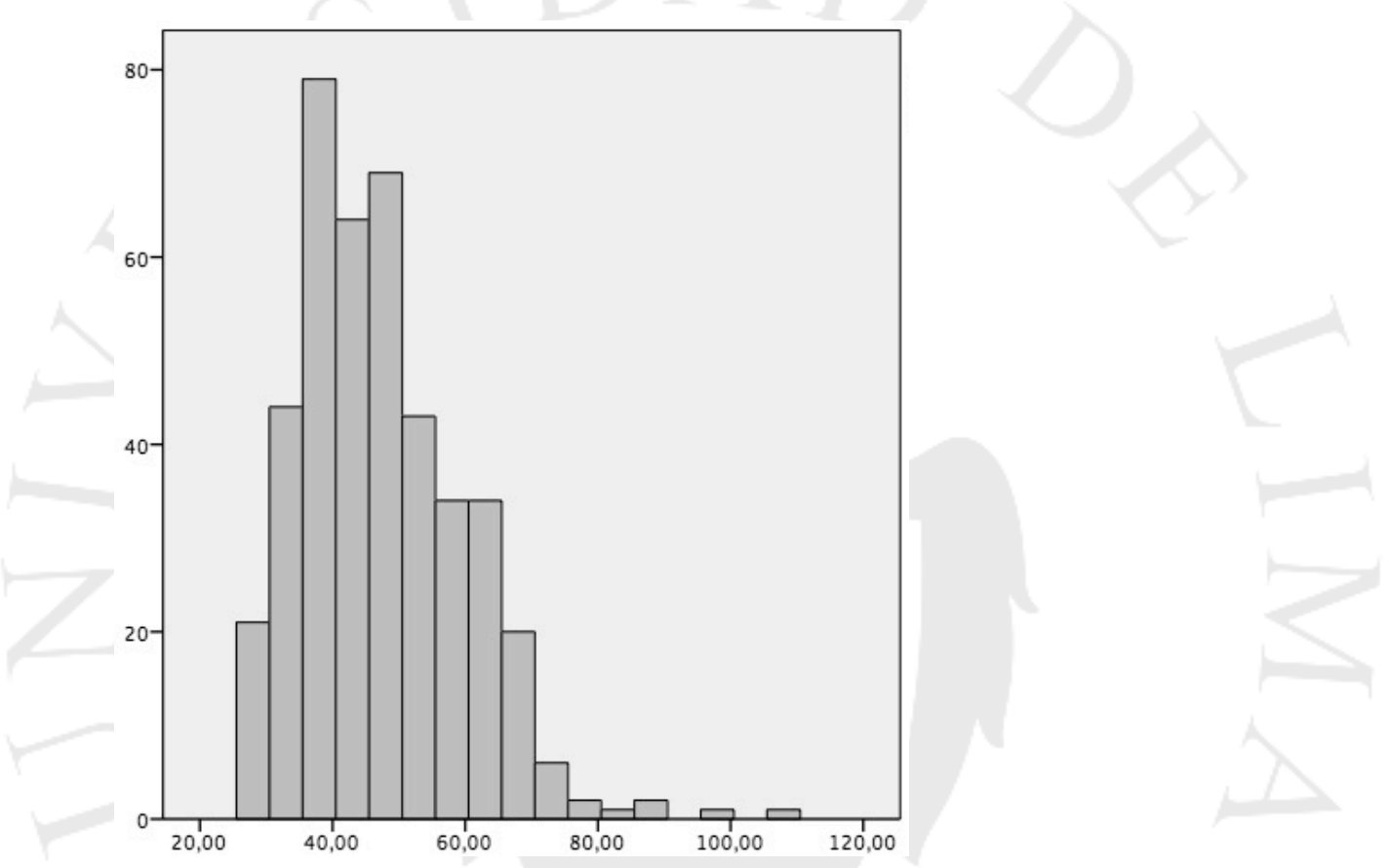

Figura 2. Histograma de las puntuaciones de la EECI

Nota: $N=421$

Debido a que no se encontró diferencias estadísticamente significativas entre las variables de acuerdo al sexo, grado y tipo de colegio, no hubo necesidad de realizar baremos diferenciados. Así, para llevar a cabo el procedimiento de baremos no diferenciados, se identificó el puntaje mínimo de la prueba, correspondiente a 28 , y el máximo, correspondiente a 106. A partir de esto, se pasó a realizar un división por quintiles entre los puntajes del medio. A continuación, la Tabla 14 muestra la distribución entre los niveles de estrés percibidos derivados de las puntuaciones de la muestra. 
Tabla 14

Baremos clasificados en quintiles de las puntuaciones de estrés de la muestra evaluada

\begin{tabular}{cc}
\hline Puntaje de estrés & Categoría \\
\hline$\leq 37$ & Muy bajo \\
$38-42$ & Bajo \\
$43-49$ & Medio \\
$50-106$ & Alto \\
$\geq 106$ & Muy alto \\
\hline
\end{tabular}

\subsection{Análisis complementarios}

Se pretendió realizar una comparación entre el puntaje total de estrés de la muestra evaluada y las variables grado, sexo y tipo de colegio.

A partir de los análisis empleados, se puede afirmar que no existen diferencias estadísticamente significativas para grado, $\chi^{2}(2, N=421)=.92, p=.63$, sexo, $U=$ $21275.500, Z=-.575, p=.57$, o tipo de colegio, $U=17714.500, Z=-.307, p=.76$. 


\section{CAPÍTULO VI: DISCUSIÓN}

En el siguiente capítulo, se expondrán tres puntos específicos. En primer lugar, se discutirán los objetivos planteados de la presente investigación, específicamente las propiedades psicométricas de la EECI y sus limitaciones. En segundo lugar, se revisará la adecuación del análisis psicométrico de la EECI de acuerdo a los estándares para la evaluación educativa y psicológica según la AERA, APA, NCME (2014). Como último punto, se discutirá la relación que guardan los resultados obtenidos con información postulada en la literatura.

\subsection{Objetivos de la investigación}

Previamente a la discusión de los objetivos de la investigación, resulta conveniente indicar las limitaciones encontradas a partir de la realización de esta. La principal dificultad estuvo centrada en el limitado acceso a la muestra. Por ello, el tipo de muestreo empleado para llevar a cabo el estudio fue no probabilístico, a partir del cual no todos los elementos de la población tuvieron igual probabilidad de ser seleccionados (Hernández et al., 2014), sino que se escogieron aquellos a los que la investigadora pudo tener acceso. Como consecuencia de esto, se encuentra como limitación la generalización de los resultados. Esta deberá ser tomada con cautela, dado que se trata de una muestra reducida con características específicas. Asimismo, ya que se trata de una prueba larga, cabe la posibilidad de que el cansancio de los participantes durante la evaluación haya interferido con sus respuestas y por lo tanto, haya perjudicado los resultados de la investigación. Una vez conocidas estas dificultades, se puede pasar a mencionar y discutir los objetivos del estudio.

El objetivo de la investigación fue reportar las propiedades psicométricas de la Escala de Estrés Cotidiano Infantil. Para ello, se obtuvo evidencias de validez vinculadas con el contenido de los ítems de la escala a través del coeficiente $\mathrm{V}$ de Aiken, evidencias de validez vinculadas a la estructura interna de la prueba a través del análisis factorial, evidencias de validez vinculadas a la relación con otras variables a través de la correlación entre la EECI y la Lista de Chequeo Conductual de Ansiedad en Niños (Alarcón, 1993) y se estimó la confiabilidad de las puntuaciones obtenidas en la escala. 
La EECI presentó un coeficiente $\mathrm{V}$ de Aiken adecuado, indicando presentar evidencias de validez vinculada al contenido de los ítems. La evaluación del instrumento se llevó a cabo por un número de 9 jueces, cantidad que según Aiken (1985) es suficiente para comprobar que se está midiendo aquello que se busca medir.

Al llevar a cabo el análisis factorial exploratorio, se esperó que los ítems se agruparan en 4 factores, correspondientes a los componentes del estrés: cognitivo, afectivo, fisiológico y conductual (Trianes et al., 2009). No obstante, lo que se encontró fue una estructura unifactorial. A partir de esta, los ítems se encontraron agrupados en un solo factor que explicó el $30 \%$ de la varianza compartida.

Se sabe que el tamaño de la muestra no es una variable que afecte este resultado, ya que se utilizó un número adecuado de participantes para llevar a cabo el análisis factorial exploratorio. Nunally (1978) señala idóneo tener un número de participantes que sea 10 veces cada ítem; Kass y Tinsley (1979) indican que el número puede variar de 5 a 10 participantes por ítem, y Field (2009) sostiene que 300 participantes es un número adecuado para realizar un análisis factorial. Se puede afirmar que, en cualquiera de los casos, la muestra alcanzó los criterios postulados.

Así, se sostiene que la existencia de un único factor guarda relación con investigaciones previas sobre estrés. Investigaciones muestran que, al estudiar estrés cotidiano en niños, o bien se encuentra una estructura con un único factor (Dise-Lewis, 1988) o los ítems de la prueba se agrupan en demasiados factores específicos, pero siempre con uno que explica una mayor cantidad de la varianza compartida (Pett y Johnson, 2005). La explicación de esta situación se debe a que, si bien la literatura divide el estrés en componentes esto no significa que éstos funcionen de manera separada (Trianes, 2003). Es decir, todos los componentes del estrés, formulados por diferentes autores (Zaira et al., 2007; Trianes, 2009; Zaira et al., 2012), trabajan de manera simultánea. De esta manera, se sabe que las respuestas cognitivas (eg. pensamientos negativos), afectivas (eg. sentirse inquieto), fisiológicas (eg. palpitaciones) y conductuales (eg. escapar o evitar la situación de estrés) guardan una estrecha relación y, en la práctica, funcionan de manera conjunta (Zaira et al., 2012). De esta manera, los resultados hallados a través del presente estudio corresponden a lo que 
postulan Zaira y sus colaboradores (2012) en vez de lo que propone la literatura (Trianes et al., 2009).

A partir de la presencia de la estructura unifactorial, se eliminaron ítems cuyas cargas factoriales fueron menores a .30 y .40 (Hair et al., 2007). Esto se llevo a cabo con la intención de incrementar el porcentaje de varianza explicada compartida que mostraba el único factor. Dentro de los ítems que fueron eliminados, el ítem 3 ("no cumplo con mis responsabilidades en casa") y 35 ("no respondo las preguntas que me hacen mis papás"), fueron los dos ítems más cuestionados por los niños en el transcurso de la evaluación. La explicación de esto recae en que los reactivos redactados en negativo pueden ser más difíciles de comprender, especialmente si se trata de una población infantil (Simms, 2008). No obstante, al alcanzar una V de Aiken adecuada por parte de los jueces para ambos ítems se decidió no cambiarlos en un primer momento. De la misma manera, los niños a los que se les consultó si comprendían la prueba, antes de realizar la aplicación, tampoco mostraron dudas al respecto.

A pesar de esto, la EECI mantuvo la misma tabla de especificaciones, a partir de la cual se siguen presentando los componentes del estrés (cognitivo, afectivo, fisiológico y conductual), así como las situaciones en donde este se lleva a cabo en los niños (social, académico y familiar). La versión final de la escala cuenta con 28 ítems (ver anexo 7).

Por otro lado, en relación a la estimación de la confiabilidad, las puntuaciones derivadas de la EECI fueron altas tanto para el alfa clásico (.86) como para el alfa ordinal (.91). Esto evidencia que las puntuaciones derivadas de la prueba en la muestra evaluada permiten obtener puntuaciones consistentes (Field, 2009).

Asimismo, se halló una correlación fuerte $(r=.70)($ Cohen, 1992) entre la Lista de Chequeo Conductual de Ansiedad en Niños (LCCAN) y la EECI. Esta fuerte relación evidencia que ambas miden constructos similares, que se relacionan entre sí y que los resultados son coherentes (Beck et al., 1985). 


\subsection{Adecuación del análisis psicométrico de la EECI de acuerdo a los estándares para la evaluación educativa y psicológica (AERA, APA, NCME, 2014)}

En el siguiente apartado, se expondrán los estándares con los que la EECI cumple, considerando los criterios de validez, confiabilidad, diseño y desarrollo de la prueba, elaboración de normas y documentación adjunta de las pruebas.

\subsubsection{Estándares para la validez}

1.0. Debe ser presentada una articulación clara de cada interpretación propuesta de las puntuaciones de la prueba para un uso específico y se deben proveer evidencias de validez apropiadas para cada interpretación que se desee formular (p. 23): La EECI fue construida por la investigadora y tiene como objetivo medir los niveles de estrés cotidiano en niños de 3ero a 5to grado de primaria. Adicionalmente, puede funcionar como un método de prevención del estrés en niños, así como de evaluación diagnóstica.

1.1. El autor de la prueba debe especificar la manera en la que los puntajes de esta se interpretarán y se usarán. La población para la cual el instrumento será destinado debe delimitarse claramente y el constructo o constructos que la prueba pretende evaluar deben describirse de manera clara (p. 23): Las puntuaciones derivadas de la aplicación de la EECI pretenden proporcionar información sobre niveles de estrés cotidiano infantil. Esta escala ha sido diseñada para ser empleada en niños de 3ero, 4to y 5 to de primaria de colegios tanto públicos como privados. Además, cada uno de los componentes del estrés en niños, así como las situaciones en donde este se lleva a cabo ha sido definido en el capítulo de Método.

1.6. Cuando el uso de una prueba es recomendada para producir beneficios indirectos, adicionalmente a la utilidad informada de las interpretaciones de los puntajes, se debe argumentar esta anticipación de beneficios indirectos con evidencias empíricas y también señalando efectos no esperados o contradictorios. Argumentos lógicos y teóricos y evidencias empíricas de los beneficios indirectos deben ser proporcionados (p. 24): A partir de la aplicación de la EECI se pueden encontrar niveles de estrés en niños y empezar un seguimiento adecuado para el manejo de este. Una vez que se lleve a cabo el tratamiento, en el caso de niños con altos niveles de estrés cotidiano, al verse reducidos los niveles de estrés, variables personales, como la autoestima y las habilidades sociales se podrán ver incrementadas generando, a su vez, un beneficio a 
largo plazo al afrontamiento de situaciones de tensión (Verduzco et al., 2004; Zaira et al., 2009).

1.8. La composición de cualquier muestra de evaluados a partir de la cual se obtienen las evidencias de validez deben ser descritas de la manera más detallada posible. Asimismo, deben incluirse los datos socioeconómicos relevantes y características de desarrollo (p. 25): La muestra fue seleccionada por medio de un muestreo no probabilístico y por conveniencia (Hernández et al., 2014). Esta estuvo conformada por 421 niños y niñas de 3ero $(41.8 \%)$, 4to $(37.1 \%)$ y 5 to grado $(21.1 \%)$ de primaria de colegios públicos y privados. Las edades de estos oscilaron entre los 7 hasta los 12 años. Información más específica sobre estas características se encuentra postulada en la sección de Método.

1.9. Cuando la validación recae sobre las decisiones u opiniones de un grupo de jueces expertos, observadores o evaluadores, es necesario especificar a detalle el proceso de selección de dichos expertos así como el medio por el cual se pueden registrar sus juicios. Se debe presentar sus cualificaciones y experiencia. Se debe reportar cualquier tipo entrenamientos e instrucciones provistas, además se indicar si los jueces llegaron a sus juicios de manera independiente y finalmente reportar el grado de acuerdo. Si los jueces interactuaron uno con el otro o intercambiaron información también debe detallarse (p. 25): El criterio de jueces realizado estuvo conformado por la evaluación de nueve jueces, cuyas especialidades pertenecieron a la psicología clínica enfocada en el trabajo con niños, psicología educativa, trabajo en investigación, construcción y diseño de instrumentos y psicometría. A partir de las califaciones de cada uno de ellos, se estimó el coeficiente $\mathrm{V}$ de Aiken adecuada para cada uno de los ítems de la EECI. La matriz de indicaciones que recibió cada uno de estos se encuentra en la sección de Anexos (ver anexo 1).

1.10. Cuando las evidencias de validez incluyen análisis estadísticos de los resultados de la prueba, de manera individual o en conjunto con los datos de otras variables, las condiciones bajo las cuales la información fue recolectada debe describirse de manera detallada para que los usuarios puedan juzgar la relevancia de los hallazgos estadísticos (p. 26): En el área de Procedimiento dentro de la sección de Método, se describe a detalle los pasos llevados a cabo para realizar la investigación, especificamente la preparación y cosntrucción de la prueba, la recolección de datos y el análisis psicométrico 
1.11. Cuando el fundamento de la interpretación de las puntuaciones de la prueba para un uso particular se apoya, en parte, en la pertinencia del contenido de la prueba, los procedimientos realizados en especificar y generar el contenido de la prueba deben ser descritos y justificados junto con la población objetivo y el constructo o dominio que la prueba pretende medir. Si la definición del contenido incluye criterios como importancia, frecuencia o criticalidad, estos criterios deben, también, ser explicados claramente y justificados (p. 26): Tal y como se presenta en la sección de Método, la EECI fue construida a partir de una matriz en donde se intersectaron los componentes del estrés propuestos por Trianes et al. (2009) y las situaciones en donde el estrés se manifiesta en los niños (Oros y Vogel, 2005). De la misma manera en aquél capítulo, se proporciona información detallada sobre la población objetivo del instrumento y la definición del constructo que se pretende medir.

1.13. Si la argumentación para las interpretaciones de las puntuaciones de una prueba para un uso determinado depende de la relación entre los ítems o entre partes del test, es necesario reportar las evidencias vinculadas a la estructura interna (p. 26): En la sección de Resultados, se muestra información sobre las evidencias que respaldan la estructura unidimensional de la EECI. Asimismo, en la sección de Discusión, se presenta información sobre la interpretación de esta estructura.

1.16. Cuando se incluyen análisis empíricos de los puntajes de una prueba junto con datos de otras variables se debe especificar el razonamiento empleado para seleccionar estas otras variables. Reportar las especificaciones técnicas de las otras pruebas (p. 27): Se realizó un análisis de evidencias de validez vinculadas a la relación con otras variables, entre la EECI y la Lista de Chequeo Conductual de Ansiedad en Niños de Alarcón (1993). Se decidió hacer el análisis con esta prueba, dado a que ambas miden constructos similares (ansiedad y estrés) (Beck et al., 1985). Tal y como se postula en la sección de Resultados, se encontró una correlación fuerte (Cohen, 1992) entre las puntuaciones de ambas pruebas.

\subsubsection{Estándares para la confiabilidad}

2.0. Se debe proporcionar evidencias de confiabilidad/precisión apropiadas para las interpretaciones de cada uso de las puntuaciones (p. 42): En la sección de Resultados, se muestra el análisis de confiabilidad realizado para las puntuaciones totales de la 
EECI. En análisis se llevó a cabo estimando el coeficiente alfa de Cronbach y alfa ordinal. No se estimó la confiabilidad para los subpuntajes, dado la estructura unifactorial de la prueba.

2.3. Para cada puntaje total, subpuntaje, o combinación de puntajes que se van a interpretar, se deben reportar índices relevantes de confiabilidad (p. 43): El nivel de confiabildiad del puntaje total se muestra en el capítulo de Resultados.

2.5. Los procedimientos para la estimación de la confiabilidad debe ser consistente con la estructura del test (p. 43): A partir del análisis factorial, se halló la existencia de una sola dimensión. La estimación de la confiabilidad de este factor se muestra en la sección de Resultados.

2.11. El autor del instrumento debe reportar la estimación de la confiabilidad para cada uno de los subgrupos relevantes para el cual se recomienda la prueba (p. 45): En la sección de Resultados se presentan los niveles de confiabilidad estimados para los grupos según sexo, grado y tipo de colegio. Para cada uno de ellos se estima el coeficiente alfa de Cronbach clásico y el alfa ordinal.

2.13. El Error Estándar de Medición (EEM), tanto el general como el condicional (de ser reportado), debe proporcionarse en unidades para cada puntuación reportada (p. 45): Los EEM para el puntaje de toda la muestra, así como para los grupos según sexo, grado y tipo de colegio, se encuentra reportados en la sección de Resultados.

\subsubsection{Estándares para el diseño y desarrollo de la prueba}

4.0. Las pruebas y programas de evaluación deben diseñarse y desarrollarse de tal manera que sustenten la validez de las interpretaciones de las puntuaciones de la prueba para los usos propuestos. Los diseñadores de la prueba deben documentar todos los pasos realizados durante el proceso de diseño y desarrollo de la prueba para así poder proporcionar evidencias de validez y confiabilidad para los usos y población que se ha definido (p. 85): Los pasos empleados para construir y analizar las propiedades psicométricas de la EECI se encuentran descritos en la sección de Método y en la sección de Resultados. En el anexo 3, se encuentra la versión inicial de la prueba, que fue aplicada a la muestra estudiada. 
4.1. Se debe especificar el propósito de la prueba, la definición del constructo y las interpretaciones de los usos de esta (p. 85): Esta información puede encontrarse explicada claramente en las secciones de Objetivos y Definición de Variables, Resultados y Discusión.

4.2. Es necesario que la prueba especifique el contenido, la duración, el formato de los ítems, las propiedades psicométricas, tanto de los ítems como de la prueba, y el ordenamiento de los ítems y las secciones. También se debe especificar los procedimientos utilizados para su administración (p. 85): La especificación del contenido, duración, formato de los ítems y propiedades psicométricas se encuentran explicados en la Ficha Técnica, que se encuentra en el anexo 2.

4.8. El proceso de revisión de la prueba debe incluir un análisis empírico o los aportes de los juicios de expertos para la revisión de ítems y los criterios de puntuación. Cuando se hace uso del juicio de expertos es importante reportar información sobre las calificaciones de los jueces, su experiencia y característica demográficas. Asimismo el entrenamiento o instrucciones dadas para el proceso de evaluación de los ítems debe ser detalladas (p.88): Los datos solicitados se muestran en la sección de Método (sub sección de Procedimiento) y de Resultados. Asimismo, tanto las instrucciones como la matriz de calificación se encuentran reportadas en el anexo 1.

4.10. Cuando el creador de la prueba evalúa las propiedades psicométricas de los ítems, debe señalar el modelo psicométrico empleado, así como la descripción de la muestra utilizada para estimar las propiedades psicométricas. Se recomienda que la muestra sea diversa y alcance un número adecuado (p. 89): El análisis psicométrico de la EECI partió de la Teoría Clásica de los Tests (TCT). La muestra evaluada ha sido definida y especificada a detalle en la sección de método, cumpliendo con los criterios propuestos de número adecuado de muestra por Nunally (1987), Kass y Tinsley (1979) y Field (2009).

4.15. Las indicaciones de administración deben ser presentadas de manera clara para que otros puedan replicar las condiciones bajo las cuales los datos de confiabilidad, validez y normas fueron obtenidos. De existir variaciones en los procedimientos de administración, estos deben ser especificados (p. 90): Los procedimientos que se llevaron a cabo para poder estimar las propiedades de confiabilidades, validez y normas de la EECI se encuentran explicados en la sección de Método. De la misma manera, en 
el anexo 3 se puede observar la versión inicial de la EECI, la cual contiene un conjunto de instrucciones claras y precisas.

4.17. Si la prueba, o parte de ella, se utiliza para investigar, y no para un uso operacional, se debe brindar afirmaciones sobre ese fin en todos los de administración e interpretación entregados al usuario de la prueba (p. 91): En el anexo 8, se puede encontrar el consentimiento informado presentado antes de realizar la investigacion, en donde se especifican los datos de la prueba indicando el fin investigativo de la prueba y la exposición de los resultados en contextos académicos. Asimismo, en este documento, se aseguró el anonimato de los participantes, así como las facilidades para comunicarse con la investigadora frente a cualquier duda.

4.22. El creador de la prueba debe especificar los procedimientos utilizados para interpretar los puntajes de esta y, en el caso se necesite, las muestras de estandarización o el criterio utilizado (p. 93): Información concerniente a los procedimientos empleados para interpretar los puntajes de la prueba se encuentran reportados en la sección de Resultados.

\subsubsection{Estándares para la elaboración de normas}

5.8. De utilizarse normas, estas deben hacer referencia a poblaciones claramente descritas. Estas poblaciones deben incluir individuos o grupos con los cuales los evaluadores querrían comparar a sus examinados (p. 104): No hubo necesidad de llevar a cabo baremos diferenciados, ya que no se hallaron diferencias estadísticamente significativas en ninguno de los grupos evaluados. No obstante, se realizaron baremos clasificados en quintiles a partir de las puntuaciones totales de estrés de la muestra evaluada. Se identificaron niveles de estrés "Muy bajo", "Bajo", "Medio", "Alto" y "Muy alto". Esta información se encuentra explicada detalladamente en la sección de Resultados.

\subsubsection{Estándares para la administración, puntuación, reporte e interpretación}

6.1. Los evaluadores deben seguir cuidadosamente los procedimientos estándar para administrar y puntuar, estos deben haber sido especificados por el desarrollador de la prueba y otras instrucciones que se indiquen (p. 114): La investigadora llevó a cabo el 
procedimiento riguroso, previamente postulado en la sección de método, para aplicar la EECI. Se siguieron todas las instrucciones señaladas y se uso una misma consigna para todos los grupos evaluados.

6.4. El ambiente de evaluación debe ser cómodo y con mínimas distracciones para evitar varianza irrelevante al constructo (p. 116): La aplicación de la EECI se llevó a cabo en los salones de clase de los participantes. Para evitar que existieran distracciones, se conversó, previamente, con los profesores encargados de cada aula, quienes, durante la evaluación, contribuyeron a que los participantes mantengan silencio.

\subsection{Análisis complementarios}

Con respecto a los análisis complementarios realizados, no se hallaron diferencias estadísticamente significativas entre los grupos evaluados. A partir de esto, se puede afirmar que existen similitudes entre los resultados obtenidos y las investigaciones previas encontradas en la literatura.

En primer lugar, se afirma que no existen diferencias estadísticamente significativas entre las variabls sexo y estrés (Oros y Vogel, 2005). Sin embargo, sí hay evidencia de una diferencia en la naturaleza de los estresores específicos entre ambos sexos. Así, como se ha mencionado previamente, los estresores de las niñas están más relacionados a las injusticias escolares, familiares, la pérdida afectiva de personas significativas, los problemas socioeconómicos y los problemas de salud. En el caso de los niños, los estresores se asocian las pérdidas afectivas de mascotas y las pérdidas materiales (Oros y Vogel, 2005).

Por otro lado, en relación a las variables estrés y grado, no hay diferencias estadísticamente significativas entre ambas (Oros y Vogel, 2005). No obstante, de manera contraria, Trianes et al. (2009) reportan que si bien no hay diferencias estadísticamente significativas entre estrés y edad (variable que afirma ser similar a la de grado) en su investigación, afirma que las diferencias no son necesariamente notables en la infancia, pero que sí pueden llegar a agudizarse en la adolescencia. Esto quiere decir que resultaría más conveniente e informativo realizar comparaciones entre estas variables, pero con adolescentes. 
Asimismo, se sostiene que, al igual que en con la variable sexo, la naturaleza de los estresores es bastante diferenciada según la edad. Esto se debe, principalmente, a que las vivencias amenazantes cambian a medida que el niño va creciendo porque también va cambiando la manera en la que ve el mundo e interactúa con él (Oros y Vogel, 2005).

Con respecto a la variable de tipo de colegio, se podría afirmar que los resultados no corroboran lo que indica la literatura. Evans y English (2002) señalan que los niños de comunidades vulnerables, ya sea de manera socioeconómica o sociocultural, presentan mayores estresores cotidianos que aquellos que no pasan por la misma situación. En el caso de la presente investigación, aquellos niños de niveles socioeconómicos y socioculturales más bajos se encontraron en el colegio público evaluado. Sin embargo, los resultados indican que no existen diferencias estadísticamente significativas entre los niveles de estrés de estos y los de los niños de otros colegios. La explicación de esto podría recaer, principalmente, en la poca representatividad de las muestras.

Por otro lado, se afirma que la carencia de diferencias estadísticamente significativas entre las variables podría basarse en la premisa de que el estrés es un fenómeno subjetivo (Oros y Vogel, 2005). Independientemente del sexo, grado o tipo de colegio, dos o más personas pueden interpretar de maneras distintas una misma situación y asumirlas como estresantes o no. Es por ello que no existe, necesariamente, una tendencia, por parte de un grupo en particular, hacia una mayor o menor cantidad de estrés.

Finalmente, se afirma que parte de los resultados complementarios podrían guardar relación con una falta de desarrollo de conciencia moral por parte de los participantes. La conciencia moral es el mecanismo que permite que una persona distinga entre lo que está bien y lo que está mal (Kohlberg y Hersh, 1977). En el caso de los participantes, Mounoud (2001) señala que los niños de hasta 12 años, edades de los evaluados, tienden a preocuparse menos por las situaciones que viven a diferencia de los adolescentes o adultos. Así, la concientización de las situaciones vividas como estresantes, en los evaluados, podría verse modificada debido al nivel de desarrollo de estos, generando una influencia en los resultados obtenidos. 


\section{CONCLUSIONES}

- Se obtuvieron evidencias adecuadas de validez de contenido, por medio del proceso de criterio de jueces, a través de la evaluación de nueve expertos.

- A partir del análisis factorial, se hallaron las evidencias de validez relacionadas a la estructura interna de la prueba. La versión final de la estructura factorial de la EECI mostró ser unidimensional, luego de haber pasado por tres análisis previos. El único factor de estrés hallado explicó el 30\% de la varianza compartida. En el proceso, ocho ítems fueron eliminados, contando con un nuevo total de 28 ítems.

- Se estimó la confiabildiad mediante el alfa de Cronbach y el alfa ordinal. En los dos casos, se alcanzó un coeficiente adecuado, que indicó que las puntuaciones derivadas de los ítems de la prueba muestran homogeneidad para evaluar el mismo constructo (Kline, 1995).

- Se encontró una correlación fuerte (Cohen, 1992) entre el constructo de estrés, medido a través de la EECI y el de ansiedad, medido a través de la LCCAN. Al ser, ambos, constructos similares (Beck et al., 1985), la fuerte relación indica que existen evidencias de validez vinculadas a la relación con otras variables.

- Se elaboraron baremos clasificados en quintiles los cuales no fueron divididos en subgrupos, dado que no se encontraron diferencias estadísticamente significativas. 


\section{RECOMENDACIONES}

- Se recomienda que el instrumento se aplique para evaluar a niños y niñas de 3ero a 5to grado de primaria de colegios públicos y privados de Lima Metropolitana.

- Se recomienda analizar niveles de estrés por medio de la EECI en contextos clínicos con el objetivo de llevar a cabo programas de intervención terapéutica para aquellos niños con elevados niveles de estrés.

- Sería recomendable que se realicen estudios en donde se comparen variables relacionadas al estrés en niños, como la estructura familiar, la resiliencia, la inteligencia o la personalidad. Así, se podrían encontrar variables moderadoras de estrés que faciliten su tratamiento.

- Se recomienda realizar otros estudios de validación del instrumento con muestras más representativas y un tipo de muestreo que permita que los resultados sean generalizables. De esta manera, se podría probar si la estructura factorial cambia o permanece como unifactorial, así como también comparar grupos y verificar si se presentan diferencias estadísticamente significativas entre estos.

- Se recomienda que, en estudios posteriores, se lleven a cabo análisis psicométricos más complejos, como el análisis factorial confirmatorio. Así, se podría verificar si la estructura factorial es replicable en una nueva muestra. 


\section{REFERENCIAS}

Aiken, L. (1985). Three coefficients for analyzing the reliability and validity of ratings. Educational and Psychological Measurement, 45, 131-142.

Alarcón, I. (1993). Lista de Chequeo Conductual de la Ansiedad en Niños. Revista Peruana de Análisis de la Conducta, 2(2), 37-42.

Alarcón, R. (2013). Métodos y diseños de investigación del comportamiento. Lima: Editorial Universitaria.

American Psychological Association. (2009). Publication manual of the American Psychological Association (6 ${ }^{\text {th }}$ ed). Washington, D.C.: American Psychological Association.

American Educational Research Association, American Psychological Association, \& National Council on Measurement in Education (2014). Standards for educational and psychological testing. Washington D.C.: American Educational Research Association.

Barlow, D. H. (1988). Anxiety and its disorders: The nature and treatment of anxiety and panic. New York: Guilford Press.

Beck, A. T., Emery, G. \& Greenberg, R. L. (1985). Anxiety disorders and phobias: A cognitive perspective. New York: Basic Books.

Bishop, D. (1996). Standard Error of Measurement (SEm) (Reporte No. 309159).

Recuperado de The New Department of Education, http://www.fldoe.org/core/fileparse.php/7567/urlt/y1996-7.pdf

Bonanomi, A., Ruscone, M. N. \& Osmetti, S. A. (2013). The Polychoric Ordinal Alpha, measuring the reliability of a set of polytomous ordinal items. In Advances in Latent Variables-Methods, Models and Applications. Recuperado de http://meetings.sisstatistica.org/index.php/sis2013/ALV/paper/viewFile/2651/424

Brietzke, E., Kauer, M., Jackowski, A., Grassi-Oliveira, R., Bucker, J., Zugman, A., Barbachan, R. \& Affonseca, R. (2012). Impact of childhood stress on psychopathology. RBP Psychiatry, 34, 480-488. 
Bremmer, J. (1999). Does stress damage the brain? Biological Psychiatry Journal, 45(7), 797-805.

Burga, A. (2006). La unidimensionalidad de un instrumento de medición: Perspectiva factorial. Revista de Psicología de la PUCP, 24(1), 54-80.

Cohen, J. (1992). A power primer. Psychological Bulletin, 112(1), 155-159. doi: 10.1037/0033-2909.112.1.155

Corraliza, J. y Collado, S. (2011). La naturaleza cercana como moderadora del estrés infantil. Psicothema, 23(2), 221-226.

Cronbach, L.J. (1951). Coefficient alpha and the internal structure of tests. Psychometrika 16(3), 297-334. doi: 10.1007/BF02310555

Dise-Lewis, J.E. (1988). Life Events and Coping Inventory: An assessment of stress in children. Psychosomatic Medicine, 50, 489-499.

Encina, Y. y Ávila, M. (2015). Validación de una escala de estrés cotidiano en escolares chilenos. Revista de Psicología, 33(2), 364-385.

Escobar, M., Alarcón, R., Blanca, M., Fernández-Baena, J, Rosel, J. \& Trianes, M. V. (2013). Daily Stressors in School-Age Children: A Multilevel Approach. School Psychology Quarterly, 28(3), 227-238. doi: 10.1037/spq0000020

Escurra, L.M. (1997). Cuantificación de la validez de contenido por criterio de jueces. Revistas de Psicología PUCP, 6(1), 103-111.

Evans, G. W. \& English, K. (2002). The enviroment of poverty: Multiple stressor exposure, psychophysiological stress, and socioemotional adjustment. Child Development, 73, 1238-1248. doi: 10.1111/1467-8624.00469

Fernández-Ballesteros, R. (1996). Introducción a la evaluación psicológica. Madrid: Pirámide.

Field, A. (2009). Discovering Statistics Using SPSS. Dubai: SAGE.

Folkman, S., Lazarus, R., Dunkel-Schetter, C., Delongis, A., \& Gruen, R. (1986). Dynamics of Stressful Encounter: Cognitive Appraisal, Coping and Encounter Outcomes. Journal of Personality and Social Psychology, 50(5), 992-1003.

Fraenkel, J., Wallen, N. \& Hyun, H. (2011). How to design and evaluate research in education ( $8^{\text {th }}$ ed.). New York, NY: McGraw-Hill Education. 
Gadermann, A. M., Guhn, M., \& Zumbo, B. D. (2012). Estimating ordinal reliability for Likert-type and ordinal item response data: A conceptual, empirical, and practical guide. Practical Assessment, Research \& Evaluation, 17(3), 1-13. Recuperado de http://www.pareonline.net/getvn.asp?v=17\&n=3

Gelhaar, T., Seiffge-krenke, I., Borge, A., Cicognani, E., Cunha, M., Loncaric, D. \& Metzke, C. W. (2007). Adolescent coping with everyday stressors: A sevennation study of youth from central, eastern, southern, and northern Europe. European Journal of Developmental Psychology, 4(2), 129-156.

González, L. (2008). Estrés infantil aumentó por presión para que sean perfectos, dice experto: Mexico-Literatura (Entrevista). ProQuest Central. Id ProQuest: 433218847

Gutiérrez, J. M. (1998). Eustrés: un modelo de superación del estrés. Revista PsicologíaCientífica.com, 1(3), 1-7.

Hair, J. F., Anderson, R. E Tatham, R. L., y Black, W. C. (2007). Análisis Multivariante ( $5^{\mathrm{a}}$ ed.). Madrid: Pearson.

Hamilton, M. (1959). The assessment of anxiety states by rating. Medicine Psychology, $32(1), 50-5$

Hernández, S. R., Fernández, C. C., y Baptista, L. P. (2014). Metodología de la investigación ( $5^{\text {ta }}$ ed.). México, D.F: McGraw-Hill Education.

Hobfoll, S. (1989). Conservation of resources: A new attempt at conceptualizing stress. American Psychologist, 44(3), 513-524.

Holmes, T.H. \& Rahe, R. H. (1967). The social readjustment rating scale. Journal of Psychosomatic Research, 11, 213-218.

Humphrey, R. \& McCarthy, P. (1998). Stress and the contemporary student. Higher Education Quarterly, 52(2), 221-242.

Hüther, G. (2012). Biología del miedo. El estrés y los sentimientos. Barcelona: Plataforma Editorial.

Ivancevich, J. y Matteson, M. (1991). Estrés y trabajo: una perspectiva gerencial. México: Trillas. 
Kanner, A.D., Coyne, J.C., Schaefer, C. \& Lazarus, R.S. (1981). Comparison or two modes of stress measurement: Daily hassles and uplifts versus major life events. Journal of Behavioral Medicine, 4(1), 1-39.

Kass, R.A. \& Tinsley, H. E. A. (1979). Factor analysis. Journal of Leisure Research, $11,120-138$.

Kearney, C., Drabman, R., \& Beasley, J. (1993). The trials of childhood: The development, reliability and validity of the Daily Life Stressors Scale. Journal of Child and Family Studies, 2, 371-388.

Kendall, M. (1938). A new measure of rank correlation. Biometrika, 30, 81-89.

Kline, P. (1999). The Handbook of psychological testing. London: Routledge.

Kohlberg, L. \& Hersh, R. H. (1977). Moral development: A review of the theory. Theory Into Practice, 16(2), 53-59.

Lau, B. W. K. (2002). Does the stress in childhood and adolescence matter?. A psychological perspective. The Journal of the Royal Society for the Promotion of Health, 122 (4), 238-244.

Lazarus, R. (2000). Estrés y emoción: manejo e implicaciones en nuestra salud. Bilbao: Desclée de Brouwer S.A.

Lazarus, R. \& Folkman, S. (1984). Stress, appraisal and coping. New York: Springer Publishing Company.

Lazarus, R. y Folkman, S. (1986). Estrés y procesos cognitivos. Barcelona: Martínez Roca.

Lazarus, R. \& Folkman, S. (1987). Transactional theory and research on emotions and coping. European Journal of Personality, 2, 141-169.

Lewis, C.E., Siegel, J.M. \& Lewis, M.A. (1984) Feeling bad: Exploring sources of distress among pre-adolescent children. American Journal of Public Health, 74, $117-122$

Lorenzo-Seva, U., Timmerman, M.E. \& Kiers, H. A. L. (2011). The Hull method for selecting the number of common factors. Multivariate Behavioral Research, $46(2), 340-364$ 
Lorenzo-Seva, U., y Ferrando, P. J. (2015). Factor (Versión 9.3.1) [Software de computación]. Recuperado de http://psico.fcep.urv.es/utilitats/factor/Download.html

Monk, C., Fifer, W., Myers, M., Sloan, R., Trien, L. \& Hurtado, A. (2000). Maternal stress responses and anxiety during pregnancy: Effects on fetal heart rate. Developmental Psychology, 36(1), 67-77.

Morales, F., Trianes, M., y Miranda, J. (2012). Diferencias por sexo y edad en afrontamiento infantil del estrés cotidiano. Electronic Journal of Research in Educational Psychology, 10(1), 95-110.

Morrison, V. y Bennett, P. (2008). Psicología de la Salud. Madrid: Pearson Education S.A.

Mounoud, P. (2001). El desarrollo cognitivo del niño: desde los descubrimientos de Piaget hasta las investigaciones actuales. Contextos Educativos, 4, 53-77.

Nunnally, J.C. (1978). Psychometric theory. New York: Mc Graw-Hill.

Nunnally, J. C., y Bernstein, I. H. (1995). Teoría psicométrica (2a ed.). México D.F.: McGraw Hill.

Oblitas, L. (2009). Psicología de la salud y calidad de vida ( $3^{\mathrm{a}}$ ed.). México D.F.: Cengage Learning Editores S.A.

Orlandini, A. (1999). El estrés: qué es y cómo evitarlo. México: La ciencia para todos.

Oros, L. y Vogel, G. (2005). Eventos que generan estrés en la infancia: diferencias por sexo y edad. Enfoques XVII, 3, 85-101.

Osika, W., Friberg, P. \& Währborg, P. (2007). A new short self-completion questionnaire to asses stress in children. International Journal of Behavioral Medicine, 14, 108-117.

Patrick, J., Dyck, M. \& Bramston, P. (2010). Depression Anxiety Stress Scale: Is it Valid for Children and Adolescents?, Journal of Clinical Psychology, 66(9), 996-1007.

Pereyra, M. (2008). Estrés y Salud. En: V. Morrison y P. Bennett, ed., Psicología de la Salud, (1 ${ }^{\mathrm{a}}$ ed.). Madrid: Pearson Educación S.A, 214 - 247. 
Pett, M.A. \& Johnson, M.J. (2005). Development and psychometric evaluation of the revised University Student Hassles Scale. Educational and Psychological Measurement, 65, 984-1010.

Pianta, R. \& Walsh, D. (1998). Applying the Construct of Resilience in Schools: Cautions From a Developmental Systems Perspective. School Psychology Review, 27(3), $407-417$.

Razali N. M. \& Wah, Y. B. (2011). Power comparison of Shapiro-Wilk, KolmogorovSmirnov, Lilliefors and Anderson Darling tests. Journal of Statistical Modeling and Analytics, 2(1), 21-33.

Sandín, B. (2003) El estrés: un análisis basado en el papel de los factores sociales. Revista Internacional de la Psicología Clínica y la Salud, 3(1), 141-157.

Sandín, B. y Chorot, P. (2003). Cuestionario de Afrontamiento del Estrés (CAE), Revista de Psicopatología y Psicología Clínica, 8(1), 39-54.

Sandín, B. (2008). El estrés. En A.Belloch, B. Sandín, y F.Ramos (Eds.), Manual de Psicopatología, Vol.2 (2aed., pp. 3-42). Madrid: MacGraw Hill Interamericana.

Sass, D.A., \& Schmitt, T.A. (2010). A comparative investigation of rotation criteria within exploratory factor analysis. Multivariate Behavioral Research 45, 73103. doi:_10.1080/00273170903504810

Seiffge-Krenke, I. (2000). Causal links between stressful events, coping and style and adolescent symptomatology. Journal of Adolescence, 23, 675-691.

Selye, H. (1950). The physiology and pathology of exposure to stress. Montreal: Acta.

Selye, H. (1956). The stress of life. New York: McGraw-Hill.

Simms, L. (2008). Classical and Modern Methods of Psychological Scale Construction. Social and Personality Psychology Compass, 2, 414-433.

Thompson, B. (2002). Exploratory and Confirmatory Factor Analysis. Washington D.C: American Psychological Association.

Toledo, M., Ferrero, J. y Barreto, P. (2000). Trastornos de ansiedad en la infancia y adolescencia. En: R. González, ed., Psicopatología del niño y del adolescente, ( $1^{\mathrm{a}}$ ed.). Madrid: Ediciones Pirámide, 157 - 180. 
Trianes, M. (2003). El estrés en la infancia: su prevención y tratamiento. Madrid:

Narcea.

Trianes, M. V. (2007). Estrés, riesgo familiar e inadaptación socioemocional y escolar en la infancia. (Tesis doctoral inédita). Departamento de Psicología Evolutiva y de la Educación. Universidad de Málaga.

Trianes, M., Mena, B., Fernández, F., Escobar, M., Maldonado, E. y Muñoz, A. (2009) Evaluación del estrés infantil: Inventario Infantil de Estresores Cotidianos (IIEC). Psicothema, 21(4), 598-603.

Tsoory, M., Cohen, H. \& Richter-Levin, G. (2007). Juvenile stress induces a predisposition to either anxiety or depressive-like symptoms following stress in adulthood. PubMed, 17(4), 245-256.

Tucker, L.R. \& MacCallum, R.C. (1997). Exploratory Factor Analysis. Recuperado en: http://www.ffzg.unizg.hr/psiho/phm/nastava/Book_Exploratory\%20Factor\%20 Analysis.PDF

Vargas, H. (2014). Tipo de familia y ansiedad y depresión. Revista Medicina Herediana, 25, 57-59.

Verduzco, M., Gómez-Marqueo, E., y Durán, C. (2004) La influencia de la autoestima en la percepción del estrés y el afrontamiento en niños de edad escolar. Salud Mental, 18-25.

Zaira, C., Hernández, Y., Juárez, B., Martínez, E., Ortega, J., y López, V. (2007). Primer estudio de validez de constructo del Inventario de Estrés Infantil (IEI). Revista Electrónica de Psicología Iztacala, 10(3), 62-70.

Zaira, C., González, F. Anguiano, S., Nava, C., y Soria, R. (2009). Habilidades sociales y estrés infantil. Revista de Conducta, Salud y Temas Sociales, 7-13.

Zaira, V., Muñoz, S., Berra, E., Nava, C., y Gómez, G. (2012). Identificación de emociones desde el modelo de Lazarus y Folkman: Propuesta del Cuestionario de Estrés, Emociones y Afrontamiento (CEEA). Revista Electrónica de Psicología Iztacala, 15(3), 1051-1067.

Zohar, D. \& Dayan, I. (1999). Must coping options be severely limited during stressful events: testing the interaction between primary and secondary appraisals. Overseas Publishers Association, 12, 191-216. 


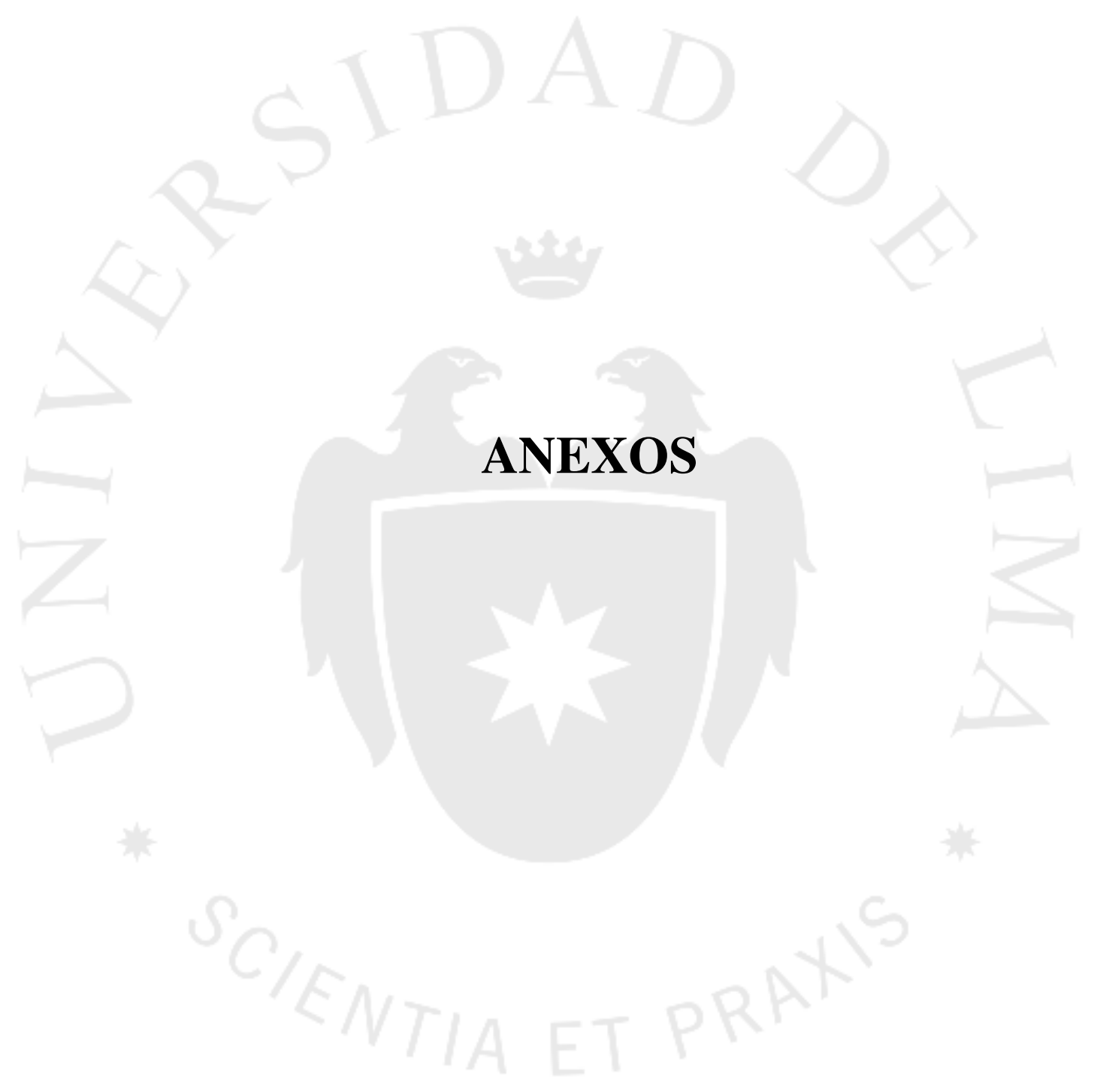




\section{ANEXO 1: Matriz de evaluación de criterio de jueces para la Escala de Estrés Cotidiano Infantil (EECI)}

Estimado(a),

Le escribo para solicitar su apoyo en el proceso de validación de la construcción de mi prueba: Escala de Estrés Cotidiano Infantil (EECl) con el fin de llevar a cabo mi proyecto de tesis de grado.

El proyecto tiene como objetivo obtener las evidencias psicométricas de la escala construida sobre estrés en niños.

La escala cuenta con 36 ítems y se agrupan bajo cuatro indicadores:

- Afectivo: Sensación emocional negativa que se experimenta al pasar por situaciones estresantes. Por ejemplo: sensaciones de angustia, ansiedad, intranquilidad.

- Cognitivo: Pensamientos ante situaciones de estrés. Por lo general, se reflejan pensamientos negativos, pesimistas y algunas veces, rumiantes. Por ejemplo: "no soy capaz de lograrlo, todo me saldrá mal".

- Conductual: Conductas que evidencian estrés, algunas de ellas son de evitación o escape. Por ejemplo: morderse las uñas, pelear, esconderse.

- $\quad$ Fisiológico: Sensaciones físicas que son experimentadas durante este tipo de situaciones. Por lo general, son desagradables y pueden llegar a ser desadaptativas. Por ejemplo: palpitaciones, sudoración, ruborización.

Es importante recalcar que, en la mayoría de los casos, los cuatro indicadores se presentan de manera simultánea, correspondiendo, todos ellos, a la experiencia de estrés.

A su vez, estos indicadores se encuentran relacionados con las situaciones o áreas que tienden a generar estresores en la vida cotidiana de los niños, propuestas por Oros y Vogel (2005):

- Social: Situaciones como la pérdida de un amigo, el ingreso a un grupo, el comienzo de actividades deportivas, inicio de relaciones con pares del sexo opuesto, etc.

- En la prueba hace referencia a situaciones que involucran relaciones sociales e interacciones con amigos en diferentes escenarios (conversaciones, juego, recreo, etc.).

- Académica: Situaciones como el cambio de colegio, la repetición de grado, el cambio de profesor, aumento de tareas, etc.

- En la prueba se refiere a situaciones académicas (prácticas, tareas, exposiciones, exámenes, trabajos en grupo).

- Familiar: Amenazantes acontecimientos como el nacimiento de un nuevo hermano, conflictos en la relación con los padres, fallecimiento de algún familiar, enfermedad de algún familiar, cambio de domicilio, etc.

- En la prueba hace referencia a situaciones cotidianas en casa y relación con miembros familiares. 
Así, los ítems resultan de una intersección de indicadores del estrés y situaciones donde el estrés se lleva a cabo.

En la tabla adjunta, se le presentarán los ítems agrupados de acuerdo a las tres áreas o situaciones donde surge el estrés, así como los indicadores en los que están basados. Estos deberán ser calificados de acuerdo a los siguientes criterios:

- Representación del área: los ítems pertenecen al área en la que han sido agrupados. Deberá calificar este criterio con un puntaje que va del 1 al 5, donde 5 significa que el ítem es "muy representativo del área"; y 1 significa que es "poco representativo del área".

- Claridad en la redacción: los ítems tienen una sintaxis y semántica que permiten entenderlos fácilmente. Deberá calificar este criterio con un puntaje que va del 1 al 5 , donde 5 significa que el ítem es "bastante claro en su redacción"; y 1 significa que el ítem "no es claro en su redacción".

En caso de considerar que un ítem es poco representativo del área o no es claro en su redacción, o en el caso de tener alguna observación adicional, indicar la razón o duda en la casilla de "Observaciones". Por favor, enviar sus respuestas por el mismo medio electrónico.

Antes de comenzar, por favor, llene la siguiente información:

Nombre:

Edad:

Profesión:

Especialidad:

Grado académico:

Muchas gracias por su tiempo y valioso apoyo.

Saludos cordiales,

María Fernanda Flores Mazulis 


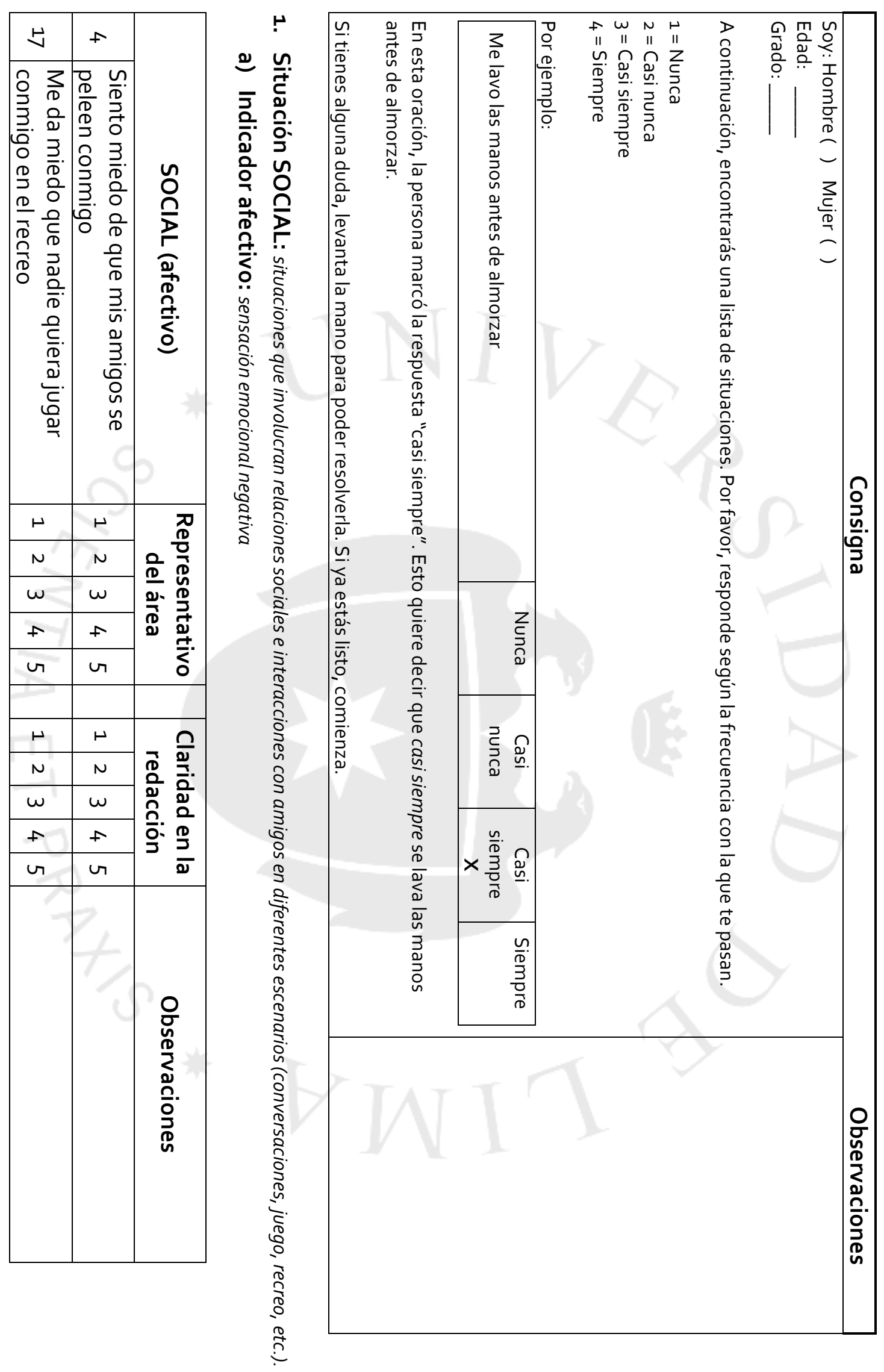




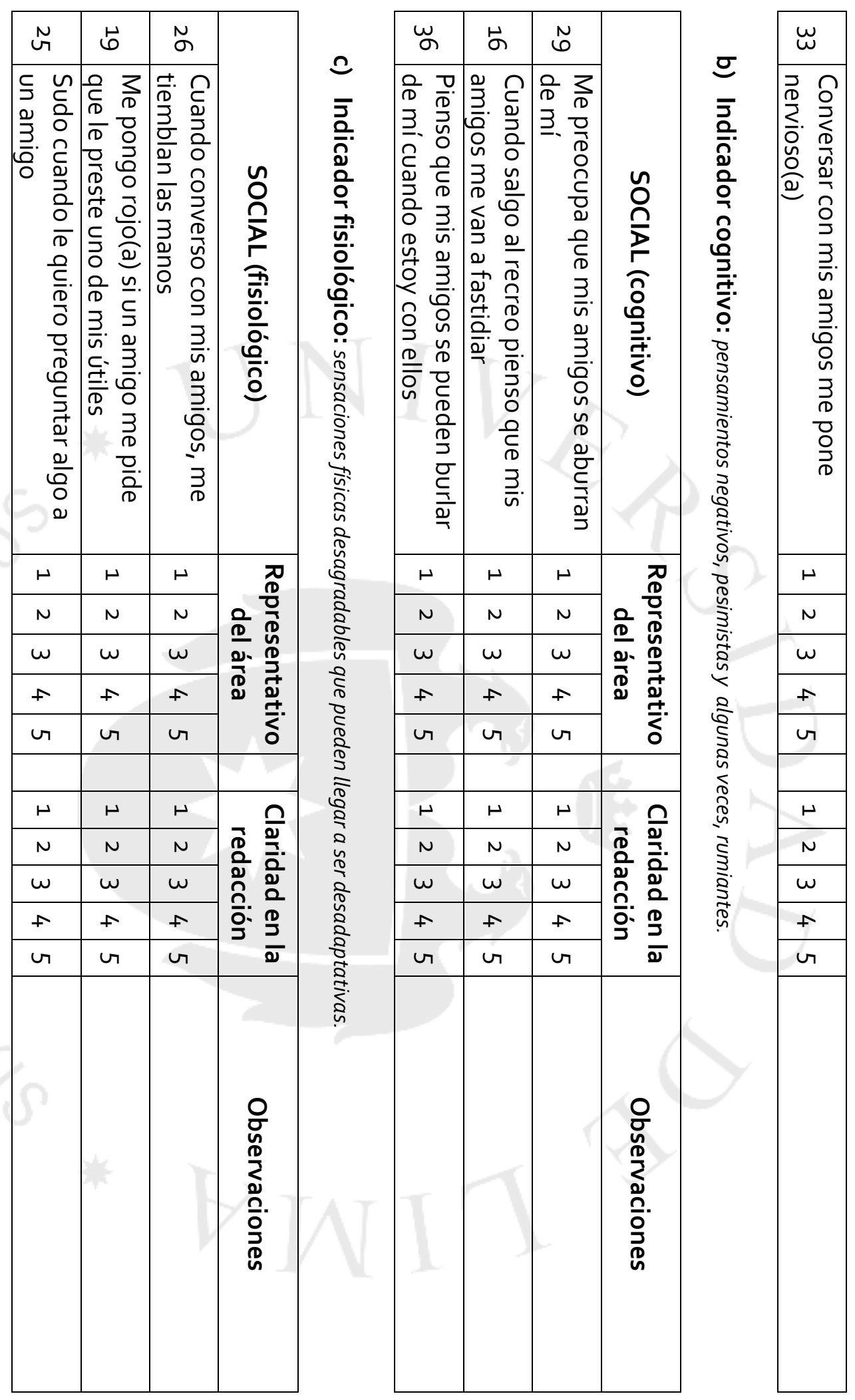




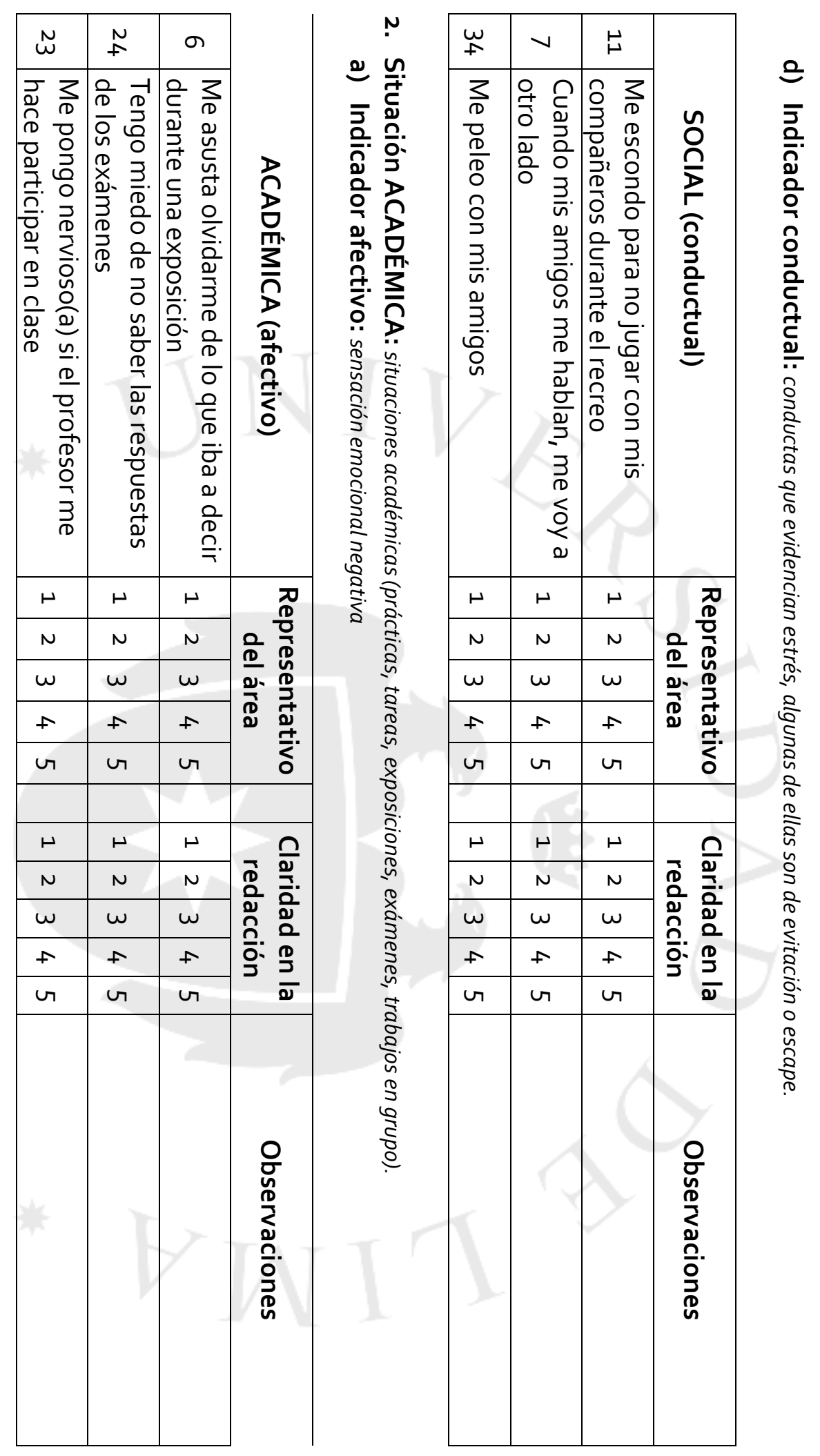




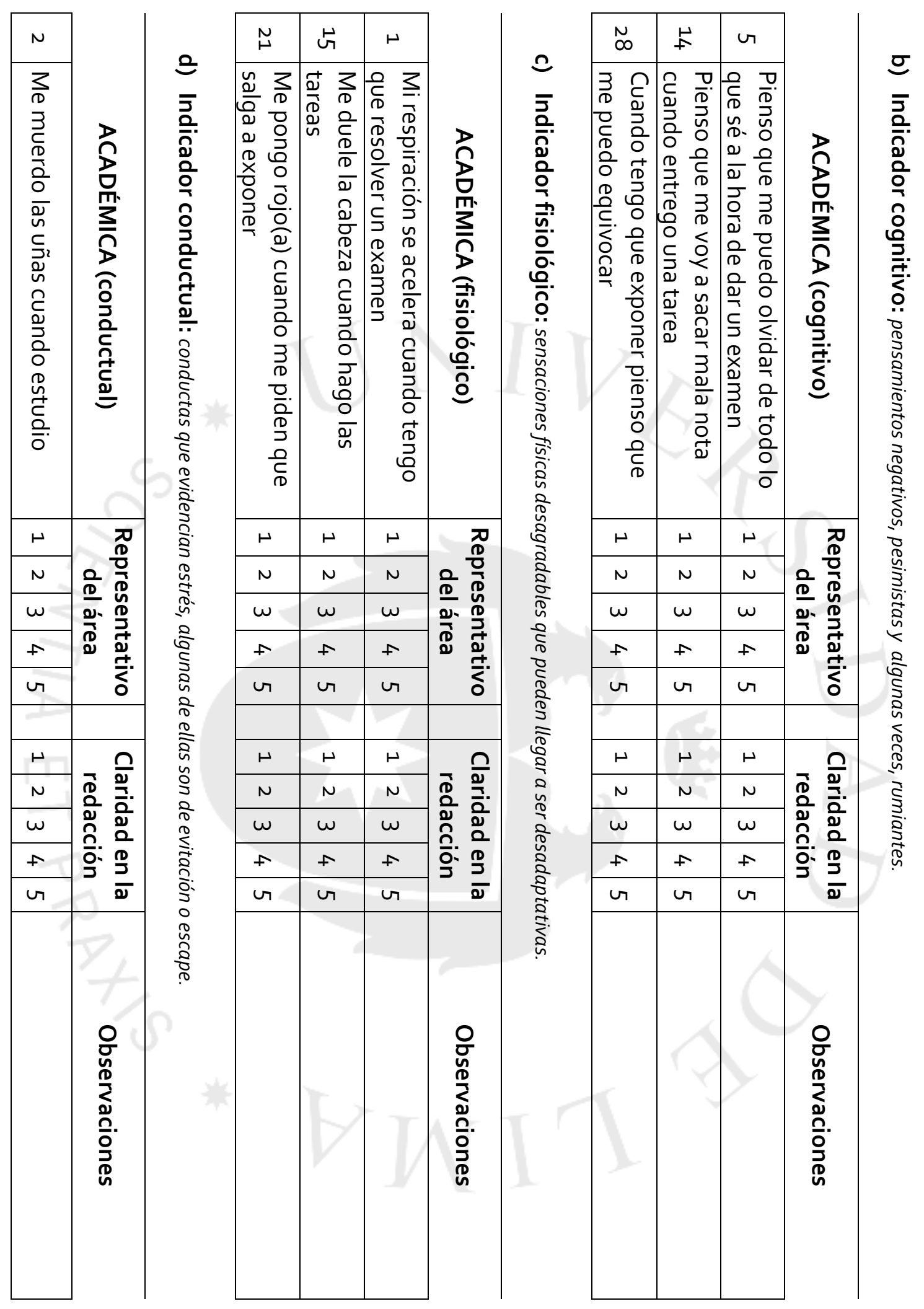




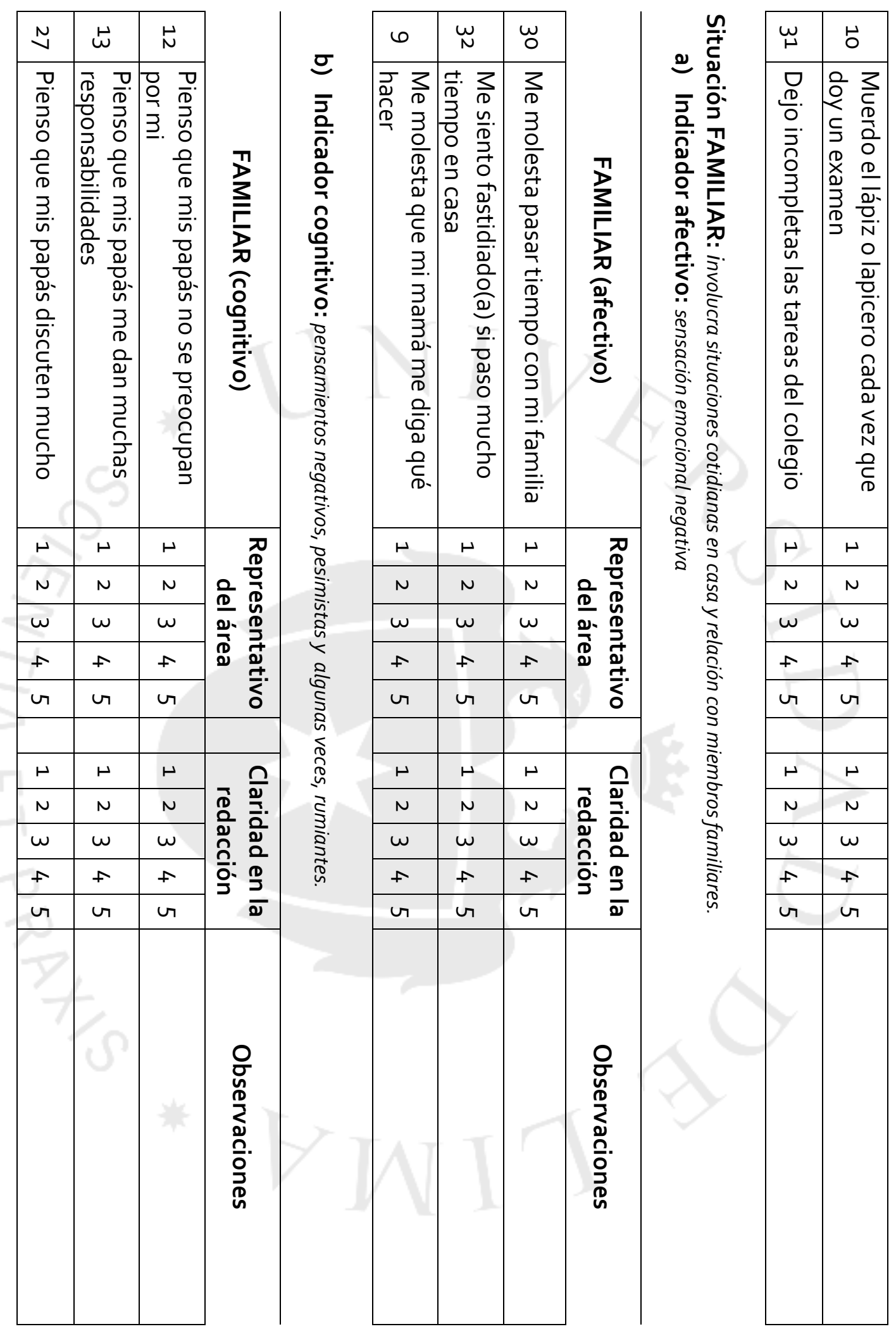




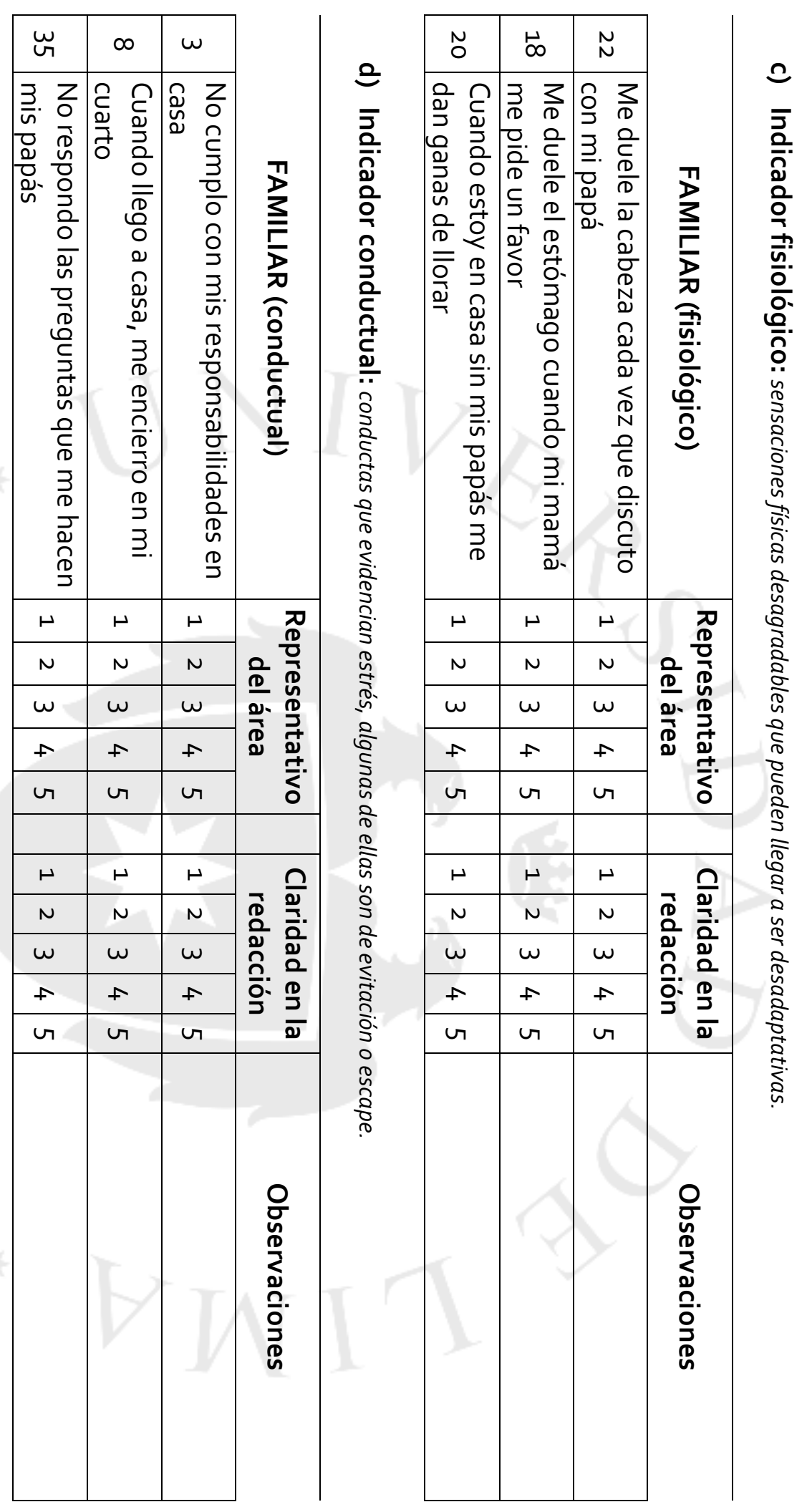




\section{ANEXO 2: Ficha técnica de la Escala de Estrés Cotidiano}

\section{Infantil (EECI)}

\begin{tabular}{|c|c|}
\hline Nombre & Escala de Estrés Cotidiano Infantil \\
\hline Objetivo & $\begin{array}{l}\text { Obtener información acerca de los niveles de estrés cotidiano } \\
\text { infantil, medido a partir de los componentes cognitivo, afectivo, } \\
\text { fisiológico y conductual del estrés y los ámbitos social, familiar y } \\
\text { académico de los niños y niñas. }\end{array}$ \\
\hline \multirow[t]{8}{*}{$\begin{array}{l}\text { Estructura del } \\
\text { instrumento }\end{array}$} & $\begin{array}{l}\text { Intersección entre los componentes del estrés y los ámbitos en } \\
\text { donde este lleva a cabo en la infancia. }\end{array}$ \\
\hline & \multirow{4}{*}{$\begin{array}{l}\text { - Componente cognitivo: pensamientos ante situaciones de } \\
\text { estrés. Por lo general, se reflejan pensamientos negativos, } \\
\text { pesimistas y algunas veces, rumiantes. Por ejemplo: "no soy } \\
\text { capaz de lograrlo, todo me saldrá mal". } \\
\text { - Componente afectivo: referido a la sensación emocional } \\
\text { negativa que se experimenta al pasar por situaciones } \\
\text { estresantes. Por ejemplo: sensaciones de angustia, ansiedad, } \\
\text { intranquilidad. } \\
\text { Componente fisiológico: sensaciones físicas que son } \\
\text { experimentadas durante este tipo de situaciones. Por lo general, } \\
\text { son desagradables y pueden llegar a ser desadaptativas. Por } \\
\text { ejemplo: palpitaciones, sudoración, ruborización. } \\
\text { Componente conductual: conductas que evidencian estrés, } \\
\text { algunas de ellas son de evitación o escape. Por ejemplo: } \\
\text { morderse las uñas, pelear, esconderse. }\end{array}$} \\
\hline & \\
\hline & \\
\hline & \\
\hline & $\begin{array}{l}\text { Ámbito social: situaciones estresantes que implican la } \\
\text { interacción con el medio social, como la pérdida de un amigo, } \\
\text { el ingreso a un grupo, el comienzo de actividades deportivas, } \\
\text { inicio de relaciones con pares del sexo opuesto, etc. }\end{array}$ \\
\hline & $\begin{array}{l}\text { - Ámbito familiar: acontecimientos percibidos como } \\
\text { amenazantes y que ocurren dentro del contexto familiar, como } \\
\text { el nacimiento de un nuevo hermano, conflictos en la relación } \\
\text { con los padres, fallecimiento de algún familiar, enfermedad de } \\
\text { algún familiar, cambio de domicilio, etc. }\end{array}$ \\
\hline & $\begin{array}{l}\text { - Ámbito académico: situaciones estresantes y cambiantes dentro } \\
\text { del ámbito escolar, como el cambio de colegio, la repetición de } \\
\text { grado, el cambio de profesor, aumento de tareas, etc. }\end{array}$ \\
\hline
\end{tabular}




\begin{tabular}{|c|c|}
\hline Autor original & María Fernanda Flores Mazulis \\
\hline $\begin{array}{l}\text { Ámbito de } \\
\text { aplicación }\end{array}$ & $\begin{array}{l}\text { Niños y niñas de } 3 \text { ero, } 4 \text { to y } 5 \text { to grado de primaria de colegios } \\
\text { públicos y privados de Lima Metropolitana. }\end{array}$ \\
\hline $\begin{array}{l}\text { Forma de } \\
\text { aplicación }\end{array}$ & Individual y colectiva \\
\hline Duración & 20 minutos \\
\hline Materiales & Cuadernillo de preguntas \\
\hline Procedencia & Lima, Perú \\
\hline $\begin{array}{l}\text { Niveles de } \\
\text { medición }\end{array}$ & 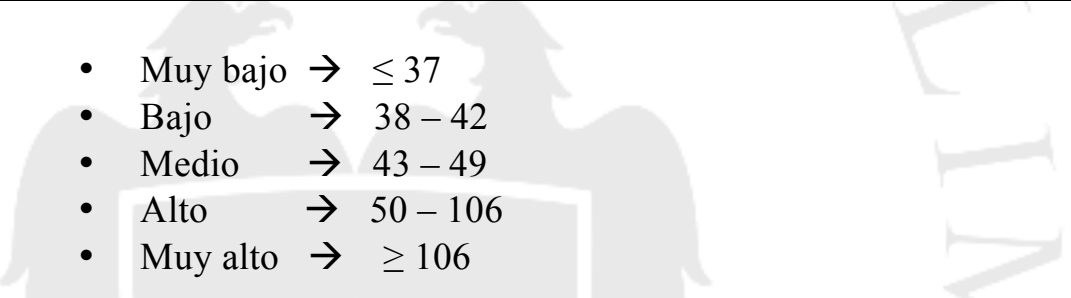 \\
\hline
\end{tabular}



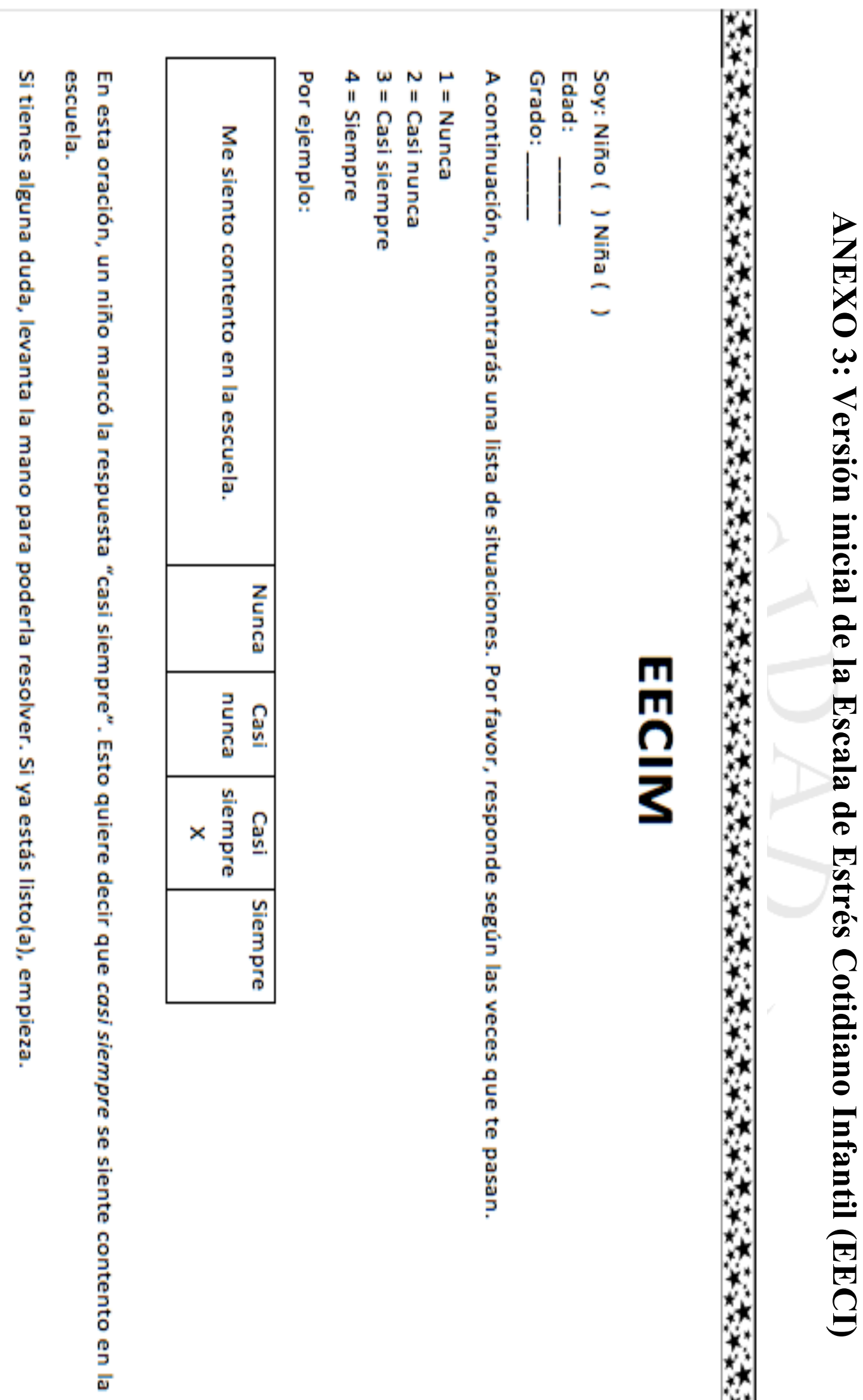

 


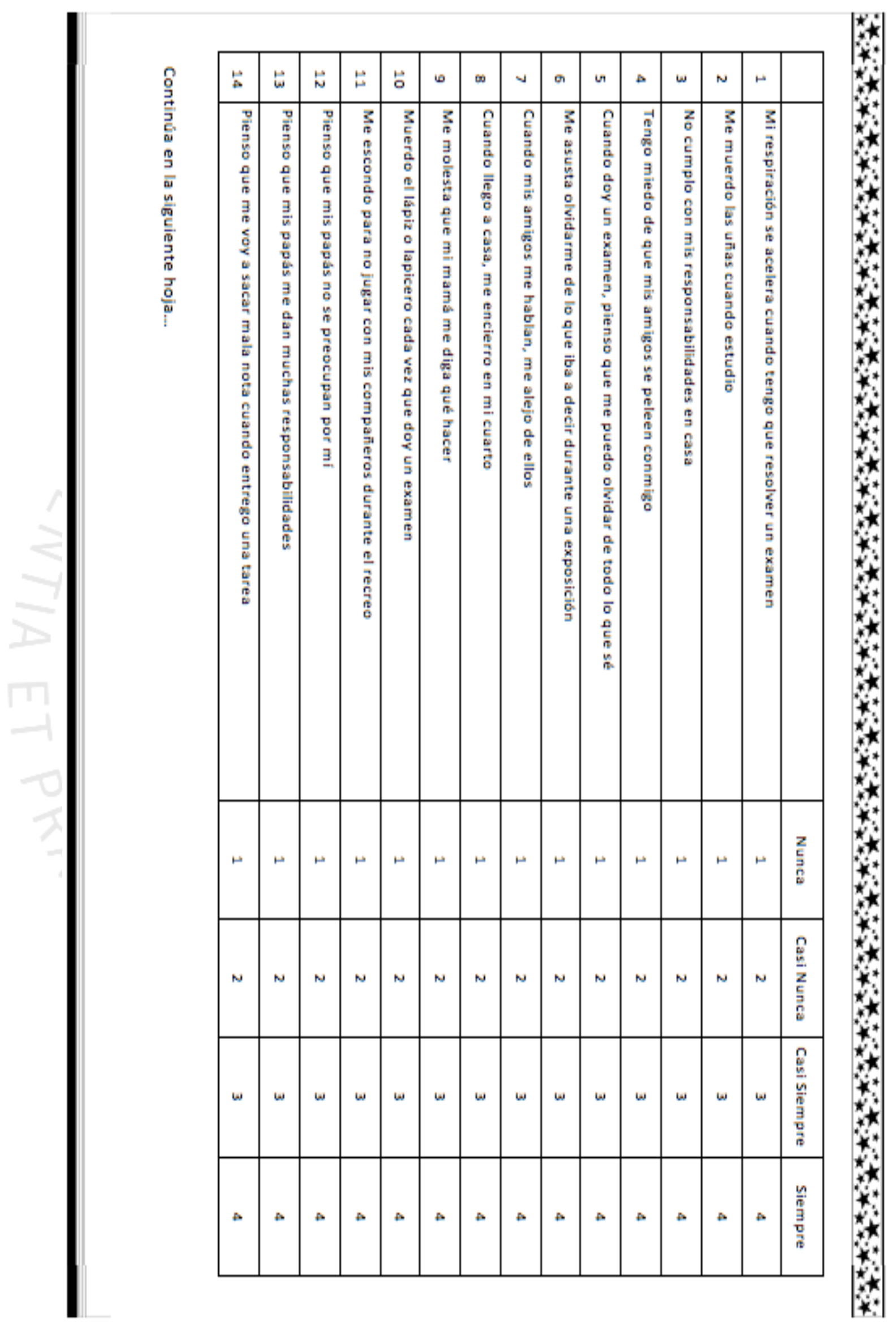




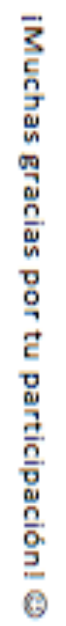

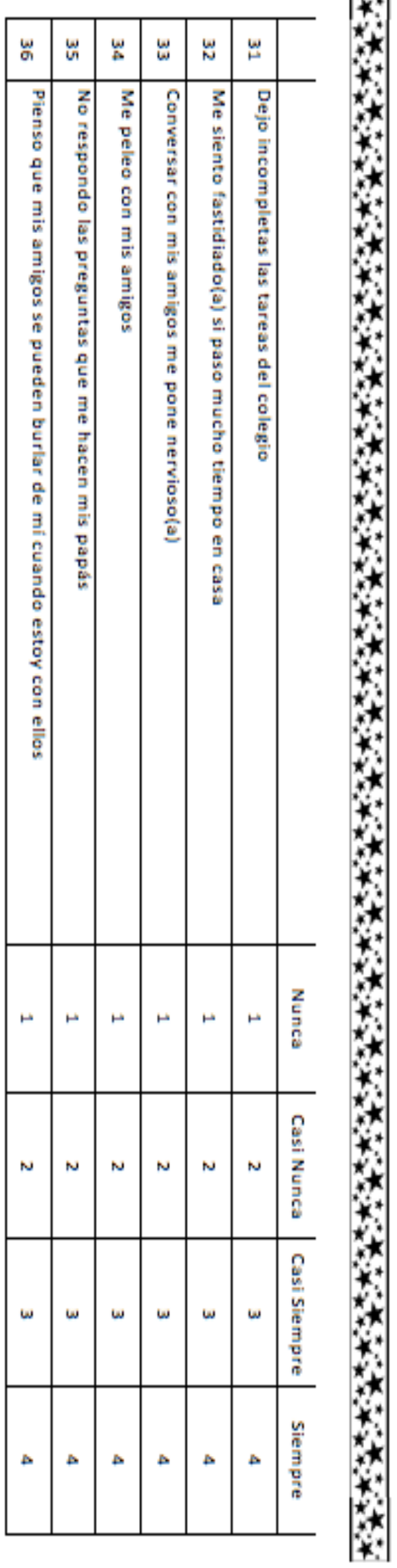




\section{ANEXO 4: Lista de Chequeo Conductual de la Ansiedad en Niños (Alarcón, 1993)}

\section{LCCAN (Alarcón, 1993)}

Instrucciones:

Aquí hay algunas preguntas acerca de la manera como te sientes, piensas y te comportas. Después de cada pregunta puedes ver que hay palabras NUNCA, ALGUNAS VECES, FRECUENTEMENTE. Marca con un aspa $(\mathrm{X})$ una de ellas, de acuerdo como te sientes, piensas o te comportas.

Trabaja rápidamente y no demores mucho tiempo en cada pregunta. Asegúrate de no dejar de responder cada pregunta.

1. Estoy intranquilo, preocupado por cualquier motivo.

2. Mi corazón late muy rápido.

3. Tengo cólera por cualquier motivo.

4. Me desmayo o siento que me voy a desmayar.

5. Tengo ganas de llorar.

6. Tengo dolores o sensaciones de opresión en el pecho.

7. Tengo pesadillas.

8. Siento miedo a varias cosas. 


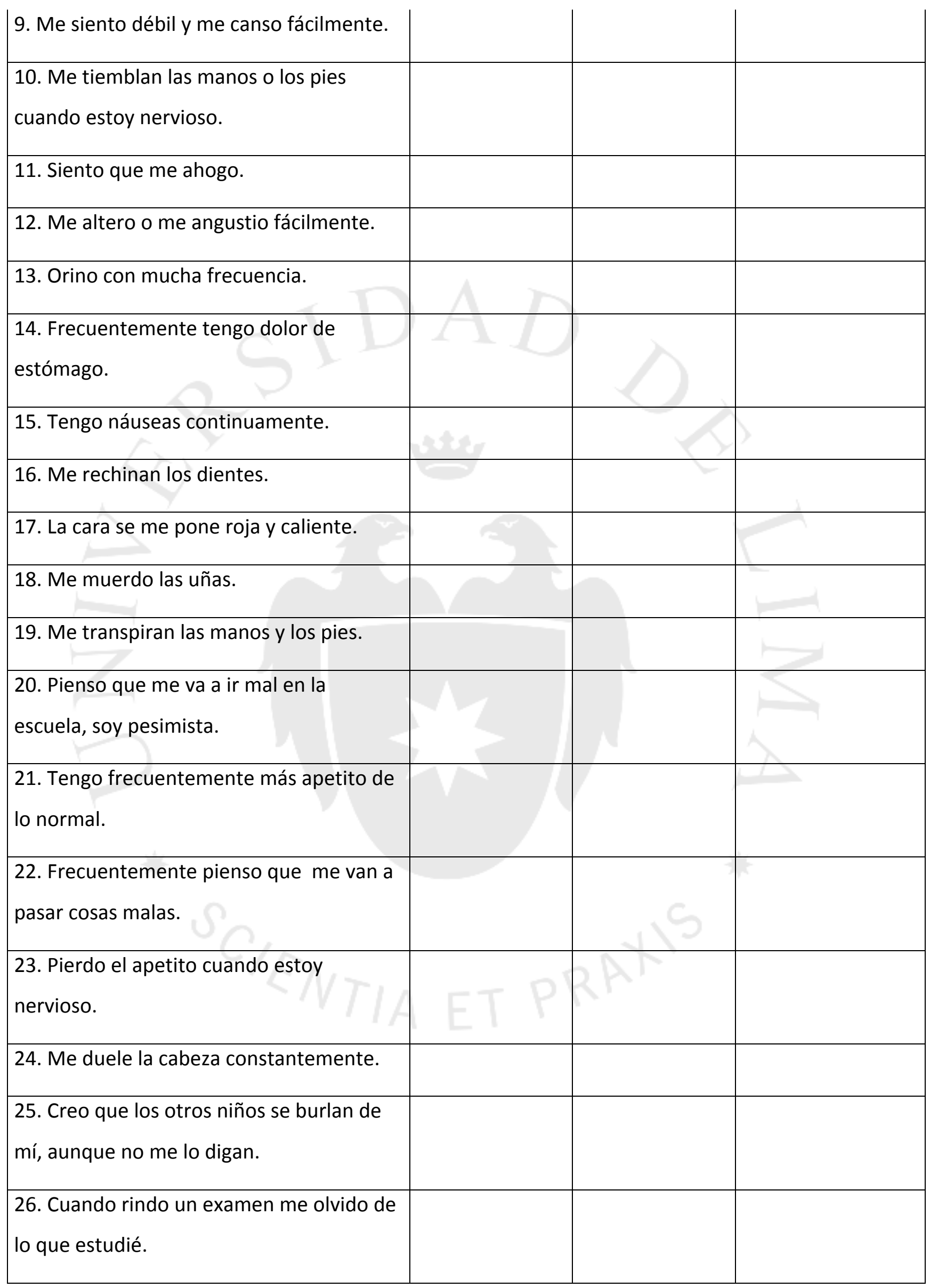




\section{ANEXO 5: Segundo procedimiento del análisis factorial exploratorio para las puntuaciones de la EECI}

Análisis factorial exploratorio sin el ítem 3.

\begin{tabular}{|c|c|}
\hline Ítem & Factor 1 \\
\hline 1 & .408 \\
\hline 2 & .379 \\
\hline 4 & .432 \\
\hline 5 & .530 \\
\hline 6 & .362 \\
\hline 7 & .550 \\
\hline 8 & .415 \\
\hline 9 & .449 \\
\hline 10 & .414 \\
\hline 11 & .591 \\
\hline 12 & .467 \\
\hline 13 & .354 \\
\hline 14 & .615 \\
\hline 15 & .492 \\
\hline 16 & .542 \\
\hline 17 & .524 \\
\hline 18 & .508 \\
\hline 19 & .619 \\
\hline 20 & .398 \\
\hline 21 & .492 \\
\hline 22 & .487 \\
\hline 23 & .514 \\
\hline 24 & .564 \\
\hline 25 & .555 \\
\hline 26 & .620 \\
\hline 27 & .415 \\
\hline 28 & .631 \\
\hline 29 & .523 \\
\hline 30 & .439 \\
\hline 31 & .444 \\
\hline 32 & .341 \\
\hline 33 & .651 \\
\hline 34 & .457 \\
\hline 35 & .327 \\
\hline 36 & .570 \\
\hline
\end{tabular}




\section{ANEXO 6: Tercer procedimiento del análisis factorial exploratorio para las puntuaciones de la EECI}

Análisis factorial exploratorio sin los ítems 2, 3, 13, 20, 32 y 35 .

\begin{tabular}{|c|c|}
\hline Ítem & Factor 1 \\
\hline 1 & .414 \\
\hline 4 & .437 \\
\hline 5 & .530 \\
\hline 6 & .373 \\
\hline 7 & .542 \\
\hline 8 & .418 \\
\hline 9 & .428 \\
\hline 10 & .397 \\
\hline 11 & .597 \\
\hline 12 & .464 \\
\hline 14 & .622 \\
\hline 15 & .490 \\
\hline 16 & .551 \\
\hline 17 & .531 \\
\hline 18 & .504 \\
\hline 19 & .618 \\
\hline 21 & .483 \\
\hline 22 & .486 \\
\hline 23 & .517 \\
\hline 24 & .573 \\
\hline 25 & .558 \\
\hline 26 & .614 \\
\hline 27 & .409 \\
\hline 28 & .629 \\
\hline 29 & .524 \\
\hline 30 & .430 \\
\hline 31 & .446 \\
\hline 33 & .656 \\
\hline 34 & .463 \\
\hline 36 & .582 \\
\hline
\end{tabular}



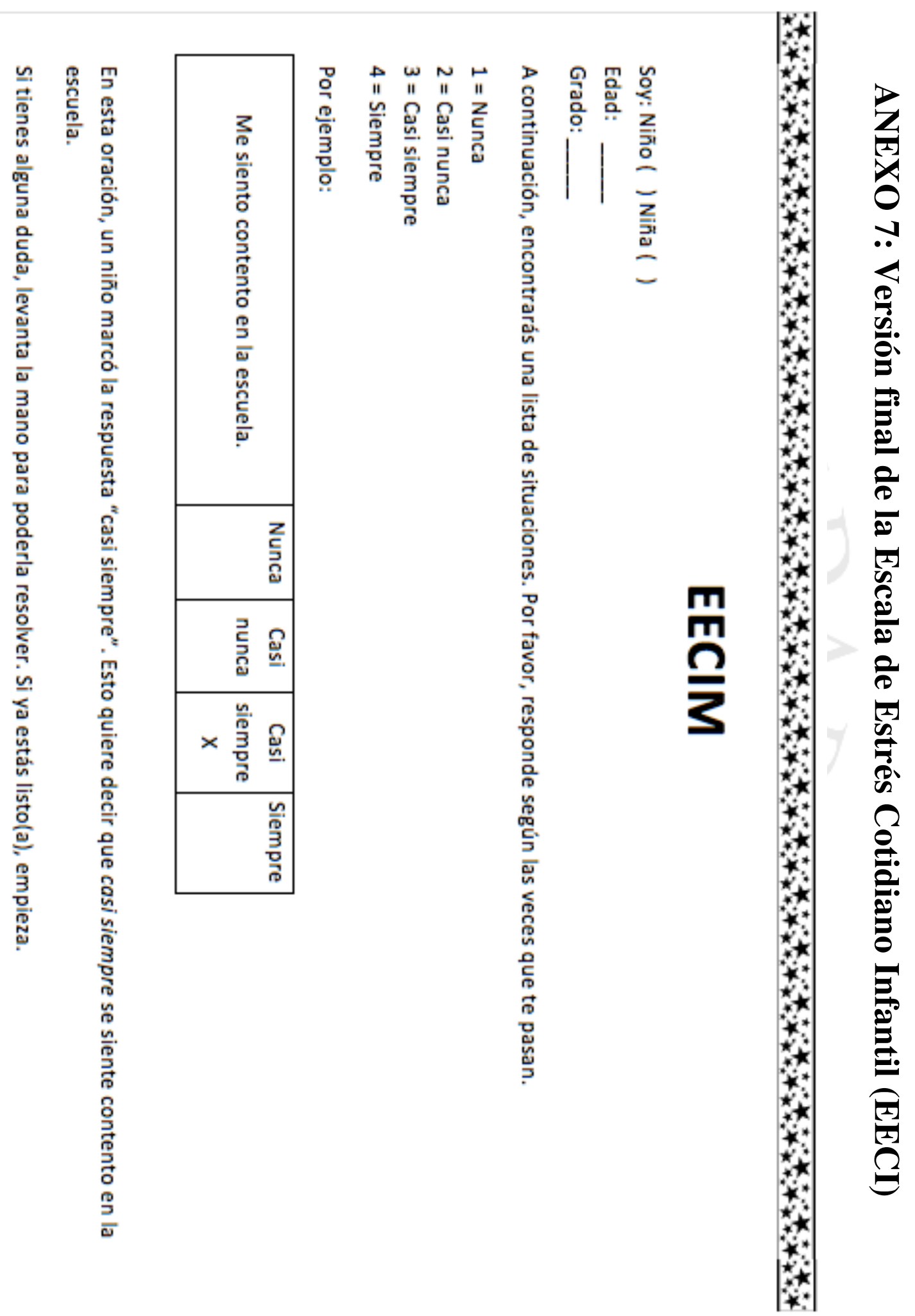


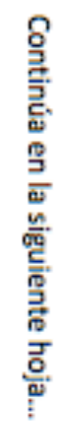

\begin{tabular}{|c|c|c|c|c|c|c|c|c|c|c|c|c|c|c|}
\hline 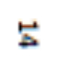 & $\vec{\omega}$ & 学 & $\Xi$ & ㄴ & 6 & $\infty$ & $\sim$ & $\sigma$ & un & $\Delta$ & $\omega$ & $N$ & $r$ & \\
\hline 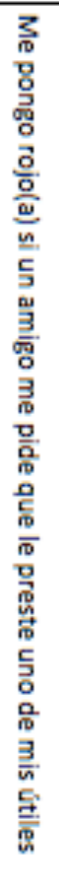 & 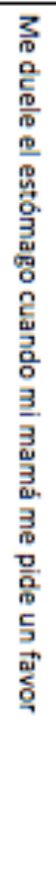 & 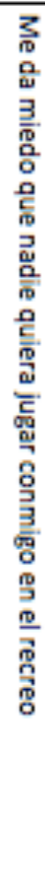 & 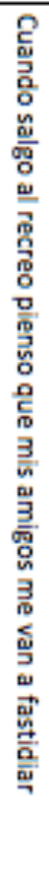 & 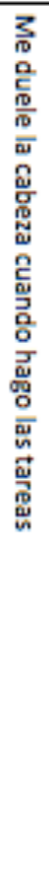 & 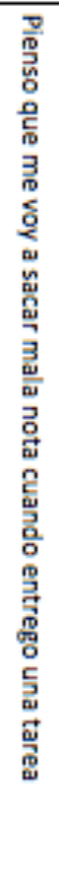 & 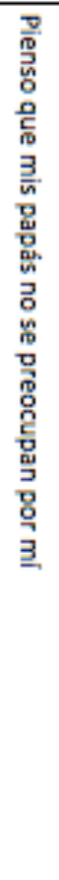 & 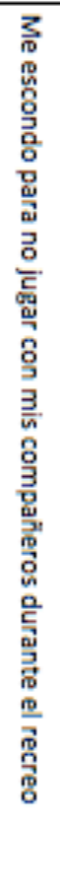 & 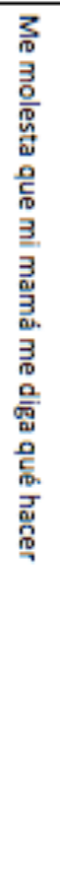 & 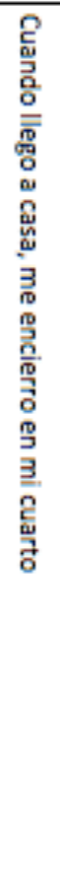 & 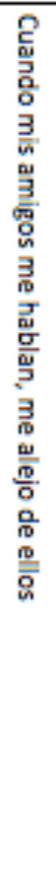 & 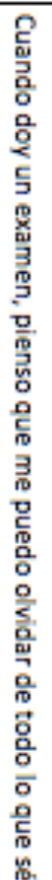 & 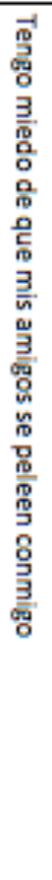 & 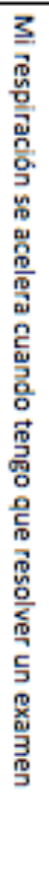 & \\
\hline$\mapsto$ & $\mapsto$ & $\rightarrow$ & $r$ & $r$ & $\mapsto$ & $\mapsto$ & $\mapsto$ & $\mapsto$ & $\mapsto$ & $r$ & $r$ & $r$ & $\mapsto$ & 롫 \\
\hline$N$ & $N$ & $N$ & $N$ & $N$ & $N$ & $N$ & $N$ & $N$ & $N$ & $N$ & $N$ & $N$ & $N$ & 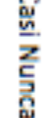 \\
\hline$\omega$ & $\omega$ & $\omega$ & $\omega$ & $\omega$ & $\omega$ & $\omega$ & $\omega$ & $\omega$ & $\omega$ & $\omega$ & $\omega$ & $\omega$ & $\omega$ & 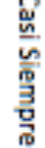 \\
\hline$\Delta$ & $\Delta$ & $\Rightarrow$ & $\Delta$ & $\Rightarrow$ & $\Delta$ & $\Delta$ & $\Delta$ & $\Delta$ & $\Delta$ & $\Delta$ & $\Delta$ & $\Delta$ & $\Rightarrow$ & $\begin{array}{l}\frac{0}{00} \\
\frac{3}{3} \\
\frac{0}{\sigma} \\
\end{array}$ \\
\hline
\end{tabular}

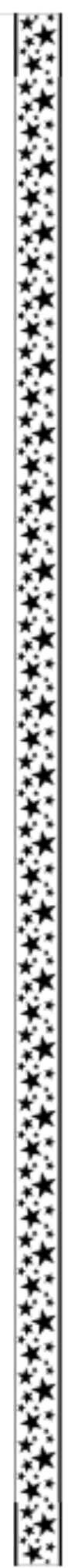




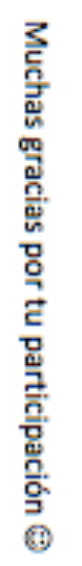

\begin{tabular}{|c|c|c|c|c|c|c|c|c|c|c|c|c|c|c|}
\hline$\tilde{\infty}$ & $\approx$ & $\tilde{\sigma}$ & N & $\approx$ & $\tilde{\omega}$ & $\mathbb{N}$ & $\tilde{\sim}$ & $\tilde{\circ}$ & $\bullet$ & $\stackrel{\infty}{\infty}$ & 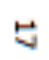 & 崩 & 光 & \\
\hline 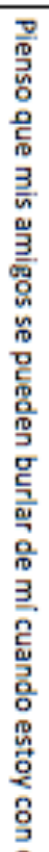 & 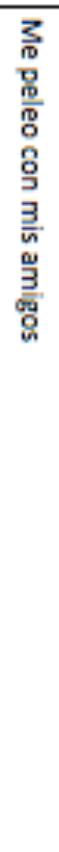 & 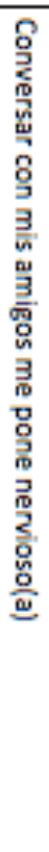 & 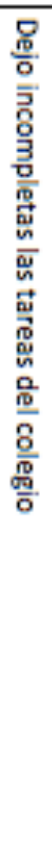 & 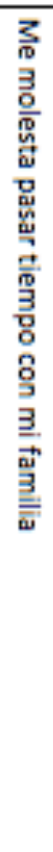 & 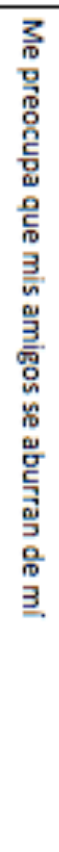 & 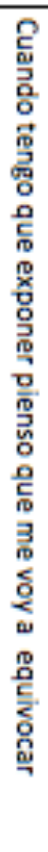 & 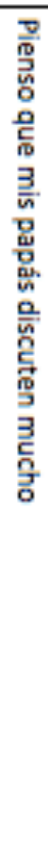 & 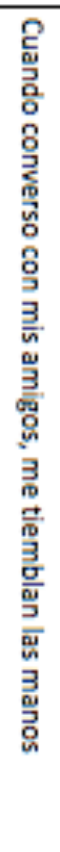 & 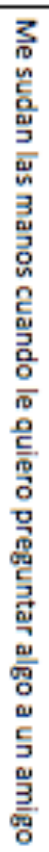 & 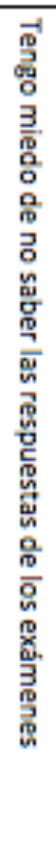 & 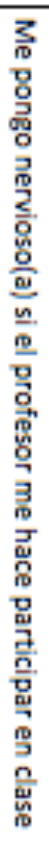 & 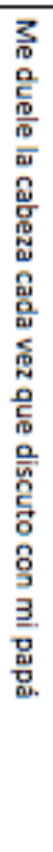 & 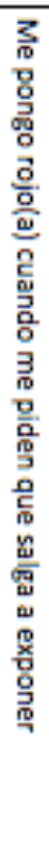 & \\
\hline$\mapsto$ & $\mapsto$ & $\mapsto$ & $\mapsto$ & $\mapsto$ & $\mapsto$ & $\mapsto$ & $\mapsto$ & $\mapsto$ & $\mapsto$ & $\mapsto$ & $\leftrightarrow$ & $\mapsto$ & $\mapsto$ & 를 \\
\hline$N$ & $N$ & $N$ & $N$ & $N$ & $N$ & $N$ & $N$ & $N$ & $N$ & $N$ & $N$ & $N$ & $N$ & 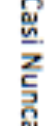 \\
\hline$\omega$ & $\omega$ & $\omega$ & $\omega$ & $\omega$ & $\omega$ & $\omega$ & $\omega$ & $\omega$ & $\omega$ & $\omega$ & $\omega$ & $\omega$ & $\omega$ & $\frac{\omega}{\omega}$ \\
\hline$\Delta$ & $\Delta$ & $\Delta$ & $\Delta$ & $\Delta$ & $\Delta$ & $\Delta$ & $\Delta$ & $\Delta$ & $\Delta$ & $\Delta$ & $\Delta$ & $\Delta$ & $\Delta$ & 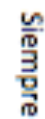 \\
\hline
\end{tabular}

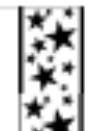

$*$

$*$

$*$

$*$

$*$

$*$

* 


\section{ANEXO 8: Consentimiento informado}

\section{Consentimiento informado}

La presente investigación tiene como fin alcanzar el grado académico de licenciada y es realizada por la bachiller María Fernanda Flores Mazulis, egresada de la carrera de psicología de la Universidad de Lima. El propósito de la tesis es construir una escala que mida estrés en niños y niñas de 3ero, 4to y 5to grado de primaria y reportar las propiedades psicométricas de este instrumento.

Para poder llevar a cabo este estudio, se requiere de la participación de estudiantes de los grados referidos. Por ello, se solicita su autorización con la posibilidad de que los estudiantes de su centro educativo puedan ser parte de la investigación.

La investigación requiere de la aplicación de dos instrumentos. Ambos tienen, en conjunto, una duración de 30 minutos. El primero es la Escala de Estrés Cotidiano Infantil y mide niveles de estrés y el segundo, la Lista de Chequeo Conductual de Ansiedad, mide niveles de ansiedad.

En caso de poder llevar a cabo la investigación, la investigadora se hará responsable de coordinar con anticipación con el departamento psicopedagógico de su institución, así como con el profesor o profesora de aula encargado(a). De esta manera, se buscará interferir lo menos posible con las actividades de clase planeadas.

Cabe resaltar que la participación en este estudio es anónima y confidencial y la información recolectada no se empleará para ningún otro propósito fuera de los de esta investigación.

Debido al carácter anónimo del estudio, no habrá una devolución de resultados individuales. Sin embargo, los resultados generales podrán serán entregados a su institución educativa. En caso de tener alguna duda, puede contactar a la investigadora al siguiente correo electrónico: maferflores02@gmail.com

Muchas gracias.

Yo autorizo que la bachiller María Fernanda Flores realice la investigación sobre construcción de una escala que mida estrés cotidiano infantil en los grados de mi centro educativo llamado

Fecha:

Firma: 


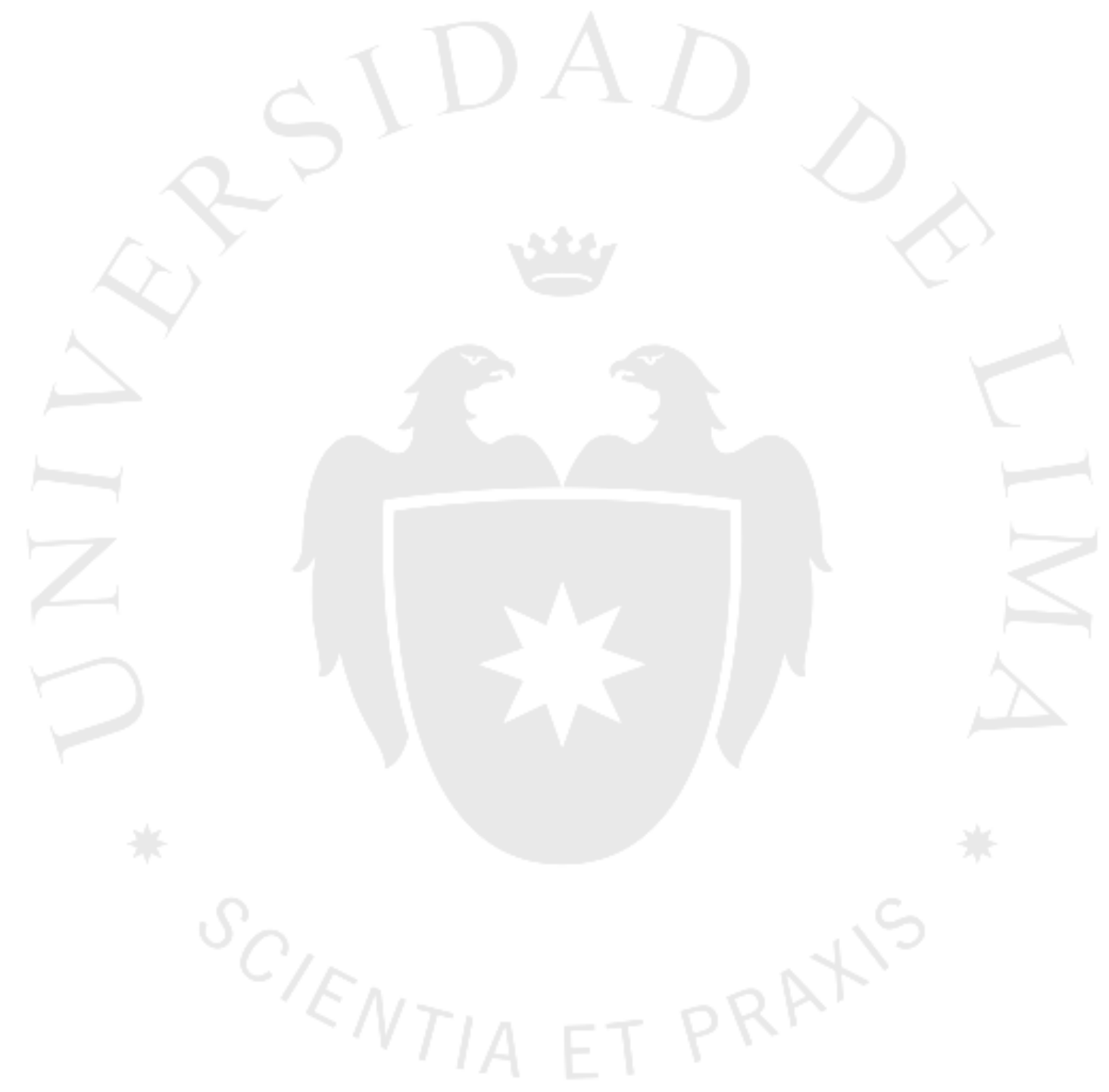

